\title{
Cumulative effects modeling in the mountaintop removal mining region of the central Appalachians
}

\author{
Eric Richard Merriam
}

Follow this and additional works at: https://researchrepository.wvu.edu/etd

\section{Recommended Citation}

Merriam, Eric Richard, "Cumulative effects modeling in the mountaintop removal mining region of the central Appalachians" (2015). Graduate Theses, Dissertations, and Problem Reports. 6221.

https://researchrepository.wvu.edu/etd/6221

This Dissertation is protected by copyright and/or related rights. It has been brought to you by the The Research Repository @ WVU with permission from the rights-holder(s). You are free to use this Dissertation in any way that is permitted by the copyright and related rights legislation that applies to your use. For other uses you must obtain permission from the rights-holder(s) directly, unless additional rights are indicated by a Creative Commons license in the record and/ or on the work itself. This Dissertation has been accepted for inclusion in WVU Graduate Theses, Dissertations, and Problem Reports collection by an authorized administrator of The Research Repository @ WVU.

For more information, please contact researchrepository@mail.wvu.edu. 


\title{
CUMULATIVE EFFECTS MODELING IN THE MOUNTAINTOP REMOVAL MINING REGION OF THE CENTRAL APPALACHIANS
}

\author{
Eric Richard Merriam
}

\begin{abstract}
Dissertation submitted to the Davis College of Agriculture, Natural Resources, and Design at West Virginia University in partial fulfillment of the requirements for the degree of
\end{abstract}

\author{
Doctor of Philosophy \\ in \\ Forest Resource Science
}

J. Todd Petty, Ph.D., Chair

Mike Strager, Ph.D.

George Merovich, Ph.D.

Nicolas Zegre, Ph.D.

Margaret Passmore, M.S.

School of Natural Resources

Wildlife and Fisheries Resources Program

\section{Morgantown, West Virginia \\ 2015}

Keywords: predictive models, scenario analysis, cumulative effects, residential development, landscape indicators, mountaintop mining, land use, multiple stressors, watershed models, water quality, water chemistry types, stream meta-community structure, local vs. regional effects 


\section{ABSTRACT \\ Cumulative effects modeling in the mountaintop removal mining region of the central Appalachians}

\section{Eric Richard Merriam}

Anthropogenic alteration of natural land cover is a global driver of aquatic resource impairment. It is increasingly recognized that aquatic systems are impacted by multiple land use activities that combine additively and interactively to result in unique patterns of degradation (i.e., cumulative effects). Moreover, stream networks are multi-scaled, hierarchically structured systems wherein localized impacts can have both local (e.g., stream segment) and regional (e.g., watershed) consequences. Thus, there has been a recent push to construct statistical models capable of predicting and forecasting aquatic conditions under current and future landuse scenarios (i.e., scenario analysis) and characterize local and regional processes dictating observed patterns of ecological degradation.

Nowhere is there a greater need for decisive and empirically-driven aquatic resource management than within the Mountaintop Removal-Valley Fill (MTR-VF) mining region of the central Appalachians, where dramatic changes in land cover associated with large scale surface mining can produce strong measurable impacts to downstream ecosystems. However, several knowledge gaps currently limit aquatic resource management within this actively developing and socioeconomically important region. Notably, the extent to which surface mining-related stressors interact with those of other landuse activities is unclear. For example, we currently have little knowledge regarding how multiple land use activities structure and contribute to the full suite of dissolved water quality characteristics in this region. Furthermore, extensive localized physicochemical degradation may degrade regional biological integrity and diversity through disruption or alteration of vital metacommunity processes (e.g., dispersal). Such regional implications of extensive local impacts have yet to be described. I seek to fill in these critical knowledge gaps in this study.

In my first chapter, I tested for additive and interactive effects of dominant landuse activities (i.e., surface mining, deep mining, and residential development) on water quality (specific conductance and Se), habitat quality, and benthic macroinvertebrates via a uniquely designed watershed-scale assessment of the Coal River, West Virginia. I derived equations for predicting in-stream response to landscape changes and predicted the outcome of a realistic future scenario involving development of 15 permitted mines. I found that surface mining, underground mining, and residential development altered physical, chemical and biological condition through additive and complex interactive effects. Scenario analysis suggested that landscape context (i.e., presence of pre-existing landuse activities) helps control impacts from construction of new surface mines owing to observed complex additive and interactive effects.

My second chapter focused on constructing landscape-based cumulative effects models capable of predicting in-stream response to future surface-mine development within the context of other landuse activities throughout the MTR-VF region. Predictive models provided precise estimates of specific conductance (model $R^{2} \leq 0.77$ and cross-validated $\left.R^{2} \leq 0.74\right)$, Se $(0.74$ and $0.70)$, and benthic macroinvertebrate community composition ( 0.72 and 0.65$)$ and predicted high levels of chemical (33\%) and biological (67\%) impairment as a result of additive and interactive effects of surface mining, underground mining, and residential development. Of this total 
impairment, however, $<25 \%$ could be attributed to surface mining alone. Furthermore, the surface-mining level that results in exceedance of the $300 \mu \mathrm{S} / \mathrm{cm}$ conductivity benchmark increased from $4.4 \%$ in the presence of other stressors to $16.6 \%$ when only surface mining was present. These results underscore the importance of multistressor landuse models for reliable predictions of stream conditions, as well as the difficulty of interpreting correlations between surface mining and stream condition without fully accounting for other landuse activities.

My third chapter focused on characterizing how multiple landuse activities control detailed patterns in local water chemistry. Principal component (PC) analysis identified 3 important dimensions of variation in water chemistry that were significantly correlated with contemporary surface mining (PC1, elevated dominant ions, sulfate, alkalinity, and selenium), coal geology and legacy mines (PC2, elevated trace metals), and residential development (PC3, elevated sodium and chloride). The combination of these 3 dominant sources of pollutants produced a complex stream-to-stream patchwork of contaminant mixtures. Seventy-five percent of headwater streams (catchments $<5 \mathrm{~km}^{2}$ ) had water chemistries that classified as either reference $(49 \%)$, development only $(18 \%)$ or mining only $(8 \%)$. Only $21 \%$ of larger streams (catchments $>5 \mathrm{~km}^{2}$ ) were classified as having reference chemistries, and chemistries indicative of combined mining and development contaminants accounted for $47 \%$ of larger streams (compared to $26 \%$ of headwater streams). Extreme degradation of larger streams within the MTR-VF region can be attributed to the accumulation of contaminants from multiple human landuse activities that include contemporary mountaintop mining, underground mining, abandoned mines, and untreated domestic wastewater. Consequently, water quality improvements in this region will require a multi-contaminant remediation approach.

My fourth chapter was focused on quantifying the extent to which pervasive physicochemical degradation throughout the MTR-VF region influences regional metacommunity structure and processes. Notably, conservation of undisturbed headwater streams is a common management activity in disturbed watersheds because of their ability to preserve regional biodiversity. However, undisturbed headwater streams are often isolated within heavily degraded regions, leaving their communities at risk of losing sensitive, poor dispersing taxa (through decreased mass and rescue effects) and gaining tolerant, widely dispersing taxa (through increased dispersal and mass effects) from nearby degraded habitats. Results of this chapter suggest that both local (observed physicochemical conditions) and neighborhood (condition of streams within a $5 \mathrm{~km}$ buffer) conditions explain significant variation in assemblage structure across all taxa. However, the strength of neighborhood effects varied as a function of taxon-specific tolerance and dispersal characteristics. Neighborhood conditions had a significant effect on low dispersing taxa with moderate and high tolerances and on high dispersing taxa with high tolerances. Decreasing neighborhood condition was associated with decreased occurrence (Baetis, Ceratopsyche) and abundance (Maccaffertium) of several taxa, as well as associated metrics (\%E, \%EPT). Several taxa (Chironomidae, Hemerodromia, Chimarra) increased in occurrence and abundance with decreasing neighborhood conditions. Thus, invertebrate communities within even the most pristine streams are at risk when isolated within heavily impacted neighborhoods. Consequently, protection of regional species' pools in heavily impacted regions will require more than simply conserving headwater catchments. 


\section{TABLE OF CONTENTS}

ACKNOWLEDGEMENTS

CHAPTER 1: Scenario analysis predicts context-dependent stream response to landuse change in a heavily mined central Appalachian watershed

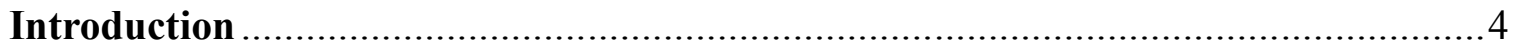

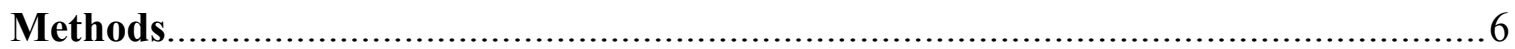

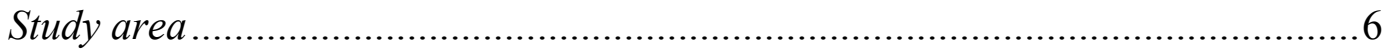

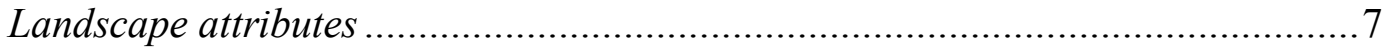

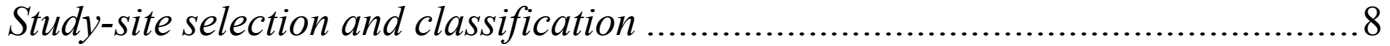

Physical, chemical, and biological attributes ................................................. 9

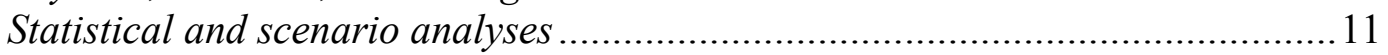

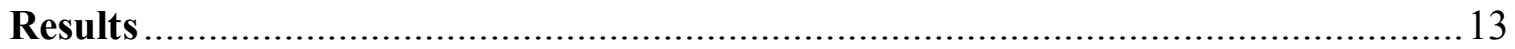

Cumulative effects of mining and development ............................................ 14

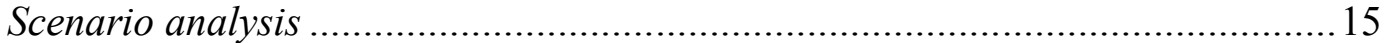

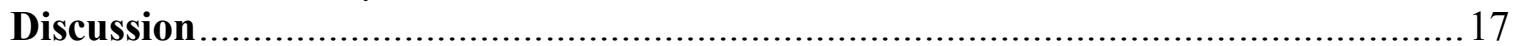

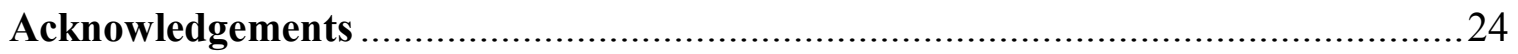

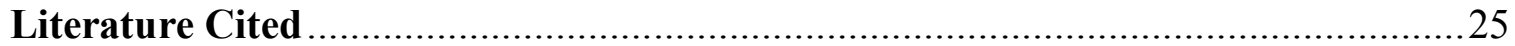

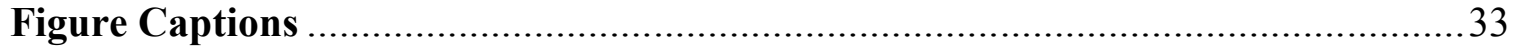

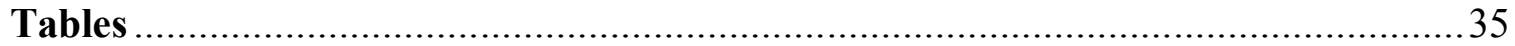

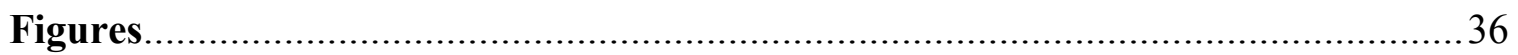

CHAPTER 2: Landscape-based cumulative effects models for predicting stream response to mountaintop mining in multistressor Appalachian watersheds ....................................... 43

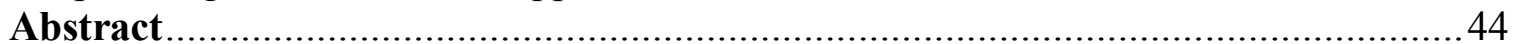

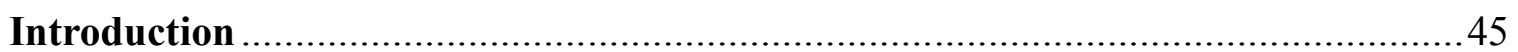

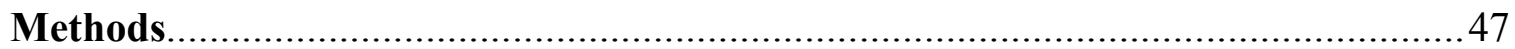

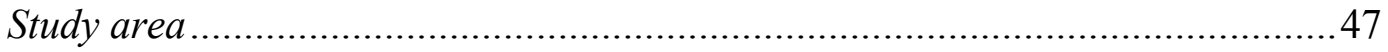

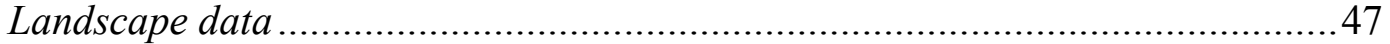

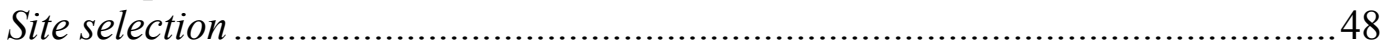

Physical, chemical, and biological attributes .............................................. 49

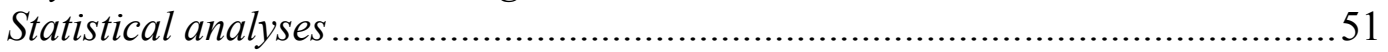

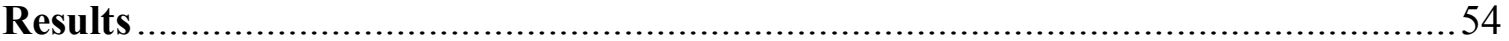

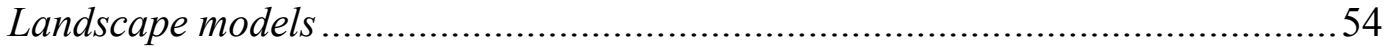

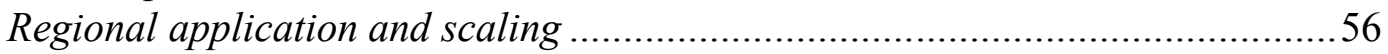

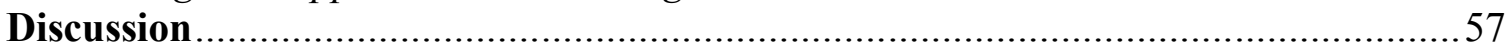

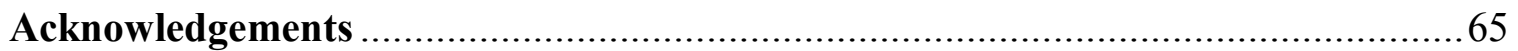

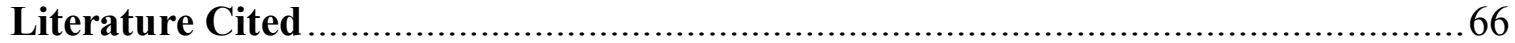

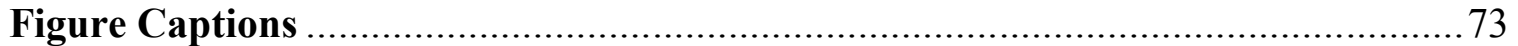

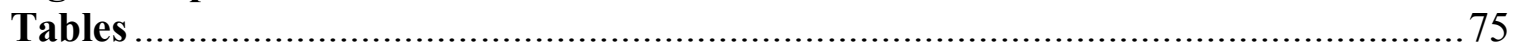

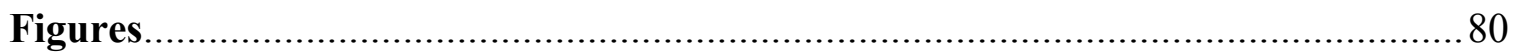

CHAPTER 3: Complex contaminant mixtures in multi-stressor Appalachian riverscapes ........85

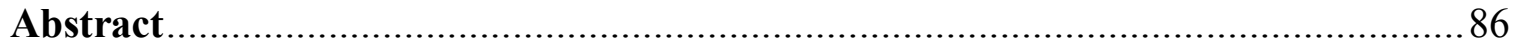




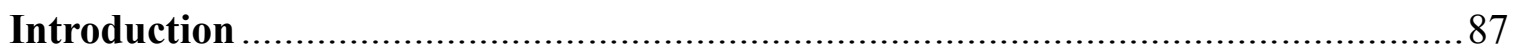

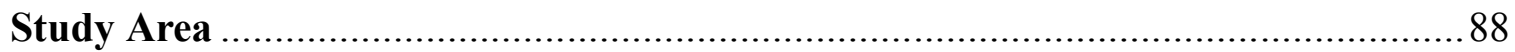

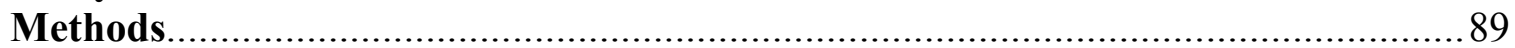

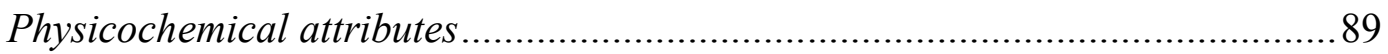

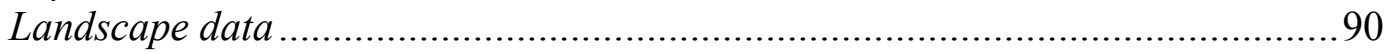

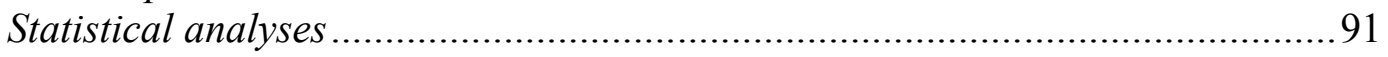

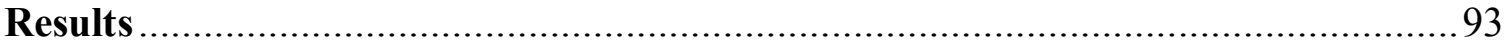

Characterizing contaminant mixtures/linking to landscape characteristics.........93

Land use contribution to regional chemical degradation .....................................96

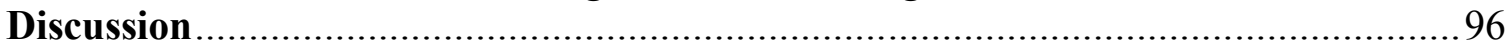

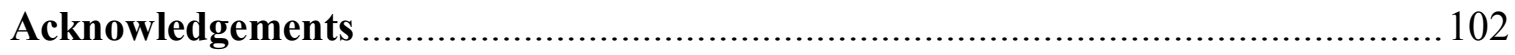

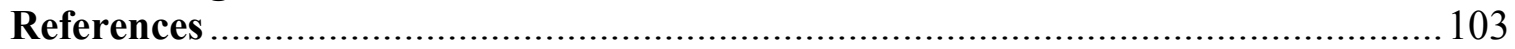

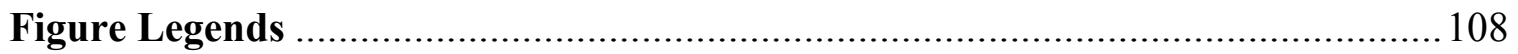

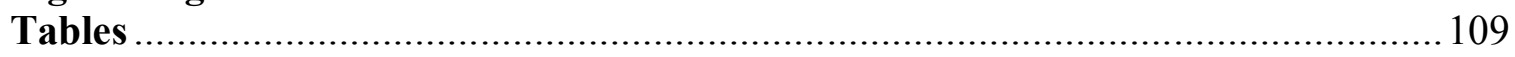

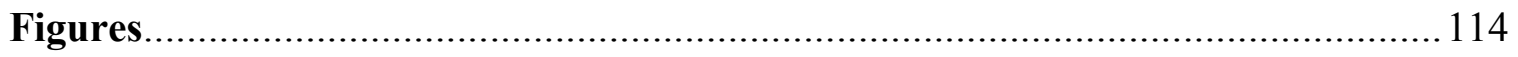

CHAPTER 4: Under siege: isolated headwater tributaries are threatened by regionally impaired

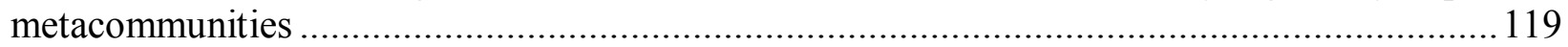

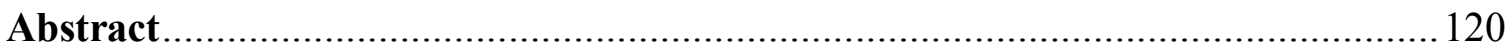

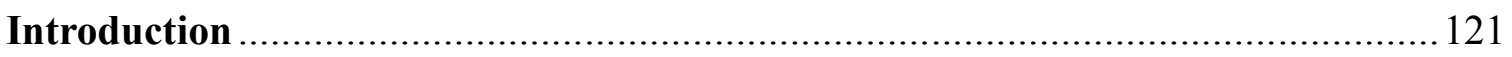

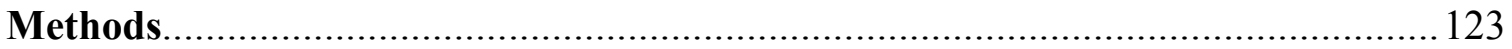

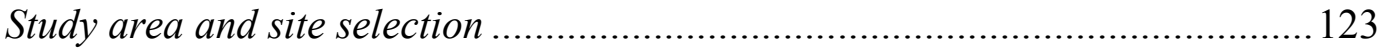

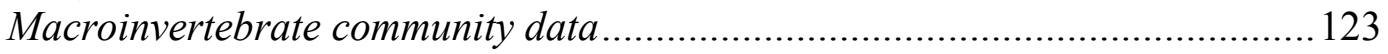

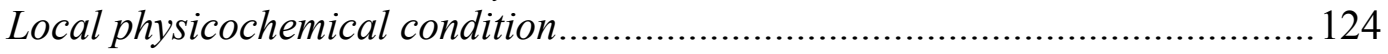

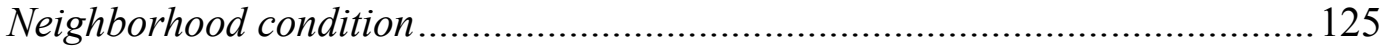

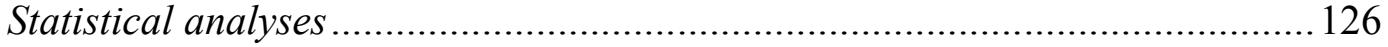

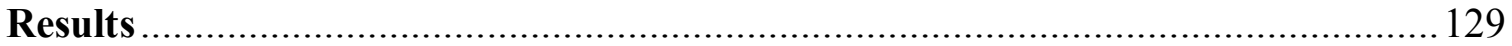

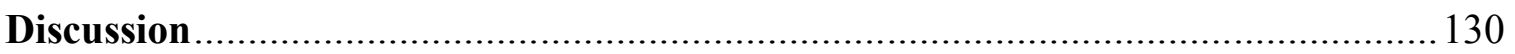

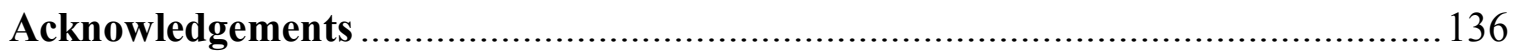

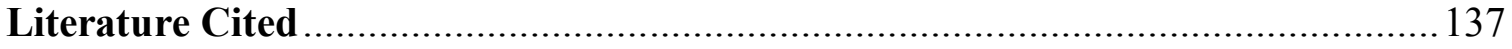

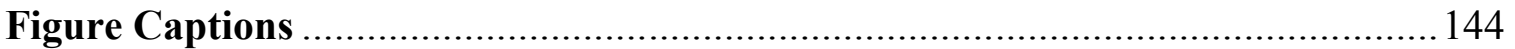

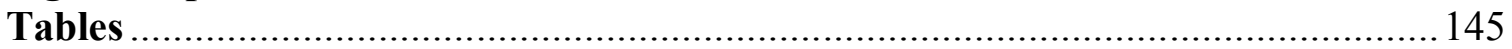

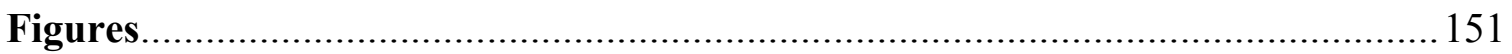

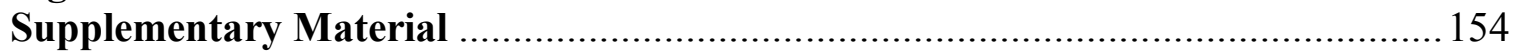

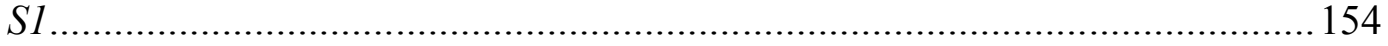

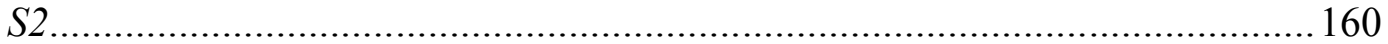




\section{ACKNOWLEDGEMENTS}

"The greatest value of having good people around you is not what you get from them but the better person you become because of them"'- Nishan Panwar

My success would not have been possible without the hard work and dedication of those I have been lucky enough to surround myself with while at West Virginia University. First and foremost, I would like to thank my advisor, Dr. Todd Petty, for his professional and personal support throughout my M.S. and Ph.D. I would also like to thank Dr. Michael Strager, Dr. George Merovich, Dr. Nicolas Zegre, and Margaret Passmore for their insight and encouragement as members of my graduate committee. Each offered a unique perspective and skill set to my research and has contributed greatly to my professional development. I would like to thank my fellow graduate students, particularly Eric Miller, Alison Anderson, and Brock Huntsman for assistance with my research and invaluable friendships that have made my time at West Virginia University extremely enjoyable. I would like to extend special thanks to Donna Hartman, not only for her help with my research, but also for her continual support with nearly every aspect of my personal and professional life. Finally, I would like to thank my family for their love and encouragement. I would especially like to thank my wife, Sarah, for her unwavering support. 
CHAPTER 1: Scenario analysis predicts context-dependent stream response to landuse change in a heavily mined central Appalachian watershed

This chapter has been accepted and published in the journal Freshwater Science and follows their required formatting.

Merriam, E. R., J. T. Petty, M. P. Strager, A. E. Maxwell, and P. Ziemkiewicz. 2013. Scenario analysis predicts context-dependent stream response to landuse change in a heavily mined central Appalachian watershed. Freshwater Science 32:1246-1259. 
Abstract. Scenario analysis has the potential to improve management of aquatic systems throughout the Mountaintop Removal-Valley Fill mining (MTR-VF) region of central Appalachia. However, the extent to which surface mining interacts with other landuse stressors (i.e., cumulative effects) is unclear, and this limits our ability to predict the effects of new mines on physical, chemical, and biological conditions downstream. We tested for additive and interactive effects of landuse change (surface mining, deep mining, residential development) on water quality (specific conductance and Se), habitat quality, and benthic macroinvertebrates via a uniquely designed watershed-scale assessment of the Coal River, West Virginia (USA). We derived equations for predicting in-stream response to landscape changes and predicted the outcome of a realistic future scenario involving development of 15 permitted mines. Elevated Se concentrations were directly correlated with incremental increases in surface-mining extent. Surface mining, deep mining, and residential development had additive effects on elevated specific conductance and reduced biological condition. We found evidence of a positive interactive effect (stressor antagonism) of deep mining and residential development on biological condition, presumably caused by stream-flow augmentation from deep mines. Landscape context influenced predicted impacts from construction of 15 new mines because of additive and interactive effects of landuse change. New surface mines increased the number of receiving streams exceeding chemical and biological criteria, but a greater proportion of receiving streams exceeded chemical and biological criteria at equivalent levels of new mine development when pre-existing stressors were present. When surface mining was the only stressor, $\geq 30$ or $40 \%$ increases in surface mining caused $100 \%$ of streams to exceed chemical or biological standards, respectively, whereas in streams stressed by deep mining and residential development, $\geq 10 \%$ additional surface mining caused $100 \%$ of streams to exceed chemical and biological standards. 
Continued progress in this area will require a better understanding of how landuse change affects aquatic systems in the rest of the MTR-VF mining region, where watershed-to-watershed variation in landuse patterns probably causes variability in ecological response. 


\section{INTRODUCTION}

Human alteration of natural landscapes is among the greatest threats to aquatic ecosystems (Allan 2004). Watershed characteristics are important determinants of aquatic ecosystem structure and function (Likens and Bormann 1974, Hynes 1975), and recent advances in geographic information systems (GIS) and enhanced resolution of spatial data sets have greatly improved our ability to model changes in stream condition in relation to catchment land use (Johnson and Host 2010). Numerous investigators have related landscape-based indicators of urbanization (Utz et al. 2010, King et al. 2011), agriculture (Cuffney et al. 2000, King et al. 2005), and mining (Petty et al. 2010, Merriam et al. 2011) to altered in-stream physical and chemical characteristics (Utz et al. 2011), community structure (Utz et al. 2010, King et al. 2011), and ecosystem functions (Clapcott et al. 2010). Knowledge of relationships between landscape indicators and aquatic condition is extremely valuable and has been used to manage watersheds affected by anthropogenic stressors (Carlisle et al. 2009, Petty et al. 2010).

Scenario analysis is a powerful method for adding objectivity to the decision-making process in watersheds undergoing development (Mahmoud et al. 2011, Kepner et al. 2012). Scenario analysis is a process for evaluating and quantifying potential changes in aquatic resources resulting from plausible landuse development scenarios (Mahmoud et al. 2011, Kepner et al. 2012). More importantly, scenario analysis provides a framework for combining scientific (statistical models and ecological relationships) and regulatory (management goals) information with stakeholder needs into a transparent decision-making process (Kepner et al. 2012).

However, the success of scenario analysis is strongly dependent on the quality of the underlying models. Projection models must provide realistic and accurate predictions of current ecological condition, and they must incorporate and accurately reflect complex interrelationships 
between landuse change and ecological responses (Kepner et al. 2012). Most natural ecosystems are affected by multiple anthropogenic stressors that accumulate and interact over space and time to cause unique patterns of degradation (Duinker and Greig 2006, Seitz et al. 2010). Thus, if underlying interactions are not incorporated into scenario-analysis models, ecological predictions of future conditions probably will be inaccurate (Kepner et al. 2012). Unreliable models create uncertainty, and uncertainty can undermine the decision-making process.

Scenario analysis has the potential to improve management of aquatic systems within the Mountaintop Removal-Valley Fill (MTR-VF) mining region of the central Appalachians, USA, where dramatic changes in land cover associated with large-scale surface mining can produce strong measurable impacts to downstream ecosystems (Palmer et al. 2010). Numerous recent studies have documented a direct effect of surface mining on downstream conditions. The amount of upstream surface mining disturbance has been linked to decreased biological condition, increased specific conductance and associated ions (i.e., $\mathrm{SO}_{4}{ }^{2-}, \mathrm{Ca}^{2+}, \mathrm{Mg}^{2+}, \mathrm{HCO}_{3}^{-}$), and increased trace element (e.g., Mn, Se) concentrations that often exceed accepted toxicity standards (Lindberg et al. 2011, Merriam et al. 2011, Bernhardt et al. 2012). Our research indicates that surface mining interacts with pre-existing mining and nonmining related stressors, such as residential development, to affect stream conditions (Merriam et al. 2011). Thus, projection models for scenario analysis that include only surface mining may not predict future context-dependent effects of new mine development accurately. This uncertainty could affect the success of watershed-management decisions.

The overriding objective of our research is to improve our ability to predict future aquatic conditions reliably in watersheds affected by extensive surface-mine development. Therefore, we conducted a synoptic watershed-scale assessment of the Coal River (West Virginia, USA; Fig. 
1). Our specific objectives were to: 1) quantify independent, additive, and interactive effects of surface mining, deep mining, and residential development on downstream aquatic conditions; 2) build spatially explicit and context-dependent interactive stressor effects into predictive models; and 3) use these models to predict current conditions and potential future stream conditions under a realistic surface-mine-development scenario.

\section{METHODS}

\section{Study area}

The Coal River is a headwater 8-digit Hydrological Unit Code (HUC) watershed in south-central West Virginia (Fig. 1). The watershed drains $\sim 2307 \mathrm{~km}^{2}$ with the mainstem of the Coal River flowing northwest until its confluence with the Kanawha River. The watershed land cover is predominantly forested $(\sim 80 \%)$ with developed and barren cover classes, which consist of residential and mining land uses, respectively. Surface-mining land use makes up $9 \%$ of the total watershed area, and $>425$ underground mine national pollution discharge elimination system (NPDES) permits are in effect (Fig. 1A). Coal mining is focused along ridgelines and in headwater catchments, whereas steep topography confines development to narrow floodplains throughout much of the study area (Fig. 1B). The underlying geology consists of interbedded Pennsylvanian-age sandstone, silt-stone, and shale, with multiple seams of high-quality, low-S

coal (Pond et al. 2008, Merriam et al. 2011). The low S content of the coal and calcareous nature of surrounding strata result in alkaline mine drainage that is different from the acidic drainage typical of mining in the northern Appalachians and Allegheny Plateau (Gerritsen et al. 2000, Merovich et al. 2007). 


\section{Landscape attributes}

We quantified landscape characteristics for all 1:24,000 segment-level watersheds (SLWs; area draining individual 1:24,000 National Hydrography Dataset stream segments) within the Coal River basin with a flow-table model linking landscape attributes in a downstream direction (Strager et al. 2009, Merriam et al. 2011). We used spatial analysis functions in ArcGIS ArcMap (version 10.0; Environmental Systems Research Institute, Redlands, California) in conjunction with flow tables to calculate cumulative measures of several landscape attributes for each SLW (Strager et al. 2009). Cumulative attributes quantified for each SLW were watershed area $\left(\mathrm{km}^{2}\right), \%$ land cover (forest, grasslands, and barren/mined), number of residential and commercial structures, and number of underground mine (deep-mining) NPDES permits.

We used 2009/2010 National Agriculture Imagery Program (NAIP) orthophotographs (1m pixel resolution at a scale of $1: 10,000)$ to map land cover and uses for the study area. True color and infrared NAIP orthophotographs were obtained from the Aerial Photography Field Office of the Farm Service Agency. We used the Feature Analyst software extension (Visual Learning Systems Inc, Version 5.0) for ArcGIS ${ }^{\circledR} 10.1$ (ESRI Corp, Redlands, CA) to differentiate forest, grassland/pasture, and barren. We then used the mining-permit boundaries layer developed by the West Virginia Department of Environmental Protection (WVDEP) to differentiate mining-related barren (i.e., active mine lands) and grasslands (i.e., reclaimed mine lands) from nonmining barren (i.e., residential impervious surfaces) and grasslands. A measure of $\%$ surface mining for each segment-level watershed was calculated by summing the cumulative area of all surface-mining-related land uses (active, reclaimed, valley fills, and slurry ponds) and dividing by the cumulative watershed area. We calculated the cumulative density of deep-mining NPDES permits (number $/ \mathrm{km}^{2}$ ) to represent deep-mine influence. We obtained 
NPDES permit data from the WVDEP Technical Applications in GIS office (http://gis.dep.wv.gov/). We calculated cumulative structure density (number/ $\mathrm{km}^{2}$ ) as our final measure of residential development within each SLW. We used the 2003 Statewide Addressing and Mapping Board structures layer consisting of mapped points for all residential and commercial structures. These data were mapped from 1:4800-scale imagery.

\section{Study-site selection and classification}

We used a unique sampling design to identify 40 SLWs as study sites within the Coal River watershed (Fig. 1C) across a range of influence from residential development, surface mining, and deep mining (Fig. 2). Twelve sites made up a distinct residential gradient (structure density: 3-94structures $/ \mathrm{km}^{2}$ ) and had $<2 \%$ surface mining. Twelve sites were part of a surfacemining gradient (surface mining: 3-67\%) and had structure density $<2$ structures $/ \mathrm{km}^{2}$ (Fig. 2). Fourteen sites (combined sites) were affected by a combination of residential development and surface mining (Fig. 2). We selected sites along the surface-mining and residential gradients and across combined sites to include varying levels of deep-mine influence (deep-mine NPDES permit densities: $0.00-1.01,0.00-0.17$, and $0.00-0.54$ permits $/ \mathrm{km}^{2}$, respectively). We included 2 sites as reference sites because they had minimal surface mining, deep mining, and development ( $<2 \%$ surface mining, 0.00 permits $/ \mathrm{km}^{2}$, and $<2$ structures $/ \mathrm{km}^{2}$, respectively) (Fig. 2). These sites represented the best possible conditions within the study area and served to anchor each gradient and our landscape-based models. This sampling design enabled us to quantify individual and combined effects of all combinations of landuse stressors. Drainage areas ranged from 1 to 36 $\mathrm{km}^{2}$, with similar averages among the surface-mining and residential gradients and combined sites $\left(12.5,12.9\right.$, and $11.3 \mathrm{~km}^{2}$, respectively). We selected all study sites to be independent of 
one another and not linked by flow.

\section{Physical, chemical, and biological attributes}

We measured physical-habitat characteristics once at each site during summer baseflow conditions from 15 July to 15 August 2011 . We delineated reach lengths as $40 \times$ mean stream width (minimum and maximum reach lengths $=150$ and $300 \mathrm{~m}$, respectively). At evenly spaced points along the thalweg, we measured water depth, channel-unit type (riffle, run, pool, glide), distance to retentive-feature type, and distance to nearest fish cover. Fish cover was defined as any structure in the active channel capable of concealing a 20.32-cm fish (Petty et al. 2001). We rated the ability of each site to retain inputs of coarse particulate organic matter with an index of total retentiveness (Merriam et al. 2011). We scored the organic (e.g., large woody debris [LWD]) and inorganic (e.g., substrate, pools) complexity of each site individually (0-10) and added them to provide a total retentiveness score (scale of $0-20$ ). We categorized LWD based on diameter and length (Petty et al. 2001) and used modified Wolman pebble counts (Wolman 1954) to characterize substrate composition. We used US Environmental Protection Agency (EPA) Rapid Visual Habitat Assessment (RVHA; Barbour et al. 1999) to assess habitat quality. We sampled quality and water chemistry during summer 2010 (August 9-27). At each

site, we obtained instantaneous measures of temperature $\left({ }^{\circ} \mathrm{C}\right), \mathrm{pH}$, specific conductance $(\mu \mathrm{S} / \mathrm{cm})$, and dissolved $\mathrm{O}_{2}(\mathrm{mg} / \mathrm{L})$ with a YSI 650 equipped with a 600XL sonde (Yellow Springs Instruments, Yellow Springs, Ohio) calibrated prior to each sampling date, and we measured average current velocity (m/s) with a digital Marsh-McBirney flow meter (Marsh-McBirney, Frederick, Maryland). We collected a 250-mL filtered sample with a Nalgene filtration unit (mixed cellulose ester membrane filter, $0.45-\mu \mathrm{m}$ pore size) and fixed the sample with $\mathrm{HNO}_{3}$ to a 
$\mathrm{pH}<2$ for analysis of $\mathrm{Al}, \mathrm{Ca}, \mathrm{Fe}, \mathrm{Mg}, \mathrm{Mn}, \mathrm{Na}, \mathrm{Zn}$, and $\mathrm{K}$ (EPA method E200.7), and $\mathrm{Ba}, \mathrm{Cd}, \mathrm{Cr}$, $\mathrm{Ni}$, and $\mathrm{Se}$ (EPA method E200.8; mg/L). We obtained two 250-mL unfiltered grab samples from each site. The $1^{\text {st }}$ was fixed with $\mathrm{H}_{2} \mathrm{SO}_{4}$ to a $\mathrm{pH}<2$ and analyzed for $\mathrm{NO}_{3}{ }^{-}$and $\mathrm{NO}_{2}{ }^{-}(\mathrm{EPA}$ method SM4110B) and total P (EPA method SM4500-P BE; mg/L). The $2^{\text {nd }}$ was analyzed for total and bicarbonate alkalinity (EPA method SM2320 B; $\mathrm{mg} / \mathrm{L} \mathrm{CaCO}$ equivalents), $\mathrm{Cl}^{-}$and $\mathrm{SO}_{4}{ }^{2-}$ (EPA method E300.0), and total dissolved solids (TDS; EPA method SM2540; mg/L). Analytical methods represent standard chemical methods for water and wastes (USEPA 1983). We stored samples at $4^{\circ} \mathrm{C}$ until all analyses were completed at Research Environmental and Industrial Consultants, Inc. (Beaver, West Virginia). We obtained duplicate YSI readings and water samples at $10 \%(n=4)$ of all sites and 1 field blank on each sampling date. Reported results for field duplicate pairs were within $\pm 20 \%$. Results of field blanks were generally below detection. However, 2 field blanks showed slight contamination, particularly for Mn and $\mathrm{Zn}$.

We sampled benthic macroinvertebrate communities immediately after collecting water samples (same sampling event) with procedures established by WVDEP Watershed Assessment Program and the USEPA Rapid Bioassessment Protocols (RBP) for wadeable streams (Barbour et al. 1999, WVDEP 2009). We obtained kick samples (net dimensions $335 \times 508 \mathrm{~mm}$ with 500 $\mu \mathrm{m}$ mesh) from 4 riffles at each site. We combined organisms and debris from the 4 kick samples into a single composite sample for each site and preserved samples in $95 \%$ ethanol. In the laboratory, we subsampled macroinvertebrates from combined kick samples with the 200-count method described by WVDEP (2009). We counted individuals and identified them to genus, except for Mollusca (family), Chironomidae, Hydracarina, Oligochaeta, and Nematoda, with the aid of keys in Peckarsky et al. (1990) and Merritt and Cummins (2008). We obtained duplicate samples from $10 \%(n=4)$ of sites. 
We compiled genus-level abundance data into a series of family- and genus-level macroinvertebrate community metrics. We used 2 benthic macroinvertebrate multimetric indices to assess ecological condition at each site. The West Virginia Stream Condition Index (WVSCI; Gerritsen et al. 2000) is a family-level index that is applied statewide within a single index period. The Genus-Level Index of Most Probable Stream Status (GLIMPSS; Pond et al. 2012) is a genus-level index that is calibrated by region and season. All sites fell within the mountain region and summer index period. We used a version of GLIMPSS that does not require genuslevel identification of individuals in the taxa Chironomidae and Oligochaeta (GLIMPSS [CF]). Both WVSCI and GLIMPSS score sites on a scale of 0 to 100 , with scores $<68$ and $<54$ being categorized as impaired, respectively.

\section{Statistical and scenario analyses}

We used general linear models and deletion tests to derive equations for predicting physical habitat (RVHA), water chemistry (specific conductance and Se), and biological condition (GLIMPSS and WVSCI) from \% surface mining, deep-mine NPDES permit density, and structure density (Crawley 2005). These response variables represent physiochemical and biological characteristics shown to be significantly influenced by landuse changes throughout the MTR-VF mining region of central Appalachia (Lindberg et al. 2011, Merriam et al. 2011, Bernhardt et al. 2012). Specific conductance benchmarks (300 $\mu \mathrm{S} / \mathrm{cm}$ : Cormier et al. 2011; 500 $\mu \mathrm{S} / \mathrm{cm}$ : Pond et al. 2008), Se chronic criteria (5 $\mu \mathrm{g} / \mathrm{L}$; USEPA 1987), and WVSCI (<68; Gerritsen et al. 2000) and GLIMPSS (<54; Pond et al. 2013) thresholds are used as standards for regulation and management of aquatic systems throughout the MTR-VF region.

We fit maximal models specifying main effects of, and all possible 2-way interactions 
between, $\%$ surface mining, deep-mine NPDES permit density, and structure density. Maximal models were developed on the entire data set $(n=40)$. We then applied backward deletion (using deletion tests) to arrive at the minimum adequate model (i.e., model in which all coefficients are significantly different from 0 and explanatory power does not differ significantly from the maximal model) for each response variable (Crawley 2005, Phillimore and Owens 2006, Hejda et al. 2009). Deletion tests assess the significance of increased deviance following removal of the least significant parameter (analysis of deviance tables and $F$-tests; $\alpha=0.05$ ) and help identify the most parsimonious model that balances complexity and error (Crawley 2005). Moreover, this process avoids many of the problems (e.g., sensitivity of order during parameter deletion) associated with automatic stepwise procedures (Crawley 2005). We began by removing all interaction terms to test whether an additive model had as much explanatory power as the maximal, interactive model. If the additive model resulted in a significant increase in deviance, we successively simplified the maximal model to identify the minimum adequate interactive model. If the additive model did not result in a significant increase in deviance, we successively removed additional parameters to identify the minimum adequate additive model.

We calculated explained variance (expressed as $R^{2}$ ) for each minimum adequate model to internally assess model performance. We performed leave-one-out cross-validations to externally assess predictive accuracy. We calculated cross-validation coefficients (i.e., $R^{2}$ between crossvalidated predictions and observed values $\left.\left[\mathrm{CV} R^{2}\right]\right)$. We transformed variables to meet assumptions of parametric analyses and linearize the data. Models were constructed in the $\mathrm{R}$ environment (version 2.15.0; R Development Core Team, Vienna, Austria). We used functions in package daag for cross-validation (Maindonald and Braun 2013).

We selected 15 surface-mine permits from WVDEP's surface-mine permit boundary 
layer data set to represent a watershed-scale future mining scenario (Fig. 1A). We updated the current landscape by converting all land within the 15 permits to surface mining-related disturbance and updated all other land-cover classes. We removed all structures and deep-mine NPDES permits falling within the permit boundaries to simulate a complete mine out of the permit area and underlying coal. Future surface mining may not completely eliminate preexisting deep-mine NPDES discharges, but detailed information regarding coal seams to be extracted in each permit was not available. We then reaccumulated and recalculated landscape metrics for all SLWs draining the 15 mine permits. We used minimum adequate multiple regression models to predict and compare current and future in-stream physical, chemical, and biological conditions. We then quantified the number of stream segments that exceeded recognized chemical standards for specific conductance and Se and the biological impairment threshold for GLIMPSS. We visually show predictions for all SLWs downstream of the 15 mine permits but constrain analyses to SLWs with cumulative basin areas $<40 \mathrm{~km}^{2}$ to remain consistent with basin areas used in model construction.

To test whether pre-existing landscape context (i.e., deep mining and residential development) affected the outcome of our future mining scenario, we separated SLWs draining the 15 mine permits into stream reaches affected by surface mining only $(n=170)$ and those affected by combinations of surface mining and residential development (i.e., structure densities $>0)(n=89)$, surface mining and deep mining $(n=36)$, and all 3 stressors $(n=154)$. We then compared the percentage of SLWs within each group with predicted specific conductance $<500$ $\mu \mathrm{S} / \mathrm{cm}$ and WVSCI score $>68$ under the 15 -permit future scenario.

\section{RESULTS}




\section{Cumulative effects of mining and development}

Minimum adequate models for RVHA and Se were single-variable models consisting of structure density and \% surface mining, respectively; i.e., the single variable models had as much explanatory power as the global interactive model (Table 1). Deletion tests supported an additive rather than interactive model for specific conductance, suggesting significant additive effects of \% surface mining, deep-mine NPDES permit density, and structure density (Table 1). We also found additive effects of surface mining, deep mining, and development on WVSCI and GLIMPSS. However, we found statistical evidence of a positive interactive effect of structure density and deep-mine NPDES permit density on biological condition (Table 1). In other words, biological condition tended to be higher than expected given structure density in situations where deep-mine NPDES permits were present.

Model performance was highly variable among response variables. The final model for specific conductance was most certain. It explained $77 \%$ of the total variation and offered good predictive ability during leave-one-out cross validation (cross-validation $[\mathrm{CV}] R^{2}=0.72$; Table 1). The minimum adequate model for Se was less certain. It explained $61 \%$ of the total variation $\left(\mathrm{CV} R^{2}=0.57\right.$; Table 1). Models predicting WVSCI and GLIMPSS explained 57 and $70 \%$ of the total variation $\left(\mathrm{CV} R^{2}=0.46\right.$ and 0.64 , respectively; Table 1$)$. The model predicting RVHA was least certain and explained $15 \%$ of the total variation across study sites $\left(\mathrm{CV} R^{2}=0.07\right.$; Table 1$)$.

The combination of additive and interactive effects was supported by regression analyses relating chemical and biological endpoints to land use. Specific conductance, Se, and GLIMPSS were strongly related to \% surface mining when no other stressors were present (Fig. 3A, D, G). Across sites without deep mining, deviations from the specific-conductance surface mining regression were accounted for by structure density (Fig. 3B). Sites with deep-mine NPDES 
permits had higher specific conductance than would be expected given current surface mining and structure density (i.e., regardless of the intensity of deep mining activity, 15 of 21 sites with deep mine NPDES permits [all larger symbols] fell above the regression in Fig. 3C). Similarly, deviations of sites without deep mining from the GLIMPSS surface-mining regression were accounted for by structure density (Fig. 3H). However, sites with surface mining and deep-mine NPDES permits consistently had lower biological condition (i.e., regardless of the intensity of deep-mining activity, all 8 sites along the surface-mining gradient with deep-mine NPDES permits [large black circles] fell below the regression; Fig. 3I) and sites with development and deep-mining NPDES permits had higher biological condition (i.e., 10 of 13 combined sites [large grey circles] and sites along the residential gradient [large hollow circles] with deep-mine NPDES permits fell above the regression; Fig. 3I) than would be expected given current $\%$ surface mining and structure densities. Deviations of sites from the Se surface-mining regression showed no significant pattern with structure density (Fig. 3E) or deep mining (Fig. 3F).

\section{Scenario analysis}

A total of 772 SLWs drained the 15 surface-mine permits. Of these, 449 SLWs had basin areas $<40 \mathrm{~km}^{2}$ and were included in analyses of the future surface-mining scenario. Prior to additional mining, landscape characteristics were highly variable with respect to pre-existing surface mining, deep mining, and residential development (Fig. 4A). As a result of the preexisting land use, $22 \%$ and $38 \%$ of SLWs were predicted to exceed the proposed specificconductance benchmarks of 300 and $500 \mu \mathrm{S} / \mathrm{cm}$, respectively (Figs 4B, 5A). Twenty-one percent exceeded the chronic criterion (Figs 4B, 5B). Fifty-five percent of the 449 SLWs were predicted as impaired as defined by WVSCI and 79\% as defined by GLIMPSS (Figs 4B, 5C). 
Under the future-mining scenario, the number of SLWs with $<25 \%$ surface mining decreased by almost $25 \%$, whereas the number of SLWs with $>75 \%$ surface mining increased by nearly $10 \%$ (Fig. 6A). This change in $\%$ surface mining mirrored a loss of $\%$ forest. The number of SLWs with fewer deep-mine NPDES permit densities increased, whereas the number of SLWs with more deep-mine NPDES permit densities decreased as simulated surface-mine development cut through pre-existing deep mines (Fig. 6A). Structure density was not altered. Under this alternative landscape, an additional 1\% of SLWs had predicted specific conductivities ranging from $300-500 \mu \mathrm{S} / \mathrm{cm}$, and an additional $22 \%$ exceeded $500 \mu \mathrm{S} / \mathrm{cm}$ (Figs $5 \mathrm{~A}, 6 \mathrm{~B}$ ). An additional $22 \%$ of SLWs exceeded the selenium chronic criterion (Figs 5B, 6B). An additional $17 \%$ of SLWs were predicted as being below the threshold for WVSCI and an additional 14\% for GLIMPSS (Figs 5C, 6B). We did not include changes to physical habitat in these analyses given the lack of change in structure density, the sole predictive component in this model.

Incremental increases in surface mining decreased percentage of SLWs remaining below $500 \mu \mathrm{S} / \mathrm{cm}$ across SLWs affected by surface-mining only and by surface mining and residential development (i.e., structure densities $>0$ ) (Fig. 7A). When pre-existing residential development was present, a greater proportion of SLWs exceeded the specific-conductance threshold at all levels of additional surface mining. All SLWs exceeded $500 \mu \mathrm{S} / \mathrm{cm}$ once additional surface mining surpassed $30 \%$. However, $100 \%$ of SLWs exceeded $500 \mu \mathrm{S} / \mathrm{cm}$ with $\geq 20 \%$ additional surface mining with pre-existing deep-mine NPDES permits. When all 3 stressors were present, $100 \%$ of SLWs exceeded $500 \mu \mathrm{S} / \mathrm{cm}$ at additional surface-mining levels $\geq 10 \%$ (Fig. 7A).

Incremental increases in surface mining resulted in a decreased percentage of SLWs exceeding the WVSCI threshold (i.e., >68) when surface mining was the only stressor (Fig. 7B). A greater proportion of sites fell below the WVSCI threshold at all levels of additional surface 
mining across SLWs with pre-existing land use. For example, $\sim 20 \%$ of SLWs with additional surface mining between 30 and $40 \%$ remained unimpaired when surface mining was the only stressor. In contrast, $100 \%$ of SLWs with pre-existing residential development were predicted to fall below the WVSCI threshold with additional surface mining $\geq 20 \%$ (Fig. 7B). 100\% of SLWs with pre-existing deep mining were below the WVSCI threshold under the 15-permit future scenario. When all 3 stressors were present, 100\% of SLWs were below the WVSCI threshold at additional surface mining levels $\geq 10 \%$ (Fig. 7B).

\section{DISCUSSION}

Of the $3089 \mathrm{~km}$ of streams incorporated in our analyses, $27 \%(826 \mathrm{~km})$ drain watersheds affected by surface mining only, whereas 59\% (1834 km) are affected by landuse stressors other than or in addition to surface mining (i.e., deep mining or structure density). When surface mining is the only stressor present, increased dissolved solids, specific conductance, and Se concentration and decreased biological conditions can be linked directly to increasing areal extent of surface mining upstream. When residential development is the only stressor present, increased dissolved constituents (especially $\mathrm{Na}$ and $\mathrm{Cl}$ ) and decreased habitat quality and biological conditions can be linked directly to increased density of built structures upstream. Across the entire watershed, where multiple landuse stressors are present, increased specific conductance can be linked to additive effects of surface mining, deep mining, and structure density. Structure density and underground mining do not contribute significantly to Se. Thus, we conclude that elevated Se concentrations can be attributed directly to increased surface-mine land use. Where multiple landuse stressors are present, decreasing biological condition can be linked to additive effects of increasing surface mining, deep mining, and structure density and a 
positive interactive effect (i.e., stressor antagonism) of structure density and deep mining.

Previous studies done in an effort to quantify cumulative effects within the MTR-VF region of central Appalachia have tended to be focused solely on the accumulation of effects from multiple surface mines (Johnson et al. 2010, Lindberg et al. 2011, Bernhardt et al. 2012). The tendency to focus on this single stressor is reasonable, given that surface mining activities are responsible for converting $980 \mathrm{~km}^{2}$ of forested land to barren or reclaimed mine land over the past 3 decades in southern West Virginia alone (Bernhardt et al. 2012). Our current results support previous research and confirm that the percentage of land area that has been surface mined is strongly correlated with changes in water quality and biological conditions downstream (Lindberg et al. 2011, Merriam et al. 2011, Bernhardt et al. 2012). However, we show that surface mining is only one of several landuse changes that affect aquatic systems in this region.

Ours is the first study to identify relationships between deep mining and in-stream conditions in this region. In the northern West Virginia coal-mining province where mining results in acidic drainage, Petty et al. (2010) identified relationships between underground and surface-mining intensity and biological condition that were dependent on coal geology and mine location. Further research on understanding such complex relationships within the MTR-VF region will be necessary for successful management of these systems.

One of the most interesting results from our study was the finding of antagonistic interactions between deep mining and residential development. Along with the positive interaction on WVSCI and GLIMPSS, we consistently observed higher total and Ephemeroptera, Plecoptera, and Trichoptera (EPT) richness values in streams draining both deep mining and residential development (mean $=19.2$ and 6.9 , respectively) compared to sites draining only residential development (15.2 and 5.5, respectively). One possible explanation for the positive 
interaction is that deep mining may augment flows with relatively good, cool water during the summer months whereas development results in warmer, more variable flow conditions (Allan 2004). Further research is needed to clarify mechanisms underlying this interaction and determine if it is a regional phenomenon or a local anomaly.

Additive and interactive effects of multiple anthropogenic stressors (i.e., physical and chemical) are well documented in aquatic systems. Crain et al. (2008) reviewed studies manipulating $\geq 2$ anthropogenic stressors in marine systems and observed high variability in strength and type (i.e., additive, synergistic, or antagonistic) of stressor interactions. Additive and interactive effects of complex metal (Clements 2004), pesticide (Junghans et al. 2006) and other chemical mixtures (Brian et al. 2005) on freshwater communities have been identified in ecotoxicological studies. Moreover, interactive effects of climate change and anthropogenic stressors, such as nutrient enrichment (Greig et al. 2012, Porter et al. 2012) and toxicants (Moe et al. 2013), on aquatic community structure and composition have been found in recent studies. In the northern mining region of West Virginia, Merovich and Petty (2007) observed interactive effects of acid mine drainage and thermal effluents from power plants on benthic communities.

Our study is unique in that we documented simultaneous additive and interactive effects of landuse change on in-stream conditions. Moreover, we know of no other field study documenting the effects of $>2$ landuse stressors. We did not test explicitly for mechanisms underlying observed additive and interactive effects, but we agree with Merriam et al. (2011) that the unique nature of residential development in this region (i.e., confined to narrow floodplains with limited centralized sewer systems) results in severe impacts via degraded physical habitat and water quality. Our results generally support the contention that mining-related waterchemistry degradation and development-related physical-habitat degradation combine additively 
to degrade biological communities (Merriam et al. 2011).

We predicted high levels of chemical (e.g., $60 \%$ of stream segments $>300 \mu \mathrm{S} / \mathrm{cm}$ specific conductance) and biological (e.g., 79\% of stream segments exceeded the threshold for GLIMPSS) impairment as a result of additive and interactive effects of current anthropogenic stressors. Under the future mining scenario, we predicted a nearly $25 \%$ increase in the number of stream reaches exceeding the recognized specific-conductance benchmark and Se criteria and a $15 \%$ increase in the number of reaches that were biologically impaired with respect to WVSCI and GLIMPSS. Moreover, a greater proportion of streams with pre-existing residential or deepmine influence exceeded chemical and biological thresholds at all levels of additional surface mining relative to streams affected by surface mining alone. Our results suggest that pre-existing landscape condition will strongly influence the impact of future mine development, and consequently, downstream ecosystem response to new mine development is context dependent.

A growing body of literature reports context-dependent responses to contaminants in aquatic systems (Clements et al. 2012). Rohr and Crumrine (2005) found that initial community composition (i.e., pre-existing community context) influenced effects of pesticides on freshwater communities. Moreover, $2 / 3$ of studies included in a meta-analysis of anthropogenic effects on marine systems found that pairwise interactions changed significantly following the addition of a $3^{\text {rd }}$ stressor (i.e., pre-existing stressor context; Crain et al. 2008). Thus, context-dependent effects of anthropogenic stressors appear to be relatively common in aquatic systems.

By including complex relationships and associated context-dependencies among landuse stressors into our models, we were able to explain $>70 \%$ of the variation in both water chemistry and macroinvertebrate community metrics, with similar predictive accuracies (i.e., $\mathrm{CV} R^{2}$ for chemical and biological endpoints $>0.70$ and 0.60 , respectively). Most studies aimed at modeling 
in-stream conditions from landuse patterns within the MTR-VF region have isolated effects of surface mining by factoring out effects of other landuse stressors. Consequently, making a direct comparison between our predictive models and those from other studies is difficult. However, our results suggest that incorporating complex relationships among landuse stressors, particularly those underlying scenario analyses, into predictive models is essential in this region. Failure to incorporate important predictor variables and underlying stressor interactions can result in models that are structurally incorrect and predictions that are fundamentally biased. More specifically, exclusion of important variables can result in biased estimation of model parameters (i.e., specification error and associated omitted variable bias) and confound interpretation of model output by leading to naive attribution of important variation to variables included in the model (Allen 1997, King et al. 2005). This situation is particularly problematic with ecological data sets, which commonly are affected by multicollinearity among landscape variables (King et al. 2005, Lucero et al. 2011). Incorrect models and associated bias can result in inaccurate predictions and lead to inappropriate and dangerous management decisions.

Our results demonstrate the utility of designing along multiple independent and combined stressor axes when attempting to relate landscape characteristics to altered in-stream conditions. Our study design resulted in a data set that was unbiased (i.e., minimized specification error and omitted variable biases) and unaffected by multicollinearity, and enabled us to quantify additive and interactive effects of landuse change. That is, it allowed us to quantify cumulative effects of surface mining in isolation and in the presence of deep mining and residential development. Furthermore, by incorporating our landscape-based models into a spatially explicit, GIS-based modeling framework (Strager et al. 2009), we were able to predict current conditions and the likely outcome of a realistic future mining scenario for all SLVs in the Coal River watershed. 
We were able to sample only 40 streams, but additional sites would be unlikely to change our final models. We specifically designed our study to provide measures of multiple landuse stressors that were well suited for multiple regression analysis (uncorrelated and representative of the full range of conditions present in the Coal River watershed along multiple stressor axes). Moreover, results of our simple linear regression analyses relating chemical and biological endpoints to land use (Fig. 3A-I) corroborated additive and interactive effects retained in our final multiple regression models. However, we do recognize that a larger sample size would improve the confidence of our parameter estimates and our ability to detect significant higherorder interactions. One goal of our continued research effort is to determine whether the complex cumulative effects observed in the Coal River watershed are consistent throughout the entire MTR-VF mining region of central Appalachia.

High rates of biological impairment observed during our study may partially reflect a metacommunity-scale deflation of aquatic assemblages (McClurg et al. 2007, Merovich and Petty 2010, Brown et al. 2011). Pond et al. (2008) observed much higher WVSCI and GLIMPSS scores in streams affected by a broad range of mining intensities in a different watershed, suggesting significant watershed-to-watershed variation in biological response to mining in this region. The Coal River watershed is embedded in an intensively mined region, with extremely high \% surface mining in all surrounding watersheds. Widespread landuse change probably reduces the surrounding species pool and limits dispersal. Such metacommunity changes could prevent mass effects (i.e., high dispersal from environmentally suitable sites) from facilitating community recovery and taxon persistence, even in streams with relatively good water and habitat quality (see Heino 2013). An important goal of our continued research in this region is to quantify cumulative localized effects of landuse change and cumulative regional effects of 
widespread localized impacts (Freund and Petty 2007).

Research and management efforts focused solely on surface mining are of limited value to scenario analysis within the MTR-VF mining region where we need to predict stream response to surface mining under realistic conditions, which often include more than a single stressor. The models provided herein can be used by managers to predict the outcome of proposed landuse change in the Coal River watershed and to make appropriate regulatory decisions based not only upon proposed activity, but also on the landuse context within which it will occur. However, continued progress in this area will require a better understanding of how landuse change affects aquatic systems throughout the remainder of the MTR-VF mining region, where watershed-towatershed variation in landuse patterns probably causes variability in ecological response. Moreover, the process outlined in our study is transferable to watersheds in other regions where successful management of aquatic systems will require a better understanding of complex cumulative effects and associated context-dependencies resulting from a broad range of landuse stressors. 


\section{ACKNOWLEDGEMENTS}

We thank the numerous field and laboratory helpers that were involved in various aspects of this study, especially Eric Miller and Donna Hartman. We also thank 2 anonymous referees for comments on earlier versions of the manuscript. Funding for this study was provided by the US Environmental Protection Agency Region III. Although the research described in this article has been funded by the US Environmental Protection Agency, it has not been subjected to the agency's required peer and policy review and, therefore, does not necessarily reflect the views of the agency, and no official endorsement should be inferred. 


\section{LITERATURE CITED}

Allan, J. D. 2004. Landscapes and riverscapes: the influence of land use on stream ecosystems. Annual Review of Ecology, Evolution, and Systematics 35:257-284.

Allen, M. P. 1997. Understanding regression analysis. Springer, New York.

Barbour, M. T., J. Gerritsen, B. D. Snyder, and J. B. Stribling. 1999. Rapid bioassessment protocols for use in streams and wadeable rivers: periphyton, benthic macroinvertebrates, and fish. $2^{\text {nd }}$ edition. EPA/841-B-99-022. US Environmental Protection Agency, Washington, DC.

Bernhardt, E. S., B. D. Lutz, R. S. King, J. P. Fay, C. E. Carter, A. M. Helton, D. Campagna, and J. Amos. 2012. How many mountains can we mine? Assessing the regional degradation of central Appalachian rivers by surface coal mining. Environmental Science and Technology 46:8115-8122.

Brian, J. V., C. A. Harris, M. Scholze, T. Backhaus, P. Booy, M. Lamoree, G. Pojana, N. Jonkers, T. Runnalls, A. Bonfa, A. Marcomini, and J. P. Sumpter. 2005. Accurate prediction of the response of freshwater fish to a mixture of extrogenic chemicals. Environmental Health Perspectives 113:721-728.

Brown, B. L., C. M. Swan, D. A. Auerbach, E. H. Campbell Grant, N. P. Hitt, K. O. Maloney, and C. Patrick. 2011. Metacommunity theory as a multispecies, multiscale framework for studying the influence of river network structure on riverine communities and ecosystems. Journal of the North American Benthological Society 30:310-327.

Carlisle, D. M., J. Falcone, and M. R. Meador. 2009. Predicting the biological condition of streams: use of geospatial indicators of natural and anthropogenic characteristics of watersheds. Environmental Monitoring and Assessment 151:143-160. 
Clapcott, J. E., R. G. Young, E. O. Goodwin, and J. R. Leathwick. 2010. Exploring the response of functional indicators of stream health to land-use gradients. Freshwater Biology $55: 2181-2199$.

Clements, W. H. 2004. Small-scale experiments support causal relationships between metal contamination and macroinvertebrate community responses. Ecological Applications 14:954-967.

Clements, W. H., C. W. Hickey, and K. A. Kidd. 2012. How do aquatic communities respond to contaminants? It depends on the ecological context. Environmental Toxicology and Chemistry 31:1932-1940.

Cormier, S. M., G. W. Suter, L. L. Yuan, and L. Zheng. 2011. A field-based aquaic life benchmark for conductivity in central Appalachian streams. EPA/600/R-10/023F. US Enviromental Protection Agency, Washington, DC.

Crawley, M. J. 2005. Statistics: an introduction using R. Wiley and Sons, Chichester, UK.

Crain, C. M., K. Kroeker, and B. S. Halpern. 2008. Interactive and cumulative effects of multiple human stressors in marine systems. Ecology Letters 11:1304-1315.

Cuffney, T. F., M. R. Meador, S. D. Porter, and M. E. Gurtz. 2000. Response of physical, chemical, and biological indicators of water quality to a gradient of agricultural land use in the Yakima River Basin, Washington. Environmental Monitoring and Assessessment 64:259-270.

Duinker, P. N., and L. A. Greig. 2006. The importance of cumulative effects assessment in Canada: ailments and ideas for redeployment. Environmental Management 37:153-161.

Freund, J. G., and J. T. Petty. 2007. Response of fish and macroinvertebrate bioassessment indices to water chemistry in a mined Appalachian watershed. Environmental 
Management 39:707-720.

Gerritsen, J., J. Burton, and M. T. Barbour. 2000. A stream condition index for West Virginia wadeable streams. Tetra Tech, Inc., Owings Mills, Maryland. (Available from: http://www.dep.wv.gov/WWE/watershed/bio_fish/Documents/WVSCI.pdf)

Greig, H. S., P. Kratina, P. L. Thompson, W. J. Palen, J. S. Richardson, and J. B. Shurin. 2012. Warming, eutrophication, and predator loss amplify subsidies between aquatic and terrestrial ecosystems. Global Change Biology 18:504-514.

Hejda, M., P. Pysek, and V. Jarosik. 2009. Impact of invasive plants on the species richness, diversity and composition of invaded communities. Journal of Ecology 97:393-403.

Heino, J. 2013. The importance of metacommunity ecology for environmental assessment research in the freshwater realm. Biological Reviews 88:166-178.

Hynes, H. B. N. 1975. The stream and its valley. Verhandlungen der Internationalen Vereinigung für theoretische und angewandte Limnologie 19:1-15.

Johnson, B. R., A. Haas, and K. M. Fritz. 2010. Use of spatially explicit physicochemical data to measure downstream impacts of headwater stream disturbance. Water Resources Research 46:W09526. doi:10.1029/2009WR008417

Johnson, L. B., and G. E. Host. 2010. Recent developments in landscape approaches for the study of aquatic ecosystems. Journal of the North American Benthological Society 29:41-66.

Junghans, M., T. Backhaus, M. Faust, M. Scholze, and L. H. Grimme. 2006. Application and validation of approaches for the predictive hazard assessent of realistic pesticide mixtures. Aquatic Toxicology 76:93-110.

Kepner, W. G., M. M. Ramsey, E. S. Brown, M. E. Jarchow, K. J. M. Dickinson, and A. F. 
Mark. 2012. Hydrologic futures: using scenario analysis to evaluate impacts of forecasted land use change on hydrologic services. Ecosphere 3:1-25.

King, R. S., M. E. Baker, P. F. Kazyak, and D. E. Weller. 2011. How novel is too novel? Stream community thresholds at exceptionally low levels of catchment urbanization. Ecological Applications 21:1659-1678.

King, R. S., M. E. Baker, D. F. Whigham, D. E. Weller, T. E. Jordan, P. F. Kazyak, and M. K. Hurd. 2005. Spatial considerations for linking watershed land cover to ecological indicators in streams. Ecological Applications 15:137-153.

Likens, G. E., and F. H. Bormann. 1974. Linkages between terrestrial and aquatic ecosystems. BioScience 24:447-456.

Lindberg, T. T., E. S. Bernhardt, R. Bier, A. M. Helton, R. B. Merola, A. Vengosh, and R. T. di Giulio. 2011. Cumulative impacts of mountaintop mining on an Appalachian watershed. Proceedings of the National Academy of Sciences of the United States of America 108:20929-20934.

Lucero, Y., E. A. Steel, K. M. Burnett, and K. Christiansen. 2011. Untangling human development and natural gradients: Implications of underlying correlation structure for linking landscapes and riverine ecosystems. River Systems 19:207-224.

Mahmoud., M. I., H. V. Gupta, and S. Rajogopal. 2011. Scenario development for water resources planning and watershed management: methodolgoy and semi-arid region case study. Ecological Modelling and Software 26:873-885.

Maindonald, J. and W. J. Braun. 2013. DAAG: data analysis and graphics data and functions. R package version 1.16. R Project for Statistical Computing, Vienna, Austria.

McClurg, S. E., J. T. Petty, P. M. Mazik, and J. L. Clayton. 2007. Stream ecosystem response to 
limestone treatment in acid impacted watersheds of the Allegheny Plateau. Ecological Applications 17:1087-1104.

Merovich, G. T., and J. T. Petty. 2007. Interactive effects of multiple stressors and restoration priorities in a mined Appalachian watershed. Hydrobiologia 575:13-31.

Merovich, G. T., and J. T. Petty. 2010. Continuous response of benthic macroinvertebrat assemblages to a discrete disturbance gradient: consequences for diagnosing stressors. Journal of the North American Benthological Society 29:1241-1257.

Merovich, G. T., J. M. Stiles, J. T. Petty, P. F. Ziemkiewicz, and J. B. Fulton. 2007. Water chemistry-based classification of streams and implications for restoring mined Appalachian watersheds. Environmental Toxicolgy and Chemistry 26:1361-1369.

Merriam, E. R., J. T. Petty, G. T. Merovich, J. B. Fulton, and M. P. Strager. 2011. Additive effects of mining and residential development on stream conditions in a central Appalachian watershed. Journal of the North American Benthological Society 30:399418.

Merritt, R. W., and K. W. Cummins (EDITORS). 2008. An introduction to the aquatic insects of North America. $4^{\text {th }}$ edition. Kendall/Hunt Publishing Co., Dubuque, Iowa.

Moe, S. J., K. de Schamphelaere, W. H. Clements, M. T. Sorensen, P. J. Van den Brink, and M. Liess. 2013. Combined and interactive effects of global climate change and toxicants on popoulations and communities. Environmental Toxicology and Chemistry 32:49-61.

Palmer, M. A., E. S. Bernhardt, W. H. Schlesinger, K.N. Eshleman, E. Foufoula-Georgiou, M. S. Hendryx, A. D. Lemly, G. E. Likens, O. L. Loucks, M. E. Power, P. S. White, and P. R. Wilcock. 2010. Mountaintop mining consequences. Science 327:148-149.

Peckarsky, B. L., P. R. Fraissinet, M. A. Penton, and D. J. Conklin. 1990. Freshwater 
macroinvertebrates of northeastern North America. Cornell University Press, Ithaca, New York.

Petty, J. T., J. Freund, P. Lamothe, and P. Mazik. 2001. Quantifying instream habitat in the upper Shavers Fork basin at multiple spatial scales. Proceedings of the Annual Conference of the Southeastern Association of Fisheries and Wildlife Agencies 55:81-94.

Petty, J. T., J. B. Fulton, M. P. Strager, G. T. Merovich, J. M. Stiles, and P. F. Ziemkiewicz. 2010. Landscape indicators and thresholds of stream ecological impairment in an intensively mined Appalachian watershed. Journal of the North American Benthological Society 29:1292-1309.

Phillimore, A. B., and P. F. Owens. 2006. Are subspecies useful in evoutionary and conservation biology. Proceedings of the Royal Society of London Series B: Biological Sciences 276:1049-1053.

Pond, G. J., J. E. Bailey, B. M. Lowman, and M. J. Whitman. 2012. Calibration and validation of a regionally and seasonally stratified macroinbertebrate index for West Virginia wadeable streams. Environmental Monitoring and Assessment. doi: 10.1007/s10661-012-2648-3

Pond, G. J., M. E. Passmore, F. A. Borsuk, L. Reynolds, and C. J. Rose. 2008. Downstream effects of mountaintop coal mining: comparing biological conditions using family- and genus-level macroinvertebrate bioassessment tools. Journal of the North American Benthological Soceity 27:717-737.

Porter, E. M., W. D. Bowman, C. M. Clark, J. E. Compton, L. H. Pardo, and J. L. Soong. 2012. Interactive effects of anthropogenic nitrogen enchriment and climate change on terrestrial and aquatic biodiversity. Biogeochemistry. doi: 10.1007/s10533-012-9803-3

Rohr, J. R., and P. W. Crumrine. 2005. Effects of an herbicide and an insecticide on pond 
community structure and processes. Ecological Applications 15:1135-1147.

Seitz, N. E., C. J. Westbrook, and B. F. Noble. 2010. Bringing science into river systems cumulative effects assessment practice. Environmental Impact Assessment and Review $31: 172-179$.

Strager, M. P., J. T. Petty, J. M. Strager, and J. Barker-Fulton. 2009. A spatially explicit framework for quantifying downstream hydrologic conditions. Journal of Environmental Management 90:1854-1861.

USEPA (US Environmental Protection Agency). 1983. Methods for chemical analysis of water and wastes. EPA-60014-79-020. Environmental Monitoring Systems Support Laboratory, Office of Research and Development, US Environmental Protection Agency, Cincinnati, Ohio.

USEPA (US Environmental Protection Agency). 1987. Ambient water quality criteria for selenium. EPA-440/445-487-006. Office of Water Regulations and Standards, US Environmental Protection Agency, Washington, DC.

Utz, R. M., K. N. Eshleman, and R. H. Hilderbrand. 2011. Variation in physicochemical responses to urbanization in streams between two mid-Atlantic physiographic regions. Ecological Applications 21:402-415.

Utz, R. M., R. H. Hilderbrand, and R. L. Reasly. 2010. Regional differences in patterns of fish species loss with changing land use. Biological Conservation 143:688-699.

Wolman, M. G. 1954. A method of sampling coarse river-bed material. Transactions of the American Geophysical Union 35:951-956.

WVDEP (West Virginia Department of Environmental Protection). 2009. Standard operating proceedures. West Virgina Department of Environmental Protection, Charleston, West 
Virginia. (Available from: http://www.dep.wv.gov/WWE/watershed/wqmonitoring/ Documents/SOP\%20Doc/WAB\%20SOP.pdf ) 


\section{FIGURE CAPTIONS}

Fig. 1. Maps of the Coal River watershed illustrated with 1:100,000-scale stream segments and surface-mine permit boundaries and deep-mine national pollution discharge elimination system (NPDES) permits (A), point locations of commercial and residential structures (B), and study sites (C). Flow direction is to the northwest.

Fig. 2. Magnitude of surface mining and residential development for selected study sites ( $n=$ 40). Larger symbols $=$ sites with deep-mining national pollution discharge elimination system (NPDES) permits.

Fig. 3. Chemical and biological response to anthropogenic stressors. Scatter plots of specific conductance (A), Se (D), and Genus-Level Index of Most Probable Stream Status (GLIMPSS) (G) vs \% surface mining across study sites without deep-mine national pollution discharge elimination system (NPDES) permits $(n=19)$; linear relationships between deviation of the 19 sites without deep-mine NPDES permits from regressions in Fig. 3A (B), Fig. 3D (E), and Fig. 3G (H) and structure density; and linear relationships between deviation of all sites (i.e., presence/absence of deep-mine NPDES permits) from regressions in Fig. 3A (C), Fig. 3D (F), and Fig. 3G (I) and structure density. Lines, equations, and $R^{2}$ values in panels $\mathrm{A}, \mathrm{D}$, and $\mathrm{G}$ represent relationships across sites along the surface-mining gradient without deep-mine NPDES permits (black circles; $n=6$ ). In all panels, hollow circles $=$ development gradient, black circles $=$ surface-mining gradient, grey circles $=$ combined sites. In panels $\mathrm{C}, \mathrm{F}$, and I, larger symbols represent sites in each category with deep-mining NPDES permits.

Fig. 4. Percentage of segment-level watersheds (SLWs) falling within discrete landscapeattribute (A) and in-stream response-variable (B) categories under the current land uses. 
Numbers denote discrete categories. WVSCI = West Virginia Stream Condition Index, GLIMPSS $=$ Genus-Level Index of Most Probable Stream Status.

Fig. 5. Predicted specific conductance (SpC) (A), Se (B), and West Virginia Stream Condition Index (WVSCI) (C) under current landscape conditions, the 15-mine-permit scenario, and relative change from current for all segment-level watersheds (SLWs) affected under the 15-mine permit scenario. HUC = Hydrologic Unit Code.

Fig. 6. Change in the percentage of segment-level watersheds (SLWs) falling within discrete landscape-attribute (A) and in-stream response-variable (B) categories under the 15-mine permit scenario. Changes are shown relative to current values. Numbers denote discrete categories. WVSCI $=$ West Virginia Stream Condition Index, GLIMPSS $=$ Genus-Level Index of Most Probable Stream Status.

Fig. 7. Percentage of segment-level watersheds (SLWs with cumulative basin areas $<40 \mathrm{~km}^{2}$ ) with specific conductance $<500 \mu \mathrm{S} / \mathrm{cm}$ (A) and with West Virginia Stream Condition Index $($ WVSCI $)>68$ (B) predicted under various levels of $\%$ change in surface mining land use associated with future implementation of surface mine permits. SLWs are grouped with respect to pre-existing landscape context. $\mathrm{SM}=$ surface mining, $\mathrm{SD}=$ structure density, $\mathrm{DM}=$ deep mining. 
Table 1. Coefficients of determination $\left(R^{2}\right)$, cross-validation coefficients $\left(\mathrm{CV} R^{2}\right)$, and parameter estimates (SE) for minimum adequate models. RVHA = Rapid Visual Habitat Assessment, SpC $=$ specific conductance, GLIMPSS $=$ Genus-Level Index of Most Probable Stream Status, WVSCI = West Virginia Stream Condition Index, SM = surface mining, DM = deep mining, SD $=$ structure density.

\begin{tabular}{lccccc}
\hline \hline \multicolumn{1}{c}{ Parameter } & $\arcsin \sqrt{(\mathrm{RVHA})}$ & $\ln (\mathrm{SpC})$ & $\ln (\mathrm{Se})$ & GLIMPSS & WVSCI \\
\hline Model $R^{2}$ & 0.15 & 0.77 & 0.61 & 0.70 & 0.57 \\
$\mathrm{CV} \mathrm{R} R^{2}$ & 0.07 & 0.72 & 0.57 & 0.64 & 0.46 \\
Intercept & $1.00(0.03)$ & $4.87(0.19)$ & $-7.39(0.21)$ & $59.46(3.63)$ & $81.16(3.75)$ \\
$\arcsin \sqrt{ }(\% \mathrm{SM})$ & - & $2.45(0.27)$ & $3.45(0.45)$ & $-25.20(4.96)$ & $-19.90(5.12)$ \\
$\ln (\mathrm{DM})$ & - & $1.07(0.42)$ & - & $-36.94(10.42)$ & $-29.94(10.76)$ \\
$\ln (\mathrm{SD})$ & $-0.04(0.01)$ & $0.24(0.06)$ & - & $-9.93(1.16)$ & $-7.74(1.19)$ \\
$\ln (\mathrm{DM}) \times \ln (\mathrm{SD})$ & - & - & - & $20.78(3.62)$ & $18.12(5.92)$ \\
\hline
\end{tabular}



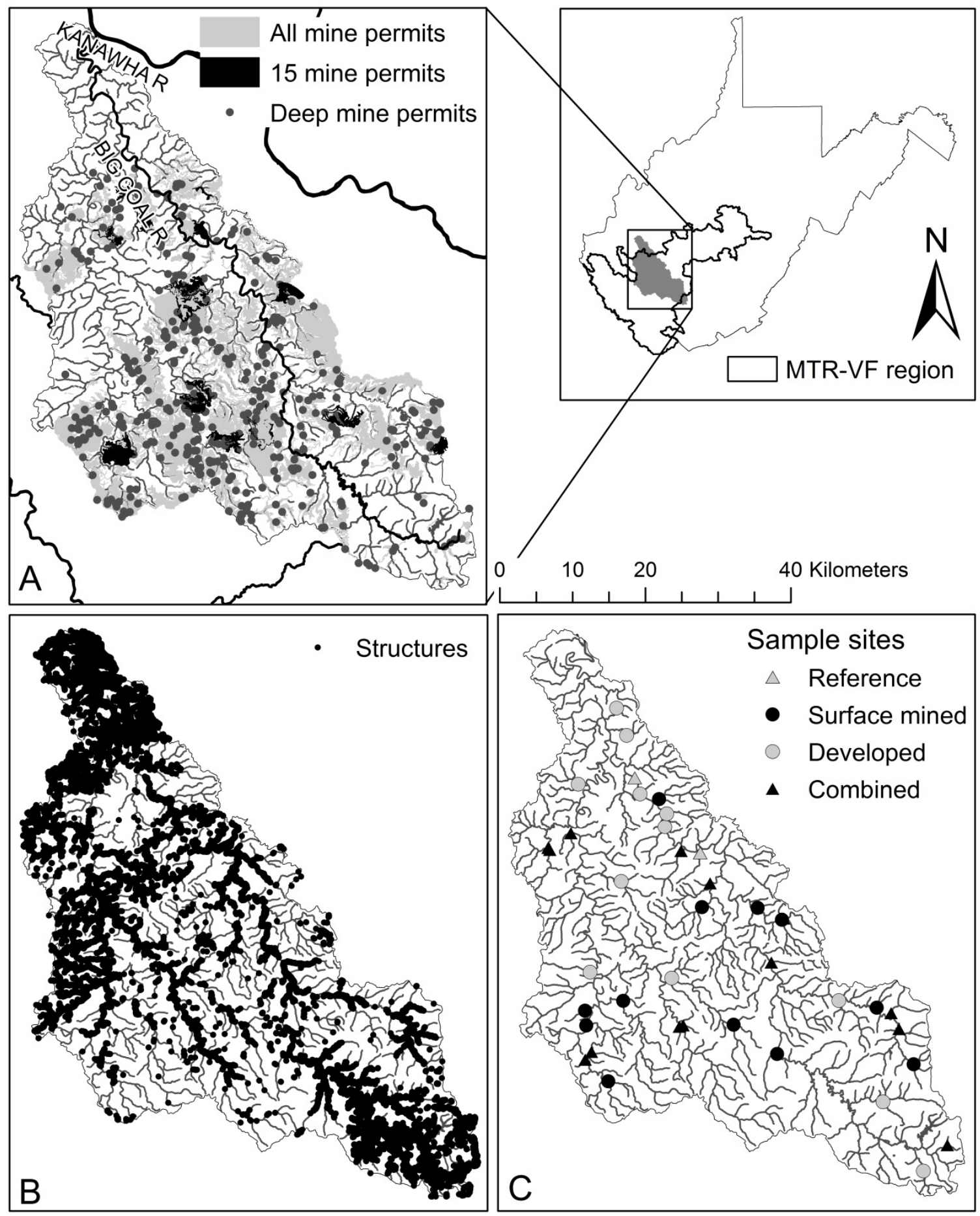

Fig. 1 


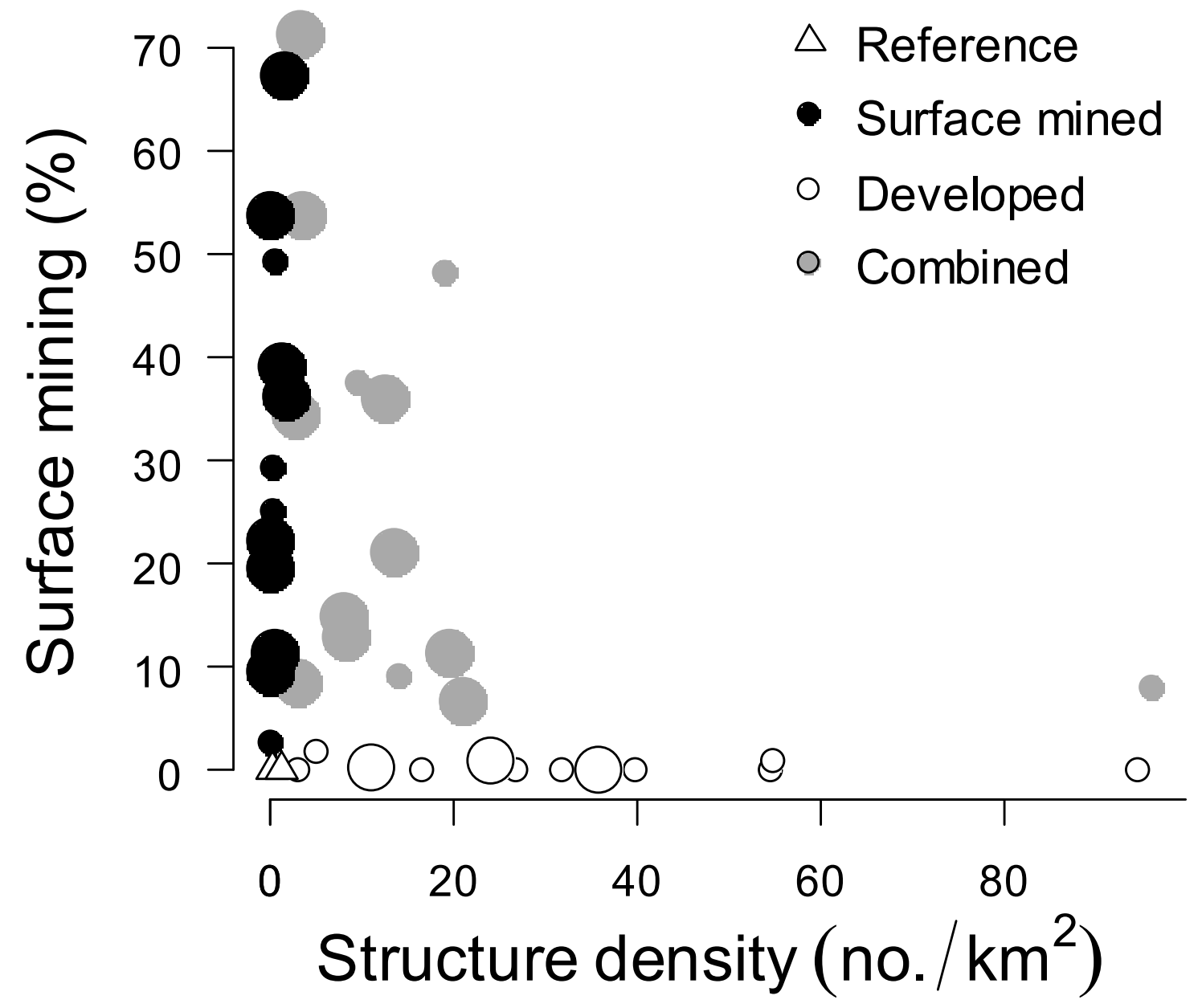

Fig. 2 

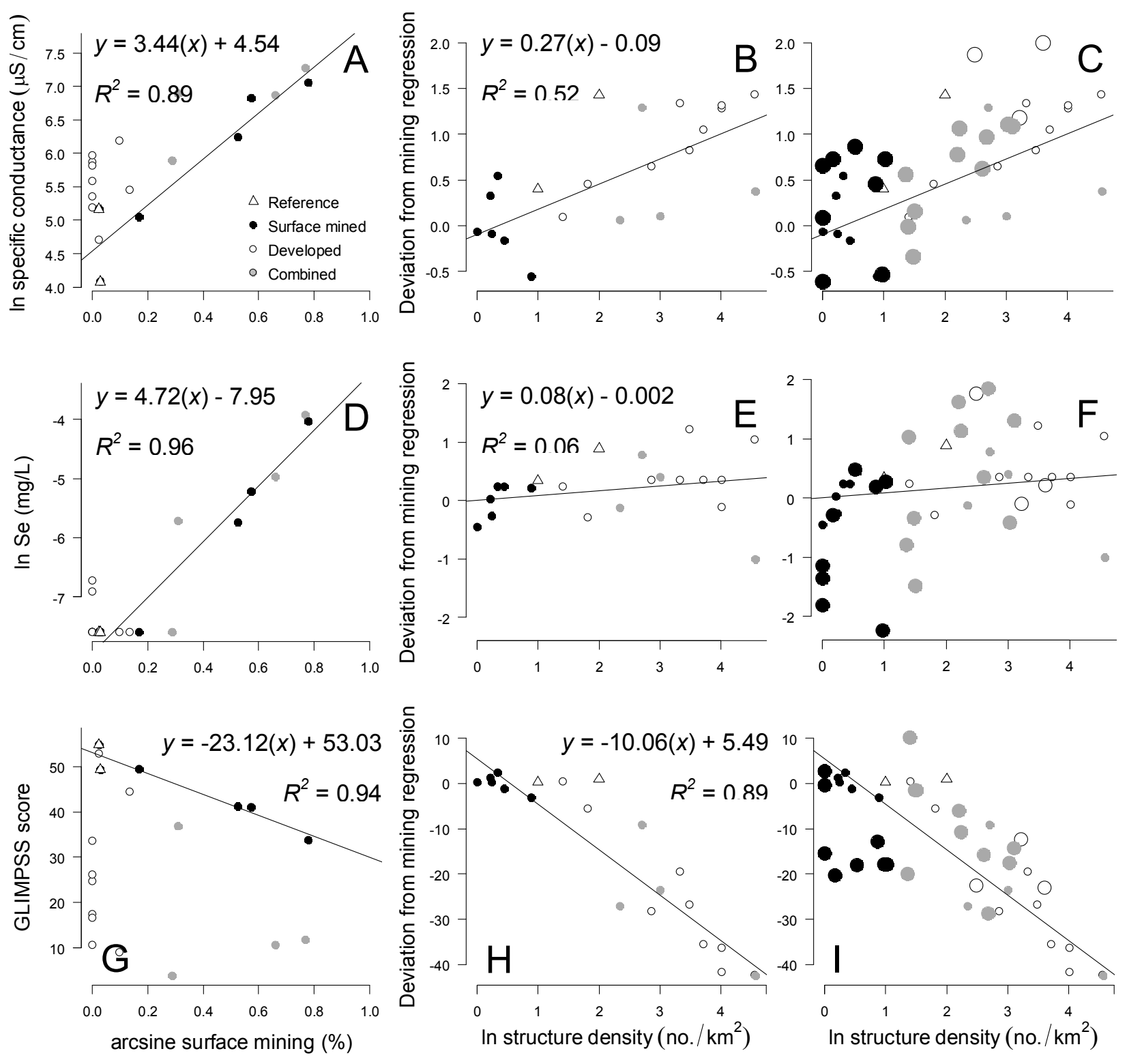

Fig. 3 


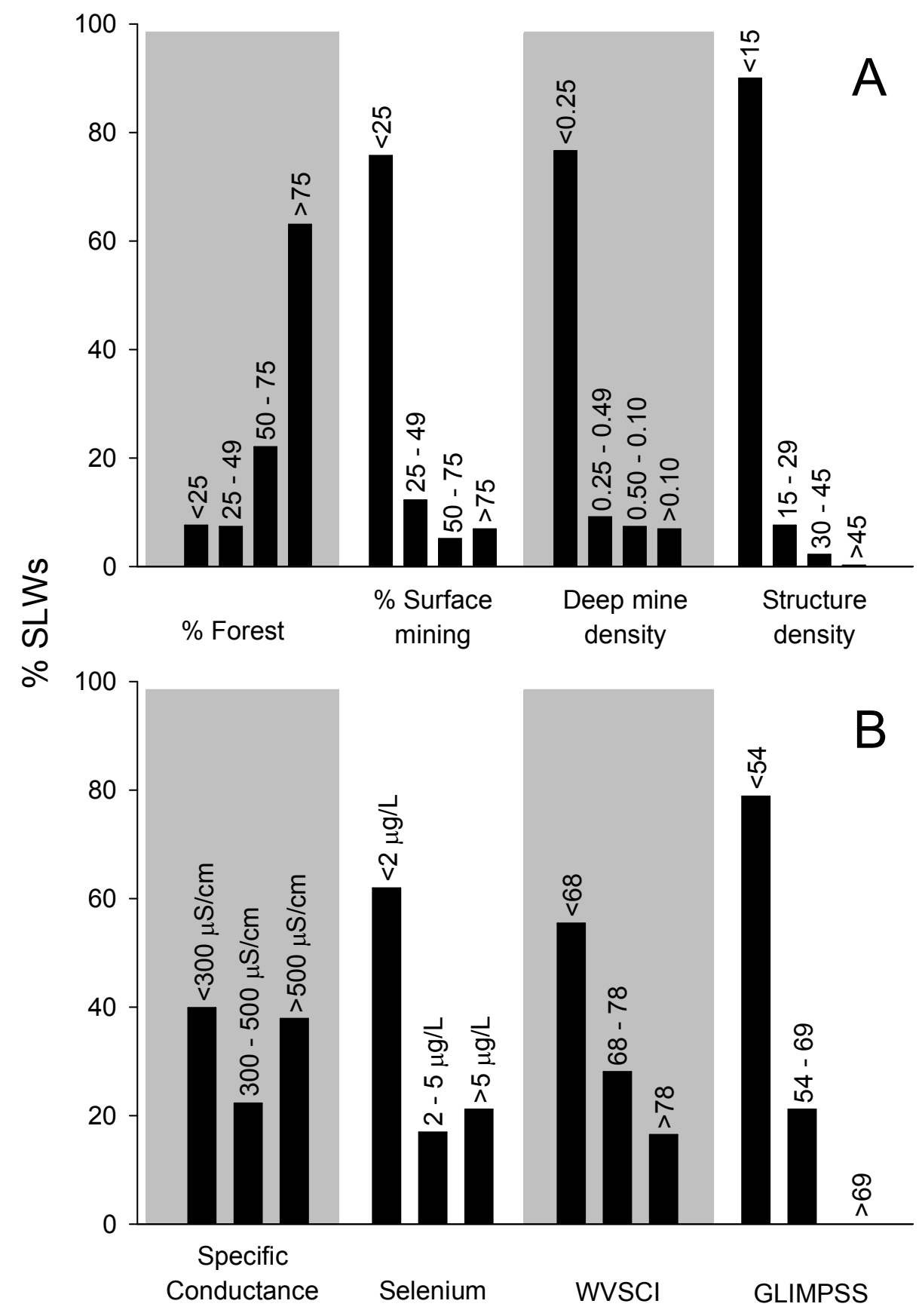

Fig. 4 


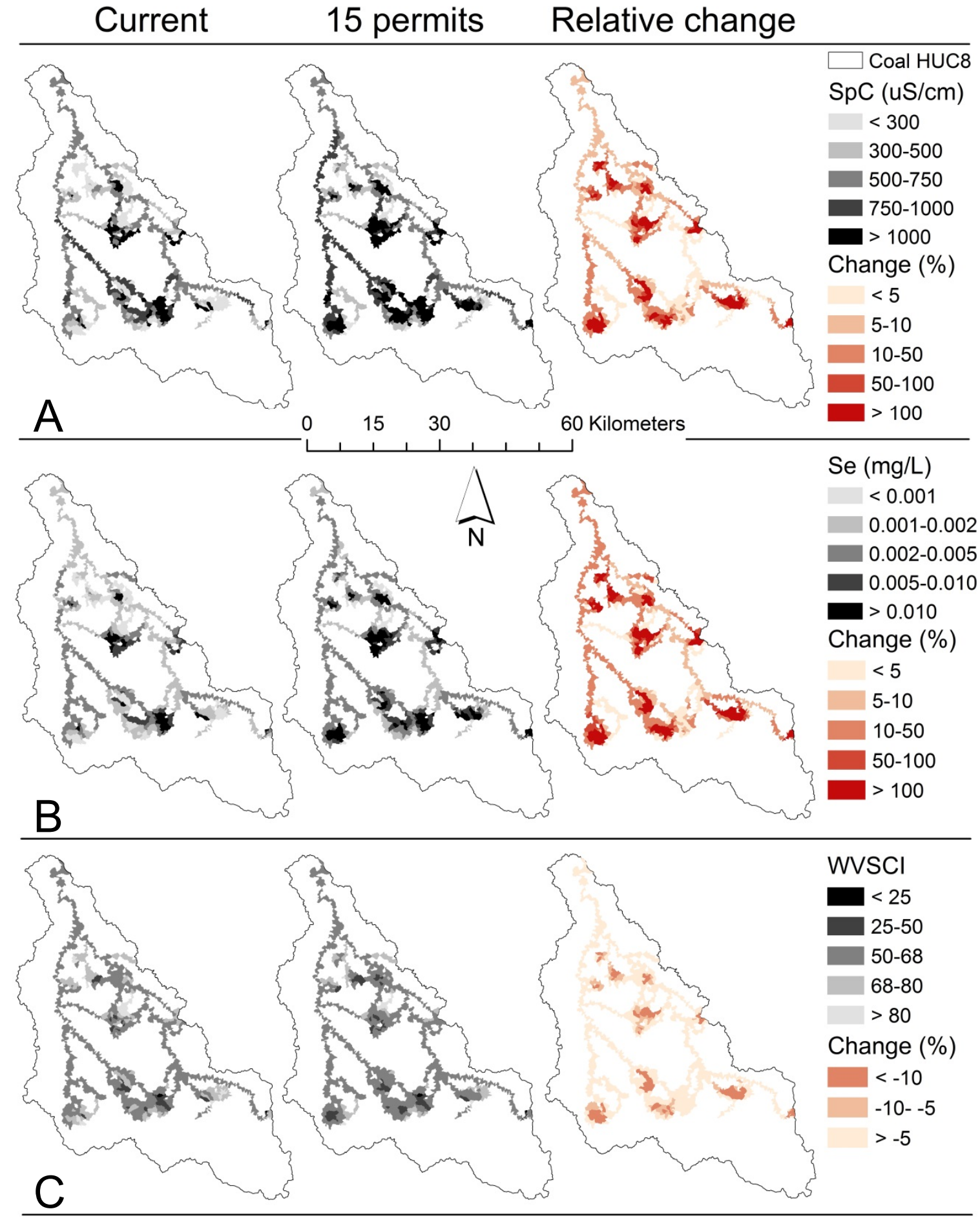

Fig. 5 


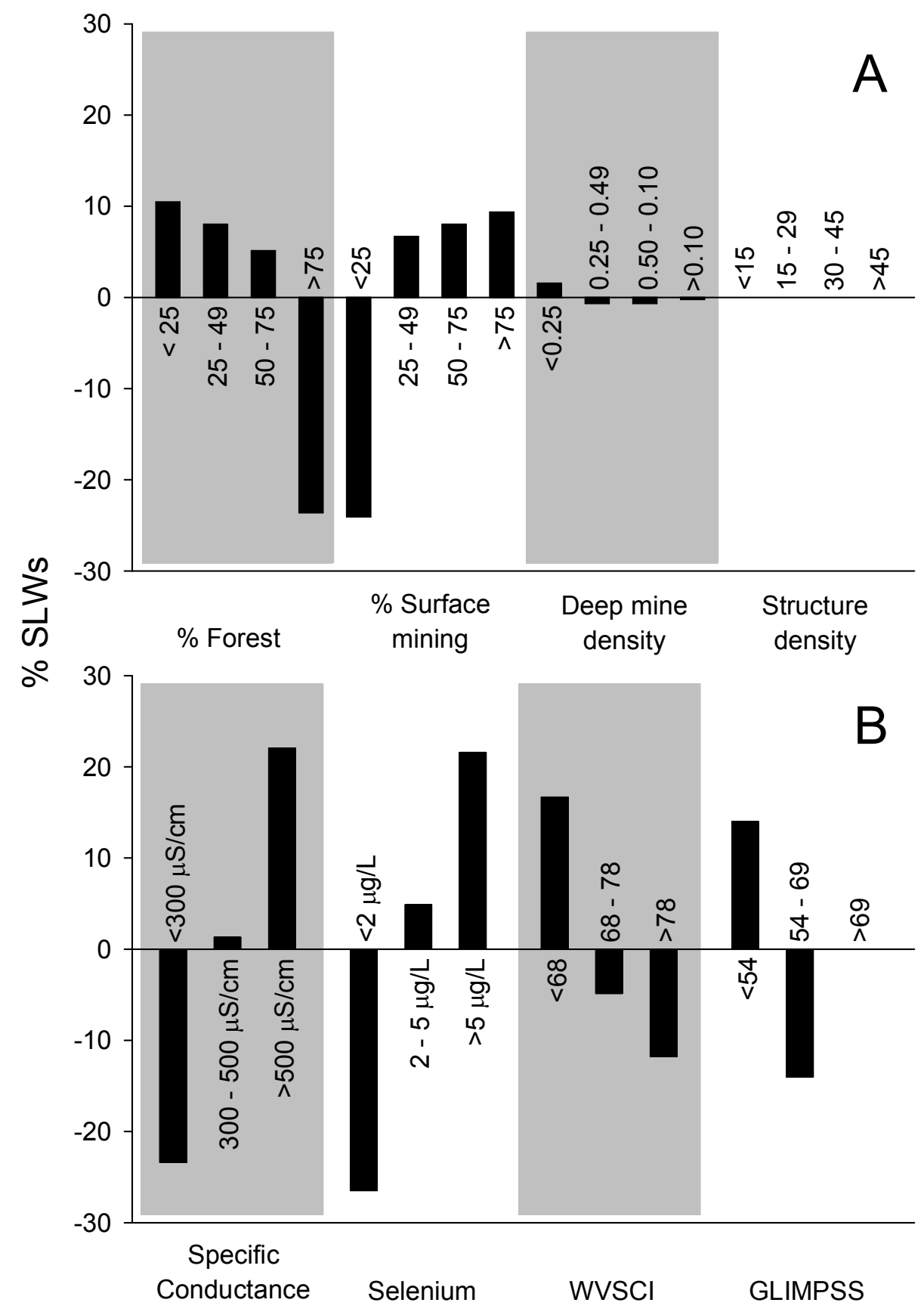

Fig. 6 


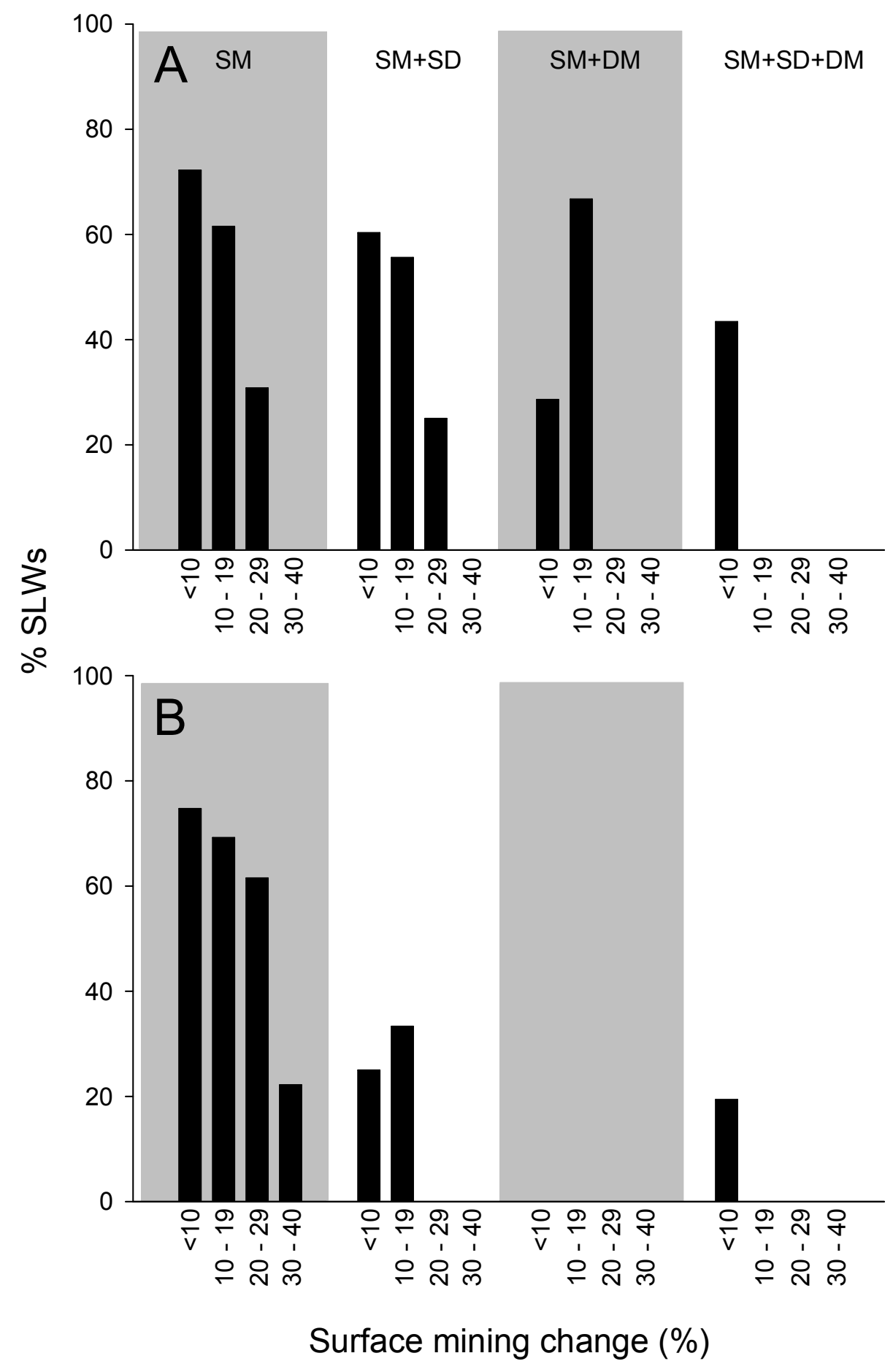

Fig. 7 
CHAPTER 2: Landscape-based cumulative effects models for predicting stream response to mountaintop mining in multistressor Appalachian watersheds

This chapter has been accepted for publication in the journal Freshwater Science and follows their required formatting.

Merriam, E. R., J. T. Petty, M. P. Strager, A. E. Maxwell, and P. Ziemkiewicz. 2015. Landscapebased cumulative effects models for predicting stream response to mountaintop mining in multistressor Appalachian watersheds. Freshwater Science 34:000-000. 
Abstract: We conducted a survey of 170 streams distributed throughout the mountaintop-mining region of West Virginia (USA) and linked stream data to a temporally consistent and comprehensive land-cover data set. We then applied a generalized linear modeling framework and constructed cumulative effects models capable of predicting in-stream response to future surface-mine development within the context of other landuse activities. Predictive models provided precise estimates of specific conductance (model $R^{2} \leq 0.77$ and cross-validated $R^{2}$ $\leq 0.74)$, Se (0.74 and 0.70$)$, and benthic macroinvertebrate community composition $(0.72$ and 0.65). Deletion tests supported the conclusion that stream degradation across the region is the result of complex but predictable additive and interactive effects of surface mining, underground mining, and residential development. Furthermore, we found that as stressors other than surface mining are factored out completely, the surface-mining level that results in exceedance of the $300 \mu \mathrm{S} / \mathrm{cm}$ conductivity benchmark increased from $4.4 \%$ in the presence of other stressors to $16.6 \%$ when only surface mining was present. Last, extrapolating model results to all unsampled stream segments in the region $(n=26,135)$, we predicted high levels of chemical $(33 \%)$ and biological (67\%) impairment to streams on the current landscape. Of this total impairment, however, $<25 \%$ could be attributed to surface mining alone. These results underscore the importance of multistressor landuse models for reliable predictions of stream conditions, and the difficulty of interpreting correlations between surface mining and stream impairment without fully accounting for other landuse activities. 


\section{INTRODUCTION}

Managing aquatic resources in actively developing watersheds requires a thorough understanding of relationships between anthropogenic activity and altered in-stream conditions. Considerable effort has been put toward assessing effects of individual landuse activities, such as urbanization (King et al. 2011), agriculture (Cuffney et al. 2000, King et al. 2005), and mining (Petty et al. 2010, Lindberg et al. 2011, Bernhardt et al. 2012, Merovich et al. 2013). However, at regional scales, the likelihood that aquatic systems are affected by multiple and often covarying landuse activities increases (King et al. 2005). Failure to properly account for important landuse activities could result in confounded relationships between individual landuse activities and aquatic conditions, which could lead to inappropriate and potentially counterproductive management decisions (King et al. 2005). Moreover, stressors associated with multiple landuse activities combine additively and synergistically across space and time to result in unique patterns of degradation (i.e., cumulative effects; Duinker and Greig 2006, Seitz et al. 2010). Thus, successful management of aquatic resources in regions influenced by multiple landuse activities will require addressing individual and cumulative effects of all current and future landuse activities at appropriate spatial scales.

A recent effort has been made to construct models capable of predicting and forecasting aquatic conditions in the face of multiple landuse activities (Luo et al. 2011, Kepner et al. 2012). Processes underlying ecosystem response to landuse change often are very complex (e.g., macroinvertebrate community response to urbanization; King et al. 2005), particularly at large spatial scales. Therefore, mechanistic models (mathematical models based on key mechanisms or processes) often are not feasible, so that statistical models (mathematical models based on correlations between predictor and response variables) are necessary when managing aquatic 
systems in actively developing watersheds (Nilsson et al. 2003, Strayer et al. 2003). Statistical models also enable continuous description of ecological conditions at multiple spatial scales and are increasingly used by resource managers to make decisions regarding proposed landuse activity (Carlisle et al. 2009, Merovich et al. 2013, Merriam et al. 2013).

The mountaintop removal-valley fill (MTR-VF) mining province of central Appalachia represents a dynamic region where present-day anthropogenic alteration of natural landscapes is a major threat to aquatic resource sustainability (Palmer et al. 2010). Recent studies have linked increased specific conductance and associated dissolved ion (e.g., $\mathrm{Ca}^{2+}, \mathrm{Mg}^{2+}, \mathrm{SO}_{4}^{-}$, and $\mathrm{HCO}_{3}^{-}$) and trace element (e.g., Se) concentrations and decreased biological condition to the extent of upstream surface mining (Lindberg et al. 2011, Bernhardt et al. 2012, Cormier et al. 2013). Our own research has shown that extent of surface mining interacts with other landuse activities, such as underground mining and residential development, to result in high levels of chemical and biological degradation within specific areas of this region (Merriam et al. 2011, 2013).

In a previous study, we developed models for predicting habitat quality, water quality, and biological condition from landscape characteristics within a single 8-digit hydrological unit code (HUC) watershed in the MTR-VF mining region of West Virginia (Coal River watershed) (Merriam et al. 2013). Our current objectives were to: 1) determine if the strength and pattern of relationships observed in the Coal River watershed are consistent across watersheds and spatial scales (i.e., within and across all watersheds) in the MTR-VF region of West Virginia; 2) develop and validate models for predicting aquatic response to landuse change, and 3) apply these models to predict and summarize aquatic conditions in all unsampled stream segments and summarize exceedance of chemical and biological criteria by landuse context (i.e., specific combinations of major landuse activities). 


\section{METHODS}

\section{Study area}

The study area consists of the eight 8-digit hydrologic unit code (HUC) watersheds that intersect the primary MTR-VF mining region in West Virginia. These watersheds collectively drain 20,795 $\mathrm{km}^{2}$ and include the Elk River, Gauley River, Upper Kanawha River, Coal River, Upper Guyandotte River, Lower Guyandotte River, Twelvepole Creek, and Tug Fork (Fig. 1). Underlying geology consists of interbedded Pennsylvanian-age sandstone, siltstone, shale, and multiple layers of low-S coal. Land cover in the study region is predominantly forested $(\sim 80 \%)$. Coal mining (surface and underground) and residential development are the dominant forms of land use. Surface mining accounts for $\sim 3 \%\left(600 \mathrm{~km}^{2}\right)$ of total land area throughout the study region, and there are $>2000$ underground mine national pollution discharge elimination system (NPDES) permits. Residential land use accounts for $6 \%$ of total land area, and there are $>325,000$ residential and commercial structures (WVSAMB 2003). The remaining land cover area is mostly composed of grass and pasture lands. Coal mining and residential land use are pervasive in the region, but their intensities vary among 8-digit HUC watersheds (Fig. 1A-D).

\section{Landscape data}

We used spatial analysis functions in ArcGIS ArcMap (version 10.1; Environmental Systems Research Institute, Redlands, California) in conjunction with flow tables to calculate cumulative measures of each landscape attribute for all 1:24,000 segment-level watersheds (SLWs) in the study region (Strager et al. 2009). We used land-cover classifications derived from 2011 National Agricultural Imagery Program (NAIP) to characterize base land cover and use 
across the study region (Maxwell et al. 2011). NAIP imagery is flown during July, so we were able to link the timing of our landuse characterization and in-stream sampling. Base land-cover classifications included forest, grass, and pasture lands, barren development, and open water. We used surface-mining permit boundaries developed by the West Virginia Department of Environmental Protection (WVDEP), which includes permitted areas for all surface-mine types and operations, to further differentiate mining related grasslands (i.e., reclaimed mine lands), barren development (i.e., active mine lands and mine facilities), and open water (i.e., mine impoundments). We used topographic maps in conjunction with known abandoned mine land locations to delineate the area of surface mining conducted prior to implementation of the Surface Mining Control and Reclamation Act (1977). We summed all surface-mining land cover classes (i.e., active and reclaimed, slurry impoundments, mine facilities, and abandoned mine lands) to obtain a measure of the total percentage of upstream surface mining land use. We obtained underground mine NPDES locations from the WVDEP and used these data to calculate the cumulative density of underground mine NPDES permits (no. $\left./ \mathrm{km}^{2}\right)$. We summarized data created by the Statewide Addressing and Mapping Board (WVSAMB 2003) to calculate the density of residential and commercial structures $\left(\right.$ no. $\left./ \mathrm{km}^{2}\right)$ as our final measure of residential development (Merriam et al. 2013). However, we also summarized \% residential development as characterized by the 2006 National Land Cover Database (NLCD), which enabled us to compare our results with those of previous studies (Bernhardt et al. 2012).

\section{Site selection}

We selected 170 SLWs throughout the MTR-VF region of West Virginia as study sites (Fig. 1A). We constrained our site selection to the 26,135 stream segments with basin areas $<40$ 
$\mathrm{km}^{2}$. All sites were selected to be independent of one another with respect to downstream drainage and to be evenly distributed across the following watershed combinations: Coal River $(n=40)$; Upper and Lower Guyandotte River $(n=40)$; Elk, Gauley, and Upper Kanawha Rivers $(n=40)$; and Tug Fork and Twelvepole Creek $(n=50)$ (Fig. 2A). We used 2009 land-cover and landuse data equivalent to the 2011 data used in analyses to guide site selection. Study sites were selected to represent the full range of regional conditions across a range of influence from surface mining (0-99\%), residential development (structure densities ranging from 0-108

structures $\left./ \mathrm{km}^{2}\right)$, and underground mining $\left(0-1.12\right.$ permits $\left./ \mathrm{km}^{2}\right)$ (Fig. 2B-E). We selected sites along independent landuse axes where each major activity (i.e., surface mining, underground mining, and residential development) occurred in isolation and in combination to the extent possible (Fig. 2B-E). This sampling design helped ensure our landscape-based measures of anthropogenic disturbance did not co-vary and that we could successfully quantify the individual and combined (i.e., additive and interactive) effects of all 3 land uses.

\section{Physical, chemical, and biological attributes}

We linked the timing of in-stream sampling to the collection of aerial photographs used to construct our landscape data set to ensure that our measures of habitat quality, water quality, and biological condition accurately reflected the degree of landscape stress. We sampled physical, chemical, and biological conditions once at each site during the summers (JulyAugust) of either 2010 or 2011 . Reaches were defined as $40 \times$ mean stream width (Barbour et al. 1999). We quantified habitat quality with US Environmental Protection Agency (EPA) rapid visual habitat assessments (RVHA; Barbour et al. 1999). We obtained instantaneous measures of temperature, $\mathrm{pH}$, dissolved $\mathrm{O}_{2}$, and specific conductance with a YSI 650 equipped with a 600XL 
sonde (Yellow Springs Instruments, Yellow Springs, Ohio) calibrated prior to each sampling date. Stream water samples were filtered using a Nalgene filtration unit with a mixed celluloseester membrane filter $\left(0.45-\mu \mathrm{m}\right.$ pore size) that was fixed with $\mathrm{HNO}_{3}$ to $\mathrm{pH}<2$ for measurement of dissolved $\mathrm{Al}, \mathrm{Ca}, \mathrm{Fe}, \mathrm{Mg}, \mathrm{Mn}, \mathrm{Na}, \mathrm{Zn}, \mathrm{K}$ (EPA method E200.7) and $\mathrm{Ba}, \mathrm{Cd}, \mathrm{Cr}$, Ni, and $\mathrm{Se}$ (EPA method E200.8; mg/L). We also obtained 2 unfiltered water samples. The first was fixed with $\mathrm{H}_{2} \mathrm{SO}_{4}$ to a $\mathrm{pH}<2$ for measurement of $\mathrm{NO}_{2}$ and $\mathrm{NO}_{3}$ (EPA method SM4110B) and total $\mathrm{P}$ (EPA method SM4500-PBE; mg/L). The $2^{\text {nd }}$ unfiltered sample was used to measure total and bicarbonate alkalinity (EPA method SM2320 B; mg/L CaCO 3 equivalents), $\mathrm{Cl}$, and $\mathrm{SO}_{4}{ }^{2-}$ (EPA method E300.0), and total dissolved solids (EPA method SM2540; mg/L). Analytical methods were standard chemical methods for water and wastes (USEPA 1983). We stored samples at $4{ }^{\circ} \mathrm{C}$ until analyses were completed at Research Environmental and Industrial Consultants, Inc., Beaver, West Virginia. Duplicate physiochemical measurements and samples were taken at $10 \%$ of sites and one field blank was obtained during each sampling event. Habitat quality scores, YSI measurements, and reported water-chemistry variables from duplicate sample pairs were within $\pm 20 \%$. Results of field blanks were generally below method detection, but several blanks showed slight contamination, particularly for $\mathrm{Mn}, \mathrm{Fe}$, and $\mathrm{Zn}$.

We sampled macroinvertebrate communities following procedures established by WVDEP Watershed Assessment Program (WVDEP 2009). We obtained kick samples (net dimensions $335 \times 508 \mathrm{~mm}$ with $500-\mu \mathrm{m}$ mesh) from 4 targeted riffles at each site. We combined organisms and debris into a single composite sample that was immediately preserved with $95 \%$ ethanol. We subsampled macroinvertebrates in the laboratory following the 200 -count method (WVDEP 2009). We identified organisms to genus, except for Mollusca (family), Chironomidae, Hydracarina, Oligochaeta, and Nematoda, with keys provided by Merritt and Cummins (2008). 
We compiled abundance data into 2 macroinvertebrate multimetric indices developed for West Virginia streams. West Virginia Stream condition index (WVSCI; Gerritsen et al. 2000) is a family-level index applied statewide within a single index period. Genus-level index of most probable stream status (GLIMPSS) (Pond et al. 2013) is calibrated by region and season. We used GLIMPSS (CF), which does not require genus-level identification of individuals within the taxa Chironomidae and Oligochaeta. Both WVSCI and GLIMPSS score sites on a scale of 0100 , with scores $<68$ and $<54$ categorized as impaired, respectively. Duplicate community samples were obtained from and taxonomic identification and enumeration were verified for $10 \%$ of study sites. WVSCI and GLIMPSS scores for duplicate sample pairs were within $\pm 20 \%$ for 94 and $65 \%$ of duplicate study sites, respectively.

\section{Statistical analyses}

We used general linear models with deletion tests to construct models for predicting instream condition from \%surface mining, underground mine NPDES permit density, and structure density. We tested for normality using Shapiro-Wilk tests and transformed variables to best approximate normality and meet assumptions of parametric analyses and linearize relationships. We fit initial maximal models specifying 2-way interactions among all landuse predictors. We included latitude and longitude to correct for any geographic effects on observed patterns of stream condition. We conducted variance inflation factor (VIF) analysis to test for potential multicollinearity among covariates in the initial maximal models. Covariates with a VIF $>10$ were removed from the global model (R package $D A A G$; Maindonald and Braun 2013). We then applied a backward deletion (using deletion tests) to remove variables until we arrived at the minimum adequate model (i.e., model in which all predictors are significantly different from 0 
and explanatory power does not differ significantly from the maximal model) for each response variable (Phillimore and Owens 2006, Hejda et al. 2009). Deletion tests assess the significance of increased residual deviance with variable removal (analysis of deviance tables and $F$-tests; $\alpha=$ 0.05) (Crawley 2005).

We constructed separate models for each of our 8-digit HUC watershed groups (i.e., Coal River; Upper and Lower Guyandotte River; Elk, Gauley, and Upper Kanawha Rivers; and Tug Fork and Twelvepole Creek), and regional models with data from all study sites. We performed leave-one-out cross-validations to assess and compare predictive accuracy for each model. We calculated cross-validation $(\mathrm{CV})$ coefficients (i.e., $R^{2}$ between $\mathrm{CV}$ predictions and observed values) and root mean square prediction error (RMSE) to assess predictive accuracy of each model. Because transformations often differed between models, we compared predictions using RMSE of back-transformed CV predictions. We assessed the power of regional models to predict within individual watersheds by comparing CV RMSE associated with regional- and watershedspecific model predictions within each watershed. We tested for independence of errors by correlating model residuals with spatial location (i.e., latitude and longitude) using Mantel tests. Models were constructed in R (version 2.15.0; R Project for Statistical Computing, Vienna, Austria). We used functions in packages $D A A G$ and ecodist for cross-validation and Mantel tests, respectively (Goslee and Urban 2007, Maindonald and Braun 2013).

We were interested in quantifying the extent to which multiple landuse activities confound relationships between surface mining, the dominant form of landuse change in the region (Palmer et al. 2010), and aquatic conditions. Previous efforts to quantify direct relationships between surface mining and altered in-stream conditions have often included sites with low levels of residential development and have not directly considered effects of 
underground mining (Bernhardt et al. 2012, Merriam et al. 2011, Cormier et al. 2013). Therefore, we constructed a series of simple linear regressions between surface mining and specific conductivity across sites within various landuse contexts (i.e., presence or absence of residential development and underground mining) and quantified the point along the surface mining gradient at which the recognized benchmark for specific conductance $(300 \mu \mathrm{S} / \mathrm{cm}$; Cormier et al. 2012) was crossed. We constructed initial relationships (and 95\% confidence intervals) across sites with $<4 \%$ development, regardless of underground mining to remain consistent with previous efforts (Bernhard et al. 2012). We then reran these analyses after removing sites with any development (i.e., structure densities $>0$ structures $/ \mathrm{km}^{2}$ ) or underground mining (i.e., NPDES permit densities $>0$ permits $/ \mathrm{km}^{2}$ ). Nonoverlapping $95 \%$ confidence intervals at recognized standards signified significant differences. We conducted Mantel tests correlating residuals with space (i.e., latitude and longitude) to ensure stream segments were unconfounded.

Last, we used minimum adequate watershed-specific and regional models to predict chemical (specific conductance and Se) and biological (WVSCI and GLIMPSS) condition throughout the study region. Predictions were constrained to SLWs with drainage areas $<40 \mathrm{~km}^{2}$ $(n=26,135)$ to remain consistent with basin areas used during model construction. We quantified the number of stream segments exceeding recognized standards for specific conductance (300 $\mu \mathrm{S} / \mathrm{cm}$; Cormier et al. 2012), Se (5 $\mu \mathrm{g} / \mathrm{L}$; USEPA 1987), and WVSCI $(<68$; Gerritsen et al. 2000) and GLIMPSS (<54; Pond et al. 2013). We characterized and summarized streams exceeding each criterion by their landuse context (i.e., combination of the 3 landuse activities). We mapped stream conditions (ArcMap version 10.1; Environmental Systems Research Institute, Redlands, California) to show spatial patterns of degradation. 


\section{RESULTS}

\section{Landscape models}

Watershed-specific minimum adequate models for RVHA consisted of single landuse variables: either structure density (Coal River, Tug Fork, and Twelvepole Creek) or surface mining (Elk, Gauley, and Kanawha Rivers). RVHA in the Coal River watershed also increased with latitude. Surface mining and structure density had additive effects on RVHA in the Upper and Lower Guyandotte Rivers. Deletion tests supported additive models for specific conductance, suggesting significant effects of surface mining and structure density in all 4 watershed groups. Underground mine density had an addititional effect on specific conductance in the Coal River and Tug Fork and Twelvepole Creek watershed groups (Table 1). Most minimum adequate models for Se consisted of surface mining only (Coal River; Elk, Gauley, and Kanawha Rivers; Tug Fork and Twelvepole Creek). However, deep mining had a significant negative effect on Se concentration within the Upper and Lower Guyandotte River watersheds. We observed significant additive effects of surface mining and structure density on decreased WVSCI and GLIMPSS across all watershed groups (Table 1). Underground mine density had an additional negative effect and a positive interactive effect with structure density on WVSCI and GLIMPSS within the Coal River watershed (Table 1). WVSCI and GLIMPSS decreased with latitude in the Tug Fork and Twelvepole Creek watershed group (Table 1). WVSCI increased with longitude in the Guyandotte and Elk, Gauley, and Kanawha River watershed groups. GLIMPSS increased with longitude in the Elk, Gauley, and Kanawha River group (Table 1).

Watershed models predicting specific conductance tended to be the most precise, explaining between 68 and $77 \%$ of variation and offering good predictive ability during leaveone-out cross-validation ( $\mathrm{CV} R^{2} 0.63-0.74$; Table 2). Se models were more variable among 
watersheds, explaining between 36 and $74 \%\left(C V R^{2} 0.31-0.70\right)$ of variation (Table 2).

Watershed models for WVSCI and GLIMPSS explained between 36 and 61\% (CV $\left.R^{2} 0.25-0.50\right)$ and 49 and $72 \%$ (CV $\left.R^{2} 0.38-0.65\right)$ of variation within a given watershed, respectively (Table 2 ). Models predicting RVHA were least certain, explaining between 14 and 29\% (CV $\left.R^{2} 0.08-0.18\right)$ of the variation among watershed groups (Table 2). Mantel tests indicated slight spatial correlation in residuals of Se (Guyandotte River and Tug Fork and Twelvepole Creek watershed groups) and specific conductivity (Elk, Gauley, and Kanawha Rivers and Tug Fork and Twelvepole Creek watershed groups) models (Table 2).

At the scale of the entire region, the minimum adequate model for RVHA was an additive model that included surface mining, structure density, and longitude (Table 1). Deletion tests supported an additive model for specific conductance, suggesting significant effects of $\%$ surface mining, underground mine density, and structure density across all study sites (Table 1). The minimum adequate model for Se was a single-variable model consisting of $\%$ surface mining. We observed significant additive effects of $\%$ surface mining, underground mine density, and structure density on decreased WVSCI and GLIMPSS, with a significant positive interaction between underground mining and structure density (Table 1). WVSCI and GLIMPSS increased with longitude, whereas GLIMPSS decreased with latitude. Regional models predicting water chemistry were more certain $\left(\mathrm{CV} R^{2}=0.69\right.$ and 0.48 for specific conductance and Se, respectively) than those for biological condition $\left(\mathrm{CV} R^{2}=0.41\right.$ and 0.51 for WVSCI and GLIMPSS, respectively). The model predicting RVHA was least certain $\left(C V R^{2}=0.11\right)$ (Table 2). Mantel tests identified weak spatial correlation among Se model residuals (Table 2).

Regional and watershed-specific models tended to have similar predictive power (i.e., similar CV RMSE of back-transformed predictions) when predicting physical, chemical, and 
biological conditions within individual watersheds (Table 2). However, watershed-specific models often performed considerably better than the regional model when predicting Se. This was particularly true within the Upper and Lower Guyandotte River watersheds (Table 2).

Surface mining was significantly related to specific conductance across sites within both landuse contexts (i.e., surface mining only and $<4 \%$ development and various underground mine densities) (Table 3). However, the surface mining extent resulting in specific conductivities $>300$ $\mu \mathrm{S} / \mathrm{cm}$ was significantly higher (nonoverlapping $95 \%$ confidence intervals) following complete removal of residential development and underground mining influence (Table 3, Fig. 3).

\section{Regional application and scaling}

A total of 26,135 SLWs drain $<40 \mathrm{~km}^{2}$ and account for $\sim 24,180$ stream $\mathrm{km}$. About $33 \%$ of these SLWs were predicted to have specific conductivity $>300 \mu \mathrm{S} / \mathrm{cm}$ by both watershedspecific (8544) and regional models (8733) (Fig. 4A). Watershed-specific and regional models predicted Se concentrations exceeding the chronic criterion in 6\% (1569) and 5\% (1287) of streams, respectively (Fig. 4B). Watershed-specific and regional models predicted biological impairment as defined by WVSCI in $41 \%(10,626$ and 10,728, respectively) and GLIMPSS in $65 \%$ (17158) and 67\% (17525) of streams, respectively (Fig. 4C, D). With the exception of the most extreme northeastern portion of the study area, biological (Fig. 4C, D) and chemical (Fig. 4A, B) degradation were pervasive at the SLW scale. However, the geography of degradation was much different for biologically and chemically impaired SLWs. Biological condition was often predicted to be lowest (red end of the color ramp) along direct tributaries to mainstem channels (Fig. 4C, D), whereas conductivity and Se were highest (brown end of the color ramp) in small headwaters along ridgelines (Fig. 4A, B). 
Approximately $50 \%$ of all biologically impaired streams (i.e., WVSCI $<68$, GLIMPSS $<$ 54) were in watersheds where residential development was the only land use (Fig. 5). About $20 \%$ of biologically impaired streams were affected by both surface mining and residential development, and an additional $20 \%$ also had underground mining. Only $\sim 10 \%$ and $15 \%$ of biologically impaired stream segments as defined by WVSCI and GLIMPSS were in watersheds where surface mining was the only land use, respectively (Fig. 5). Nearly $30 \%$ of streams with specific conductivities $>300 \mu \mathrm{S} / \mathrm{cm}$ were in watersheds affected by surface mining, underground mining, and residential development (Fig. 5). Approximately 25\% of chemically impaired stream segments were in watersheds affected by surface mining and development, whereas an additional $25 \%$ were characterized by surface mining only (Fig. 5). Only $14 \%$ of chemically impaired streams were in watersheds affected by only residential development. We did not consider contexts for streams exceeding the Se chronic criterion because surface mining was consistently the only land use variable to result in increased concentrations (Table 1).

\section{DISCUSSION}

Complex cumulative (i.e., additive and interactive) effects of multiple landuse activities, including mountaintop mining, influenced aquatic conditions throughout the MTR-VF mining region. The effects of surface mining and residential development were largely consistent across all watershed groups. Surface mining and residential development resulted in consistent, additive effects that increased specific conductance and decreased biological condition. Surface mining also resulted in increased Se concentrations in all focal 8-digit HUC watersheds. Residential development resulted in decreased habitat quality in all watersheds except the Elk, Gauley, and Kanawha Rivers, where surface mining was the sole landuse variable to have a significant effect 
on habitat quality. Surface mining and residential development had additive effects that decreased habitat quality in the Upper and Lower Guyandotte watersheds.

The effects of underground mining on aquatic conditions were highly variable. In the Coal River and Tug Fork and Twelevepole Creek watersheds, underground mining had an additive effect that increased specific conductance, and in the Coal River, it had an additive effect that decreased biological condition. Underground mining exhibited inconsistent positive effects on water chemistry and biological condition. Underground mining had an additive effect that decreased Se (lower Se concentrations when deep mining occurred in combination with surface mining) in the Upper and Lower Guyandotte watersheds. Moreover, underground mining exhibited a positive interaction with residential development on biological condition (higher condition at equivalent levels of residential development when underground mining was also present) in the Coal River watershed. We know of no other landuse activity that can have positive and negative influences on aquatic conditions.

Our results add to a growing list of studies linking surface mining to degraded aquatic conditions in the MTR-VF region. Several studies have documented increased specific conductance and Se and decreased biological condition proportional to incremental increases in the extent of surface-mine land use (i.e., simple cumulative effects of increasing a single land use) (Lindberg et al. 2011, Merriam et al. 2011, Bernhardt et al. 2012, Cormier et al. 2013, Merriam et al. 2013). Previous work has also quantified significant impacts on RVHA score (Pond et al. 2008) and component metrics, such as increases in fine sediments (Wiley et al. 2001, Paybins et al. 2000). Our results also support studies documenting strong effects of residential development on in-stream physical, chemical, and biological condition and additive cumulative effects of residential development and surface mining on decreased chemical and biological 
conditions (Pond 2010, Merriam et al. 2011, 2013).

Previous studies also have identified significant effects of underground mining on specific conductance and biological condition in the MTR-VR region. Notably, Merriam et al. (2013) observed effects of underground mining within the Coal River watershed, West Virginia, that mirrored those of our study (i.e., additive effect on specific conductivity and biological condition and a positive interactive effect with residential development on biological condition). They postulated that underground mine effluents ameliorate effects of untreated residential wastewater on macroinvertebrate community composition. Our results support this assertion and further suggest that underground mines are associated with decreased Se concentrations in certain regions. Underground mines might dilute concentrations of surface mine-controlled contaminants or might tend to occur in geologic regions with lower Se availability in parent materials. However, the patterns appear to be localized in individual watersheds, and the effects of underground mining are highly variable among watershed groups in the MTR-VF region.

Incorporating complex additive and interactive effects associated with multiple landuse activities enabled us to construct statistical models capable of predicting specific conductance $\left(R^{2} \leq 0.77\right.$ and $\left.\mathrm{CV} R^{2} \leq 0.74\right)$, Se $\left(R^{2} \leq 0.74\right.$ and $\left.R^{2} \leq 0.70\right)$, and biological condition $\left(R^{2} \leq 0.71\right.$ and $R^{2} \leq 0.65$ ) with a high degree of precision. Our current results add to previous studies modeling aquatic condition from correlative relationships with landuse characteristics (see Strayer et al. 2003, Merovich et al. 2013). Advances in geographic information system and remote sensing technologies and enhanced availability and quality of ecological data sets have improved our ability to link spatial patterns in land use to altered in-stream conditions (see Merovich et al. 2013). Empirical models often represent the best or only option in complex systems that are difficult to model mechanistically (Nilsson et al. 2003, Strayer et al. 2003). Few 
mechanistic models exist for predicting biological endpoints from land use because these relationships are influenced by numerous physical, chemical, and hydrological intermediaries (Van Sickle et al. 2004, King et al. 2005).

However, care must be taken when using correlative statistical models to manage aquatic systems in actively developing watersheds. We demonstrated that low levels of residential development (i.e., $<4 \%$ ) and underground mining activity significantly alter statistical relationships between surface mining and in-stream conditions (i.e., omitted variable bias), and highlight the need for models that incorporate all relevant landuse activities. We also observed potential biases resulting from the spatial scale at which our statistical models were constructed. In some instances, watershed-specific models considerably out-performed regional models, particularly when predicting Se in the Upper and Lower Guyandotte watersheds. These results confirm previous work noting the importance of spatial scale when modeling in-stream conditions from landuse characteristics (Strayer et al. 2003, Ode et al. 2008, Waite et al. 2010). Models constructed at incorrect spatial scales are likely to be based on correlations that fail to accurately reflect causal relationships and may produce inaccurate predictions of current or future condition. Regional and watershed-specific models tended to predict with similar accuracies, but models incorporating data from more than one 8-digit HUC watershed in the MTR-VF region may fail to accurately predict watershed-specific nuances between land use and in-stream conditions (e.g., positive effect of underground mining on Se in the Upper and Lower Guyandotte watershed).

Proper study design can help ensure that statistical models accurately reflect mechanisms underlying aquatic responses to landuse change. We took several measures to minimize potential biases. First, we linked the timing of in-stream sampling with the construction of an up-to-date 
landscape data set. Temporal congruency among data sets helps ensure accurate statistical relationships between land use and observed in-stream conditions (Strayer et al. 2003, Allan 2004). Second, we sampled along independent and combined landuse gradients to produce a data set largely free of confounding, multicollinearity, and bias (i.e., VIF $<10$ and minimal spatial correlation among residuals). Our sampling design also enabled us to quantify additive and interactive effects of multiple landuse activities. Third, we replicated sampling along each gradient at multiple spatial scales to enable us to quantify spatial variability in relationships and the spatial scale most appropriate for modeling aquatic conditions in response to landuse change. Thus, we are confident that our current models can be used to reliably predict aquatic response to landuse change within the MTR-VF region of West Virginia. One caveat, however, is the models for Se, which tended to have significant spatial correlation among residuals and the lowest observed $R^{2}$ values. These results suggest that other factors, such as coal and surrounding geology, probably strongly affect Se concentrations throughout much of the MTR-VF region (see Vengosh et al. 2013).

We predicted high levels of chemical (33\% of streams and $8071 \mathrm{~km}$ with specific conductivities $>300 \mu \mathrm{S} / \mathrm{cm}$ ) and biological ( $41 \%$ and $9654 \mathrm{~km}$ with WVSCI $<68 ; 67 \%$ and $15614 \mathrm{~km}$ with GLIMPSS < 54) impairment resulting from cumulative effects of multiple landuse activities. However, only $\sim 10 \%$ of streams predicted to be biologically impaired occurred in watersheds where surface mining was the only land use. Approximately $40 \%$ were predicted as impaired as a result of surface mining and at least one additional land use, and 50\% were impaired as a result of residential development alone.

These results agree with previous conclusions in which investigators have argued the importance of addressing nonsurface-mining stressors when managing aquatic resources in the 
MTR-VF region (Merriam et al. 2013, Petty et al. 2013). Merriam et al. (2013) used similar equations to predict aquatic responses to simulated future surface-mine scenarios in the Coal River watershed, West Virginia, and found that effects of new simulated surface mines were highly dependent on pre-existing landuse context (i.e., presence of pre-existing surface mines, underground mines, and residential development). Petty et al. (2013) predicted watershed-scale improvement in aquatic conditions (also within the Coal River watershed) when effects of underground mining and residential development were addressed. Our current results further suggest that context-dependent response to surface mines and restoration potential of nonsurfacemining stressors will vary among watersheds throughout the central Appalachian region.

The differences in complex effects of multiple land uses among watersheds could be explained in several ways. Most notably, natural variability in physiographic and biotic conditions often results in differences in observed relationships between land use and in-stream conditions at larger spatial scales (Ode et al. 2008, Petty et al. 2010, Heino 2013). Numerous investigators have observed considerable variability in relationships between land use and physiochemical (Utz et al. 2011) and biological (Mykra et al. 2008, Waite et al. 2010, Utz et al. 2010) conditions across ecoregion boundaries and physiographic provinces. In the northern coalfields of West Virginia, relationships between mining intensity and in-stream condition were highly dependent on underlying coal geology (Petty et al. 2010). Eight-digit HUC watershed appears to be an important regional variable when attempting to relate land use to degraded aquatic conditions in the MTR-VF mining region. Thus, models probably should not be used to predict aquatic conditions outside of the watershed for which they were constructed.

We observed considerable differences in certainty and accuracy among watershedspecific models predicting WVSCI and GLIMPSS ( $R^{2}$ range: $0.36-0.61$ and $0.49-0.72$, 
respectively). Moreover, we predicted impairment in $\sim 25 \%$ of additional streams when modeling GLIMPSS compared to WVSCI. These results corroborate those of previous efforts to compare the response of these 2 metrics to land use in the MTR-VF region. Pond et al. (2008) observed stronger correlations with and better responsiveness to stressors associated with surface mining when using GLIMPSS than when using WVSCI. In the same study, GLIMPSS detected impairment in $\sim 20 \%$ of moderately impacted sites that went undetected by WVSCI (Pond et al. 2008). These results suggest taxonomic resolution probably is important to our ability to model the integrity of benthic communities and designate impairment in the MTR-VF region.

Variability in metacommunity processes also may have influenced our ability to predict biological condition at the watershed scale (see Heino 2013). Recent research suggests that metacommunity dynamics (i.e., species sorting and mass effects) often are embedded within watershed-scale models of biological condition and that environmental variables probably affect community structure differently among watersheds (Mykra et al. 2007, Heino et al. 2012). Testing for underlying metacommunity processes was outside of the scope of our study, but continued research should be aimed at quantifying the extent to which metacommunity processes control spatial patterns of observed community composition.

Successful management of aquatic systems in the MTR-VF region will require addressing the effects of multiple landuse activities (surface and underground mining, and residential development) through targeted restoration and protection actions aimed at improving conditions across hierarchical spatial scales. We provided statistical models for predicting current in-stream physical, chemical, and biological conditions for the entire MTR-VF region of West Virginia. These models can be combined with scenario analysis to predict aquatic responses to proposed landuse and management activities in watersheds throughout the central 
Appalachian region (see Merriam et al. 2013, Petty et al. 2013). The framework outlined here is transferrable to other regions where aquatic systems are affected by multiple landuse activities. 


\section{ACKNOWLEDGEMENTS}

We thank the numerous field and laboratory helpers that were involved in various aspects of our study, especially Donna Hartman, Eric Miller, and Alison Anderson. Funding for this study was provided by the US Geological Survey through support from US Environmental Protection Agency (EPA) Region III. This study was also partially developed under a Science To Achieve Results Fellowship Assistance Agreement number FP-91766601-0 awarded by the US EPA. Although the research described in this article has been funded by the US Environmental Protection Agency, it has not been subjected to the agency's required peer and policy review and, therefore, does not necessarily reflect the views of the agency, and no official endorsement should be inferred. 


\section{LITERATURE CITED}

Allan, J. D. 2004. Landscapes and riverscapes: the influence of land use on stream ecosystems. Annual Review of Ecology, Evolution, and Systematics 35:257-284.

Barbour, M. T., J. Gerritsen, B. D. Snyder, and J. B. Stribling. 1999. Rapid bioassessment protocols for use in streams and wadeable rivers: periphyton, benthic macroinvertebrates, and fish. $2^{\text {nd }}$ edition. EPA/841-B-99-022. US Environmental Protection Agency, Washington, DC.

Bernhardt, E. S., B. D. Lutz, R. S. King, J. P. Fay, C. E. Carter, A. M. Helton, D. Campagna, and J. Amos. 2012. How many mountains can we mine? Assessing the regional degradation of central Appalachian rivers by surface coal mining. Environmental Science and Technology 46:8115-8122.

Carlisle, D. M., J. Falcone, and M. R. Meador. 2009. Predicting the biological condition of streams: use of geospatial indicators of natural and anthropogenic characteristics of watersheds. Environmental Monitoring and Assessment 151:143-160.

Cormier, S. M., G. W. Suter II, and L. Zheng. 2012. Derivation of a benchmark for freshwater ionic strength. Environmental Toxicology and Chemistry 32:263-271.

Cormier, S. M., S. P. Wilkes, and L. Zheng. 2013. Relationship of land use and elevated ionic strength in Appalachian watersheds. Environmental Toxicology and Chemistry 32:296303.

Crawley, M. J. 2005. Statistics: an introduction using R. Wiley and Sons, Chichester, UK.

Cuffney, T. F., M. R. Meador, S. D. Porter, and M. E. Gurtz. 2000. Response of physical, chemical, and biological indicators of water quality to a gradient of agricultural land use in the Yakima River Basin, Washington. Environmental Monitoring and Assessessment 
64:259-270.

Duinker, P. N., and L. A. Greig. 2006. The importance of cumulative effects assessment in Canada: ailments and ideas for redeployment. Environmental Management 37:153-161.

Gerritsen, J., J. Burton, and M. T. Barbour. 2000. A stream condition index for West Virginia wadeable streams. Tetra Tech, Inc., Owings Mills, Maryland. (Available from: http://www.dep.wv.gov/WWE/watershed/bio_fish/Documents/WVSCI.pdf )

Goslee, S. C., and D. L. Urban. 2007. The ecodist package for dissimilarity-based analysis of ecological data. Journal of Statistical Software 22:1-19.

Heino, J. 2013. The importance of metacommunity ecology for environmental assessment research in the freshwater realm. Biological Reviews 88:166-178.

Heino, J., M. Gronroos, J. Soininen, R. Virtanen, and T Muotka. 2012. Context dependency and metacommunity structure in boreal headwater streams. Oikos 121:537-544.

Hejda, M., P. Pysek, and V. Jarosik. 2009. Impact of invasive plants on the species richness, diversity and composition of invaded communities. Journal of Ecology 97:393-403.

Hitt, N. P, and P. L. Angermeier. 2008. River-stream connectivity affects fish bioassessment performance. Environmental Management 42:132-150.

Hitt, N. P., and P. L. Angermeier. 2011. Fish community and bioassessment responses to stream network position. Journal of the North American Benthological Society 30:296-309.

Kepner, W. G., M. M. Ramsey, E. S. Brown, M. E. Jarchow, K. J. M. Dickinson, and A. F. Mark. 2012. Hydrologic futures: using scenario analysis to evaluate impacts of forecasted land use change on hydrologic services. Ecosphere 3:1-25.

King, R. S., M. E. Baker, P. F. Kazyak, and D. E. Weller. 2011. How novel is too noval? Stream community thresholds at exceptionally low levels of catchment urbanization. Ecological 
Applications 21:1659-1678.

King, R. S., M. E. Baker, D. F. Whigham, D. E. Weller, T. E. Jordan, P. F. Kazyak, and M. K. Hurd. 2005. Spatial considerations for linking watershed land cover to ecological indicators in streams. Ecological Applications 15:137-153.

Lindberg, T. T., E. S. Bernhardt, R. Bier, A. M. Helton, R. B. Merola, A. Vengosh, and R. T. di Giulio. 2011. Cumulative impacts of mountaintop mining on an Appalachian watershed. Proceedings of the National Academy of Sciences of the United States of America 108:20929-20934.

Luo, Y., K. Ogle, C. Tucker, S. Fei, C. Gao, S. LaDeau, J. S. Clark, and D. S. Schimel. 2011. Ecological forecasting and data assimilation in a data-rich era. Ecological Applications 21:1429-1442.

Maindonald, J., and W. J. Braun. 2013. DAAG: data analysis and graphics data and functions. R package version 1.16. R Project for Statistical Computing, Vienna, Austria.

Maxwell, A. E., M. P. Strager, C. Yuill, J. T. Petty, E. R. Merriam, and C. Mazzarella. 2011. Disturbance mapping and landscape modeling of mountaintop mining using ArcGIS. Proceedings of the ESRI International User Conference, San Diego, California.

Merovich, G. T., and J. T. Petty. 2010. Continuous response of benthic macroinvertebrat assemblages to a discrete disturbance gradient: consequences for diagnosing stressors. Journal of the North American Benthological Society 29:1241-1257.

Merovich, G. T., J. T. Petty, M. P. Strager, and J. B. Fulton. 2013. Hierarchical classification of stream condition: a house-neighborhood framework for establishing conservartion priorities in complex riverscapes. Freshwater Science 32:874-891.

Merriam, E. R., J. T. Petty, G. T. Merovich, J. B. Fulton, and M. P. Strager. 2011. Additive 
effects of mining and residential development on stream conditions in a central Appalachian watershed. Journal of the North American Benthological Society 30:399418.

Merriam, E. R., J. T. Petty, M. P. Strager, A. E. Maxwell, and P. F. Ziemkiewicz. 2013. Scenario analysis predicts context-dependent stream response to land use change in a heavily mined central Appalachian watershed. Freshwater Science 32:1246-1259.

Merritt, R. W., and K. W. Cummins (editors). 2008. An introduction to the aquatic insects of North America. $4^{\text {th }}$ edition. Kendall/Hunt Publishing Co., Dubuque, Iowa.

Mykra, H. J. Aroviita, J. Kotanen, H. Hamalainen, and T. Muotka. 2008. Predicng the stream macroinvertebrate fauna across regional scales: influence of geographical extent and model performance. Journal of the North American Benthological Society 27:705-716.

Mykra, H., J. Heino, and T. Muotka. 2007. Scale-related patterns in the spatial and environmental components of stream macroinvertebrate assemblage variation. Global Ecology and Biogeography 16:149-159.

Nilsson, C., J. E. Pizzuto, G. E. Moglen, M. A. Palmer, E. H. Stanley, N. E. Bockstael, and L. C. Thompson. 2003. Ecological forecasting and the urbanization of stream ecosystems: challenges for economists, hydrologists, geomorphologists, and ecologists. Ecosystems 6:659-674.

Ode, P. R., C. P. Hawkins, and R. D. Mazor. 2008. Comparability of biological assessments derived from predictive models and multtimetric indices of increasing geographic scope. Journal of the North American Benthological Society 27:967-985.

Palmer, M. A., E. S. Bernhardt, W. H. Schlesinger, K.N. Eshleman, E. Foufoula-Georgiou, M. S. Hendryx, A. D. Lemly, G. E. Likens, O. L. Loucks, M. E. Power, P. S. White, and P. R. 
Wilcock. 2010. Mountaintop mining consequences. Science 327:148-149.

Paybins, K. S., T. Messinger, J. H. Eychaner, D. B. Chambers, and M. D. Kozar. 2000. Water quality in the Kanawha-New River basin, West Virginia, Virginia, and North Carolina, 1996-98. Circular 1204. US Geological Survey, Washington, DC.

Petty, J. T., J. B. Fulton, M. P. Strager, G. T. Merovich, J. M. Stiles, and P. F. Ziemkiewicz. 2010. Landscape indicators and thresholds of stream ecological impairment in an intensively mined Appalachian watershed. Journal of the North American Benthological Society 29:1292-1309.

Petty, J. T., M. P. Strager, E. R. Merriam, and P. F. Ziemkiewicz. 2013. Scenario analysis and the Watershed Futures Planner: predicting future aquatic condiditons in an intensively mined Appalachian watershed. Environmental Considerations in Energy Productions $5: 5-19$.

Phillimore, A. B., and P. F. Owens. 2006. Are subspecies useful in evoutionary and conservation biology. Proceedings of the Royal Society of London Series B: Biological Sciences 276:1049-1053.

Pond, G. J. 2010. Patterns of Ephemeroptera loss in Appalachian headwaters treams (Kentucky, USA). Hydroblogia 64:185-201.

Pond, G. J., J. E. Bailey, B. M. Lowman, and M. J. Whitman. 2013. Calibration and validation of a regionally and seasonally stratified macroinbertebrate index for West Virginia wadeable streams. Environmental Monitoring and Assessment 185:1515-1540.

Pond, G. J., M. E. Passmore, F. A. Borsuk, L. Reynolds, and C. J. Rose. 2008. Downstream effects of mountaintop coal mining: comparing biological conditions using family- and genus-level macroinvertebrate bioassessment tools. Journal of the North American 
Benthological Soceity 27:717-737.

Seitz, N. E., C. J. Westbrook, and B. F. Noble. 2010. Bringing science into river systems cumulative effects assessment practice. Environmental Impact Assessment and Review $31: 172-179$.

Strager, M. P., J. T. Petty, J. M. Strager, and J. Barker-Fulton. 2009. A spatially explicit framework for quantifying downstream hydrologic conditions. Journal of Environmental Management 90:1854-1861.

Strayer, D. L., R. E. Beighley, L. C. Thompson, S. Brooks, C. Nilsson, G. Pinay, and R. J. Naiman. 2003. Effects of land cover on stream ecosystems: roles of empical models and scaling issues. Ecosystems 6:407-423.

USEPA (US Environmental Protection Agency). 1983. Methods for chemical analysis of water and wastes. EPA-60014-79-020. Environmental Monitoring Systems Support Laboratory, Office of Research and Development, US Environmental Protection Agency, Cincinnati, Ohio.

USEPA (US Environmental Protection Agency). 1987. Ambient water quality criteria for selenium. EPA-440/445-487-006. Office of Water Regulations and Standards, US Environmental Protection Agency, Washington, DC.

Utz, R. M., K. N. Eshleman, and R. H. Hilderbrand. 2011. Variation in physicochemical responses to urbanization in streams between two mid-Atlantic physiographic regions. Ecological Applications 21:402-415.

Utz, R. M., R. H. Hilderbrand, and R. L. Reasly. 2010. Regional differences in patterns of fish species loss with changing land use. Biological Conservation 143:688-699.

Van Sickle, J., J. Baker, A. Herlihy, P. Bayley, S. Gregory, P. Haggerty, L. Ashkenas, and J. Li. 
2004. Projecting the biological condition of streams under alternative scnearios of human health. Ecological Applications 14:368-380.

Vengosh, A., T. T. Lindberg, B. R. Merola, L. Ruhl, N. R. Warner, A. White, G. S. Dwyer, and R. T. Di Giulio. 2013. Isotopic imprints of mountaintop mining contaminants. Environmental Science and Technology 47:10041-10048.

Waite, I. R., L. R. Brown, J. G. Kennen, J. T. May, T. F. Cuffney, J. L. Orlando, and K. A. Jones. 2010. Comparison of watershed disturgance predictive models for stream benthic macroinvertebrates for three distinct ecoreions in western US. Ecological Indicators $10: 1125-1136$.

Wiley, J. B., R. D. Evaldi, J. H. Eychaner, and D. B. Chambers. 2001. Reconnaissance of stream geomorphology, low streamflow, and stream temperature in the mountaintop coal-mining region, southern West Virginia, 1999-2000. Water-Resources Investigations Report 014092. US Geological Survey, Charleston, West Virginia.

WVDEP (West Virginia Department of Environmental Protection). 2009. Standard operating proceedures. West Virgina Department of Environmental Protection, Charleston, West Virginia. (Available from: http://www.dep.wv.gov/WWE/watershed/wqmonitoring/Documents/SOP\%20 Doc/WAB\%20SOP.pdf)

WVSAMB (West Virginia State Address Mapping Board). 2003. 1:4,800 scale orthophotography, building points and polygons. West Virginia GIS Technical Center, Morgantown, West Virginia. (Available from: http://wvgis.wvu.edu/data/dataset.php?ID=288) 


\section{FIGURE CAPTIONS}

Fig. 1. Location of focal hydrological unit code (HUC)-8 watershed groups that intersect the primary mountaintop removal-valley fill (MTR-VF) region in West Virginia and locations of study sites $(n=170)(A)$, surface mine permit boundaries (B), underground mine national pollution discharge elimination system (NPDES) permits (C), and residential and commercial structures (D). UK $=$ Upper Kanawha, $\mathrm{UG}=$ Upper Guyandotte, $\mathrm{LG}=$ Lower Guyandotte.

Fig. 2. Scatter plots showing influence of structure density and surface mining across all study sites $(n=170)(\mathrm{A})$, and in the Coal River $(n=40)(\mathrm{B})$, Upper and Lower Guyandotte River $(n=40)(C)$, Elk, Gauley, and Upper Kanawha Rivers $(n=40)(D)$, and Tug Fork and Twelvepole Creek $(n=50)(\mathrm{E})$ watershed groups. Size of symbols in panels B-E reflect the relative number of underground mine national pollution discharge elimination system (NPDES) permits upstream of each site.

Fig. 3. Relationships (and $95 \%$ confidence intervals) between specific conductance $(\mu \mathrm{S} / \mathrm{cm})$ and $\%$ surface mining across sites with a combination of residential development characterized by structure density, underground mining, and \% surface mining (hollow circles; $n=89)$, and across sites with only surface mining $(n=18)$. Horizontal dotted lines correspond to the $300 \mu \mathrm{S} / \mathrm{cm}$ specific conductance benchmark. Specific conductance was cube-root transformed and surface mining was arcsine $\sqrt{ }$-transformed.

Fig. 4. Mapped watershed-specific model predictions of specific conductance (A), Se (B), West Virginia Stream Condition Index (WVSCI) (C), and the genus-level index of most probable stream status (GLIMPSS) (D) for all segment-level watersheds with basin areas $>40 \mathrm{~km}^{2}$. Stream segments are shown with respect to severity of impairment associated 
with specific conductivity $(>300 \mu \mathrm{S} / \mathrm{cm})$, Se $(>5 \mu \mathrm{g} / \mathrm{L})$, WVSCI $(<68)$, and GLIMPSS $(<54)$.

Fig. 5. Percentages of segment-level watersheds (SLWs) predicted to be below the West Virginia Stream Condition Index (WVSCI) impairment threshold $(<68)$ and the genuslevel index of most probable stream status (GLIMPSS) impairment threshold $(<54)$ and predicted to exceed the specific conductivity benchmark of $300 \mu \mathrm{S} / \mathrm{cm}$ that fall within discrete landuse contexts. $\mathrm{S}=$ surface mining, $\mathrm{D}=$ residential development, and $\mathrm{U}=$ underground mining. Numbers represent the total number of SLWs exceeding each criterion. Predictions were derived from watershed-specific models. 
Table 1. Mean (SE) parameter estimates for minimum adequate models (of the form $y=b+m x$, where $b$ is the intercept and $m$ is the coefficient for predictor variable $x$ ) predicting rapid visual habitat assessment (RVHA), specific conductance $(\mathrm{SpC} ; \mu \mathrm{S} / \mathrm{cm}), \mathrm{Se}$ (mg/L), West Virginia stream condition index (WVSCI), and genus-level index of most probable stream status (GLIMPSS) from landuse characteristics. $\mathrm{SM}=$ surface mining (\%), UM = underground mine national pollution discharge elimination system (NPDES) permits $\left(\right.$ no. $\left./ \mathrm{km}^{2}\right)$, and SD $=$ structure density $\left(\right.$ no. $\left./ \mathrm{km}^{2}\right)$. Models were constructed for the entire study area $(n=170)$ and the Coal River $(n=40)$; Upper and Lower Guyandotte River $(n=40)$; Elk, Gauley, and Upper Kanawha Rivers $(n=40)$; and Tug Fork and Twelvepole Creek $(n=50)$ watershed groups. Letters indicate variable transformations $\left(\mathrm{a}=x^{2}, \mathrm{~b}=\sqrt{ }(x), \mathrm{c}=\arcsin \sqrt{ }(x), \mathrm{d}=\mathrm{cube}\right.$ root $)$.

\begin{tabular}{|c|c|c|c|c|c|c|c|}
\hline \multirow{2}{*}{$\begin{array}{l}\text { Variable } \\
\text { Coal River }\end{array}$} & \multicolumn{7}{|c|}{ Watershed-specific models } \\
\hline & Intercept & $\mathrm{SM}^{\mathrm{c}}$ & $\mathrm{UM}^{\mathrm{b}}$ & $\mathrm{SD}^{\mathrm{b}}$ & $\mathrm{UM}^{\mathrm{b}} \times \mathrm{SD}^{\mathrm{b}}$ & Longitude & Latitude \\
\hline RVHA & $-2060.6(902.0)$ & - & - & $-4.4(1.3)$ & - & - & $57.9(23.7)$ \\
\hline $\mathrm{SpC}^{\mathrm{d}}$ & $3.99(0.626)$ & $7.55(0.984)$ & $1.66(0.746)$ & $0.40(0.097)$ & - & - & - \\
\hline $\mathrm{Se}^{\mathrm{d}}$ & $0.08(0.014)$ & $0.16(0.028)$ & - & - & - & - & - \\
\hline $\mathrm{WVSCI}^{\mathrm{a}}$ & $6231.6(447.0)$ & $-2638.7(701.4)$ & $-1622.8(717.4)$ & $-507.3(72.6)$ & $588.4(230.2)$ & - & - \\
\hline GLIMPSS $^{\mathrm{c}}$ & $0.92(0.045)$ & $-0.34(0.071)$ & $-0.18(0.072)$ & $-0.07(0.007)$ & $0.07(0.023)$ & - & - \\
\hline Guyandotte River & Intercept & $\mathrm{SM}^{\mathrm{c}}$ & UM & $\mathrm{SD}^{\mathrm{b}}$ & $\mathrm{UM} \times \mathrm{SD}^{\mathrm{b}}$ & Longitude & Latitude \\
\hline RVHA & $150.3(11.2)$ & $-29.6(13.1)$ & - & $-7.2(2.1)$ & - & - & - \\
\hline $\mathrm{SpC}^{\mathrm{d}}$ & $4.50(0.595)$ & $6.10(0.697)$ & - & $0.48(0.111)$ & - & - & - \\
\hline $\mathrm{Se}^{\mathrm{d}}$ & $0.06(0.011)$ & $0.19(0.019)$ & $-0.06(0.023)$ & - & - & - & - \\
\hline
\end{tabular}




\begin{tabular}{|c|c|c|c|c|c|c|c|}
\hline $\mathrm{WVSCI}^{\mathrm{a}}$ & $6108.9(548.7)$ & $-1677.7(642.0)$ & - & $-461.9(102.1)$ & - & - & - \\
\hline GLIMPSS $^{\mathrm{c}}$ & $18.90(8.02)$ & $-0.18(0.079)$ & - & $-0.06(0.012)$ & - & $0.22(0.098)$ & - \\
\hline Elk/Gauley/Kanawha & Intercept & $\mathrm{SM}^{\mathrm{c}}$ & $\mathrm{UM}$ & $\mathrm{SD}^{\mathrm{b}}$ & $\mathrm{UM} \times \mathrm{SD}^{\mathrm{b}}$ & Longitude & Latitude \\
\hline $\mathrm{RVHA}^{\mathrm{a}}$ & $22245(1818)$ & $-8383(3310)$ & - & - & - & - & - \\
\hline $\mathrm{SpC}^{\mathrm{d}}$ & $4.33(0.538)$ & $7.77(0.713)$ & - & $0.24(0.083)$ & - & - & - \\
\hline $\mathrm{Se}$ & $3.32 \times 10^{-4}(0.001)$ & $6.58 \times 10^{-3}(0.001)$ & - & - & - & - & - \\
\hline WVSCI & $1526.6(448.4)$ & $-20.0(5.2)$ & - & $-4.2(0.7)$ & - & $17.8(5.5)$ & - \\
\hline GLIMPSS $^{\mathrm{c}}$ & $22.52(5.17)$ & $-0.28(0.060)$ & - & $-0.06(0.007)$ & - & $0.27(0.064)$ & - \\
\hline Tug/Twelvepole & Intercept & $\mathrm{SM}^{\mathrm{c}}$ & $\mathrm{UM}^{\mathrm{b}}$ & $\mathrm{SD}^{\mathrm{b}}$ & $\mathrm{UM}^{\mathrm{b}} \times \mathrm{SD}^{\mathrm{b}}$ & Longitude & Latitude \\
\hline RVHA & $142.53(6.190)$ & - & - & $-5.03(1.560)$ & - & - & - \\
\hline $\mathrm{SpC}^{\mathrm{d}}$ & $5.15(0.478)$ & $6.06(0.597)$ & $1.58(0.553)$ & $0.27(0.089)$ & - & - & - \\
\hline $\mathrm{Se}^{\mathrm{d}}$ & $0.08(0.008)$ & $0.09(0.017)$ & - & - & - & - & - \\
\hline WVSCI & $914.4(188.3)$ & $-19.7(5.6)$ & - & $-2.9(0.9)$ & - & - & $-22.3(5.00)$ \\
\hline GLIMPSS $^{\mathrm{c}}$ & $10.97(2.41)$ & $-0.33(0.07)$ & - & $-0.05(0.01)$ & - & - & $-0.27(0.06)$ \\
\hline Regional models & Intercept & $\mathrm{SM}^{\mathrm{c}}$ & $\mathrm{UM}^{\mathrm{b}}$ & $\mathrm{SD}^{\mathrm{b}}$ & $\mathrm{UM}^{\mathrm{b}} \times \mathrm{SD}^{\mathrm{b}}$ & Longitude & Latitude \\
\hline RVHA & $1074.2(383.7)$ & $-24.5(7.1)$ & - & $-4.3(0.9)$ & - & $11.3(4.7)$ & - \\
\hline $\mathrm{SpC}^{\mathrm{d}}$ & $4.60(0.278)$ & $6.55(0.356)$ & $1.49(0.338)$ & $0.32(0.047)$ & - & - & - \\
\hline $\mathrm{Se}^{\mathrm{d}}$ & $0.07(0.006)$ & $0.14(0.011)$ & - & - & - & - & - \\
\hline WVSCI $^{\mathrm{a}}$ & 72854 (17722) & $-2259(329)$ & $-1373(526)$ & $-503(47)$ & 452 (147) & $816(217)$ & - \\
\hline GLIMPSS $^{\mathrm{c}}$ & $14.88(2.79)$ & $-0.28(0.037)$ & $-0.16(0.059)$ & $-0.07(0.005)$ & $0.04(0.017)$ & $0.14(0.025)$ & $-0.08(0.038)$ \\
\hline
\end{tabular}


Table 2. Coefficients of determination $\left(R^{2}\right)$ and root mean square error (RMSE) for minimum adequate models and for backtransformed results of leave-one-out cross-validation (CV). CV RMSE is presented for regional and watershed-specific (WS) model predictions within each watershed for model comparison. Mantel $r$ coefficients indicate correlations between model residuals and spatial location (latitude and longitude). See Table 1 for abbreviations. Bold indicates $p<0.05$.

\begin{tabular}{|c|c|c|c|c|c|c|}
\hline & & & & WS-specific CV & Regional CV & \\
\hline & Model $R^{2}$ & Model RMSE & $\mathrm{CV} R^{2}$ & RMSE & RMSE & Mantel $r$ \\
\hline \multicolumn{7}{|c|}{ Watershed-specific models } \\
\hline \multicolumn{7}{|l|}{ Coal River } \\
\hline RVHA & 0.29 & 22.0 & 0.18 & 22.0 & 22.7 & -0.039 \\
\hline $\mathrm{SpC}^{\mathrm{d}}$ & 0.73 & 1.18 & 0.67 & 325 & 309 & -0.032 \\
\hline $\mathrm{Se}^{\mathrm{d}}$ & 0.47 & 0.047 & 0.43 & $5.65 \times 10^{-3}$ & $6.17 \times 10^{-3}$ & -0.098 \\
\hline $\mathrm{WVSCI}^{\mathrm{a}}$ & 0.59 & 827 & 0.49 & 7.81 & 8.00 & -0.039 \\
\hline GLIMPSS $^{\mathrm{c}}$ & 0.71 & 0.084 & 0.65 & 8.24 & 9.09 & -0.036 \\
\hline \multicolumn{7}{|c|}{ Guyandotte River } \\
\hline RVHA & 0.25 & 25.2 & 0.14 & 27.2 & 28.1 & 0.046 \\
\hline $\mathrm{SpC}^{\mathrm{d}}$ & 0.68 & 1.34 & 0.63 & 329 & 330 & 0.014 \\
\hline $\mathrm{Se}^{\mathrm{d}}$ & 0.74 & 0.043 & 0.70 & $5.72 \times 10^{-3}$ & $8.05 \times 10^{-3}$ & -0.123 \\
\hline $\mathrm{WVSCI}^{\mathrm{a}}$ & 0.36 & 1234 & 0.25 & 13.2 & 13.5 & 0.025 \\
\hline GLIMPSS $^{\mathrm{c}}$ & 0.49 & 0.141 & 0.38 & 13.2 & 13.6 & 0.013 \\
\hline
\end{tabular}


Elk/Gauley/Kanawha

\begin{tabular}{|c|c|c|c|c|c|c|}
\hline $\mathrm{RVHA}^{\mathrm{a}}$ & 0.14 & 6870 & 0.08 & 28.9 & 30.6 & 0.048 \\
\hline $\mathrm{SpC}^{\mathrm{d}}$ & 0.77 & 1.30 & 0.74 & 328 & 312 & 0.195 \\
\hline $\mathrm{Se}$ & 0.40 & $2.71 \times 10^{-3}$ & 0.31 & $2.92 \times 10^{-3}$ & $3.51 \times 10^{-3}$ & -0.106 \\
\hline WVSCI & 0.61 & 9.39 & 0.50 & 10.7 & 10.6 & 0.043 \\
\hline GLIMPSS $^{c}$ & 0.72 & 0.108 & 0.65 & 11.1 & 10.4 & 0.105 \\
\hline \multicolumn{7}{|c|}{ Tug/Twelvepole } \\
\hline RVHA & 0.18 & 23.1 & 0.11 & 24.3 & 27.4 & -0.010 \\
\hline $\mathrm{SpC}^{\mathrm{d}}$ & 0.74 & 1.11 & 0.69 & 313 & 303 & -0.152 \\
\hline $\mathrm{Se}^{\mathrm{d}}$ & 0.36 & 0.037 & 0.31 & $3.77 \times 10^{-3}$ & $3.78 \times 10^{-3}$ & -0.172 \\
\hline WVSCI & 0.48 & 10.4 & 0.39 & 11.3 & 12.0 & 0.002 \\
\hline GLIMPSS $^{c}$ & 0.54 & 0.133 & 0.46 & 11.4 & 11.8 & -0.017 \\
\hline \multicolumn{7}{|l|}{ gional models } \\
\hline RVHA & 0.15 & 25.7 & 0.11 & - & 26.4 & 0.008 \\
\hline $\mathrm{SpC}^{\mathrm{d}}$ & 0.71 & 1.28 & 0.69 & - & 313 & 0.027 \\
\hline $\mathrm{Se}^{\mathrm{d}}$ & 0.49 & 0.046 & 0.48 & - & $5.59 \times 10^{-3}$ & -0.107 \\
\hline $\mathrm{WVSCI}^{\mathrm{a}}$ & 0.45 & 1178 & 0.41 & - & 11.3 & 0.025 \\
\hline GLIMPSS $^{c}$ & 0.55 & 0.130 & 0.51 & - & 11.4 & 0.021 \\
\hline
\end{tabular}


Table 3. Linear regressions between specific conductance ( $\mathrm{SpC}, \mu \mathrm{S} / \mathrm{cm}$, cube-root transformed) and surface mining (SM, arcsin $\sqrt{ }$ transformed). Initial regressions were constructed across sites with $<4 \%$ development, regardless of underground mining intensity (initial; $n=89$ ). We then constructed regressions following removal of sites with any remaining development or underground mining (surface mining [SM]-only; $n=18$ ). Equations and $R^{2}$ are presented for each relationship. Both were significant at $p<0.05$. Exceedance criteria represent the point along each linear relationship at which the $\mathrm{SpC}$ benchmark $(300 \mu \mathrm{S} / \mathrm{cm})$ is crossed. Mantel $r$ ( $p$-value) coefficients indicate correlations between residuals of each relationship and spatial location (latitude and longitude).

\begin{tabular}{lcccc}
\hline \multicolumn{1}{c}{ Variable } & Equation & $R^{2}$ & Exceedance criteria & Mantel $r$ \\
\hline $\mathrm{SpC}$ & & & & \\
Initial & $\mathrm{SpC}^{\mathrm{d}}=5.25+6.82 \mathrm{SM}$ & 0.70 & $4.4 \%$ & $0.087(0.17)$ \\
SM only & $\mathrm{SpC}^{\mathrm{d}}=3.81+6.87 \mathrm{SM}$ & 0.90 & $16.6 \%$ & $-0.028(0.46)$ \\
\hline
\end{tabular}




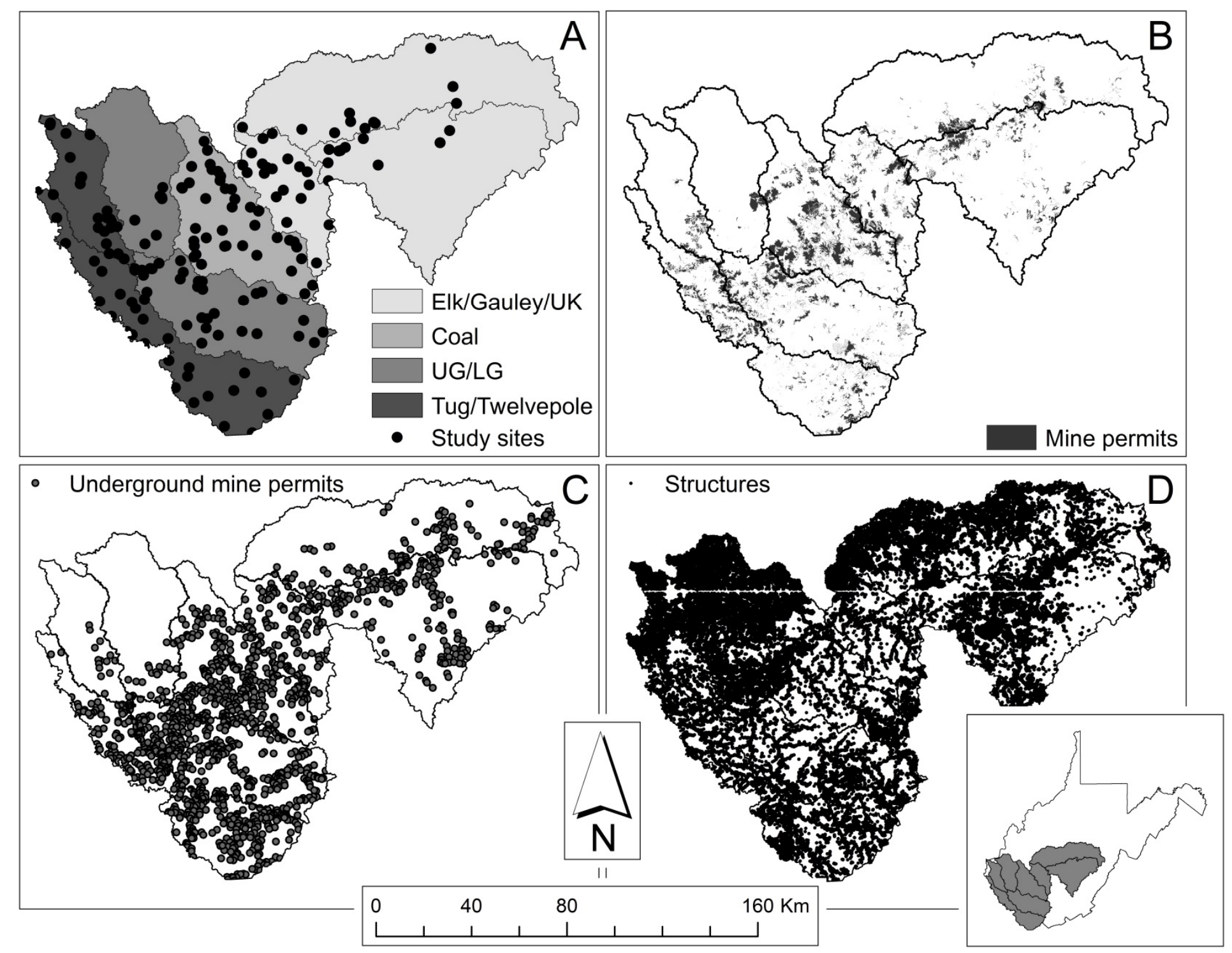

Fig. 1 

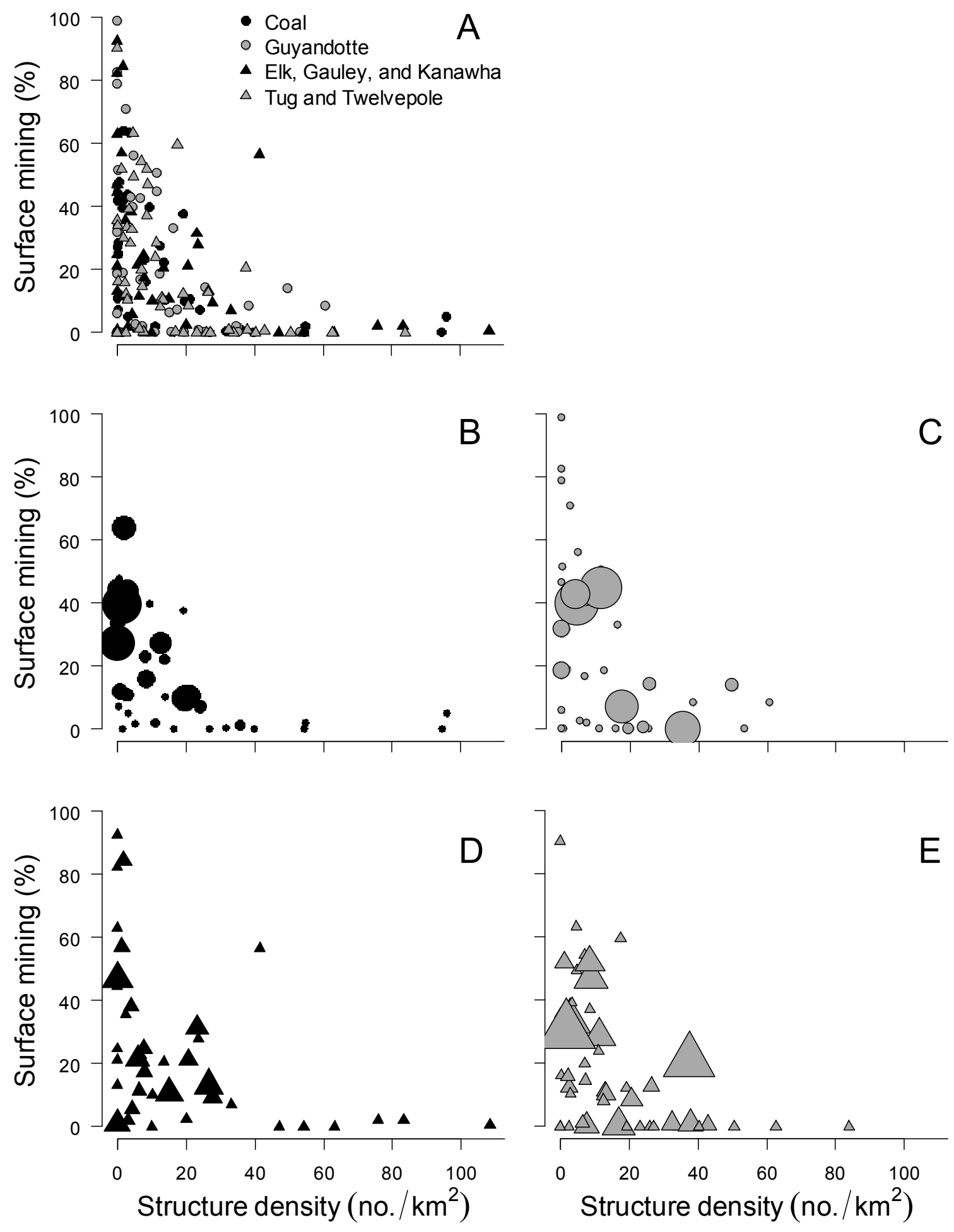

Fig. 2 


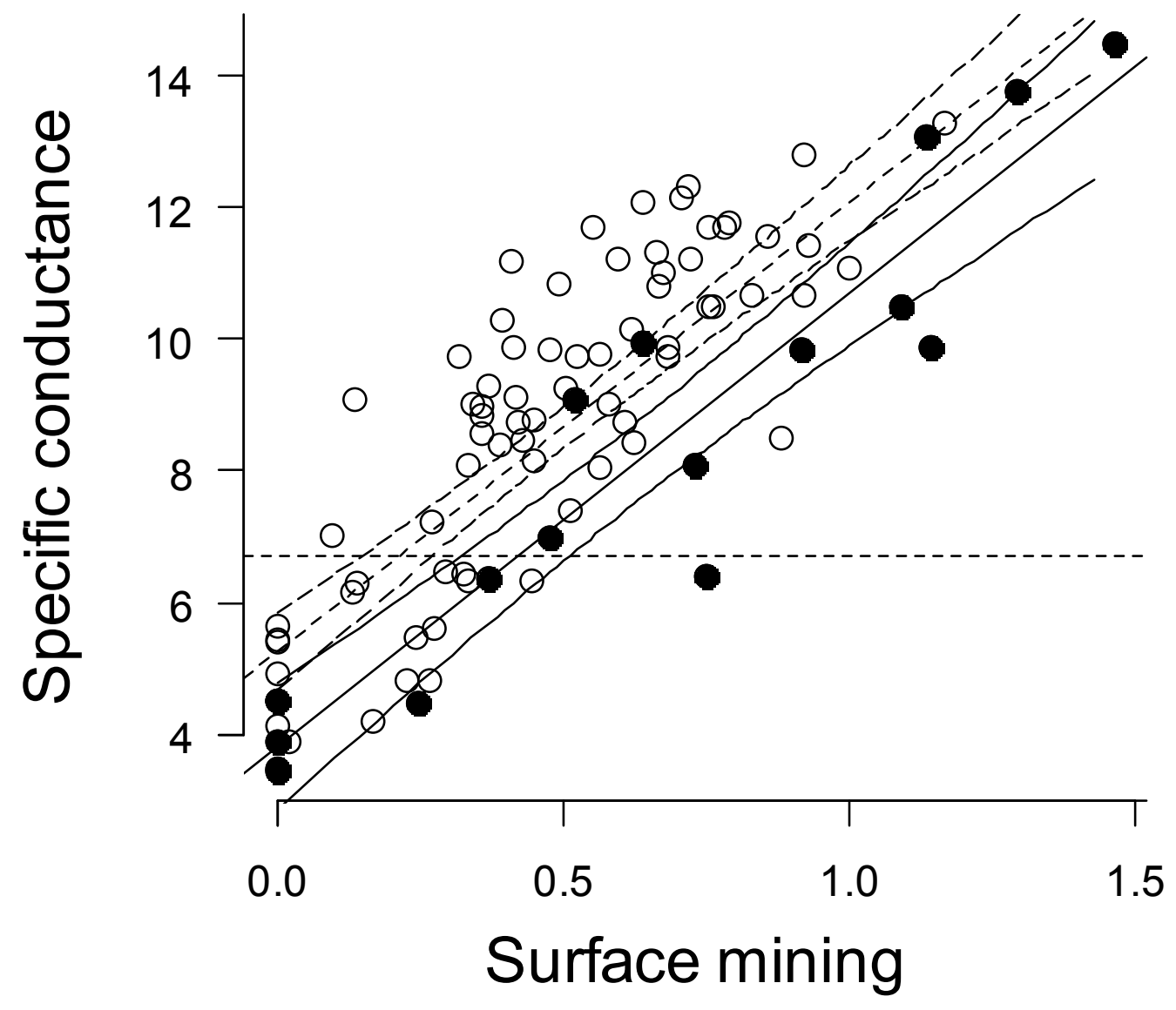

Fig. 3 


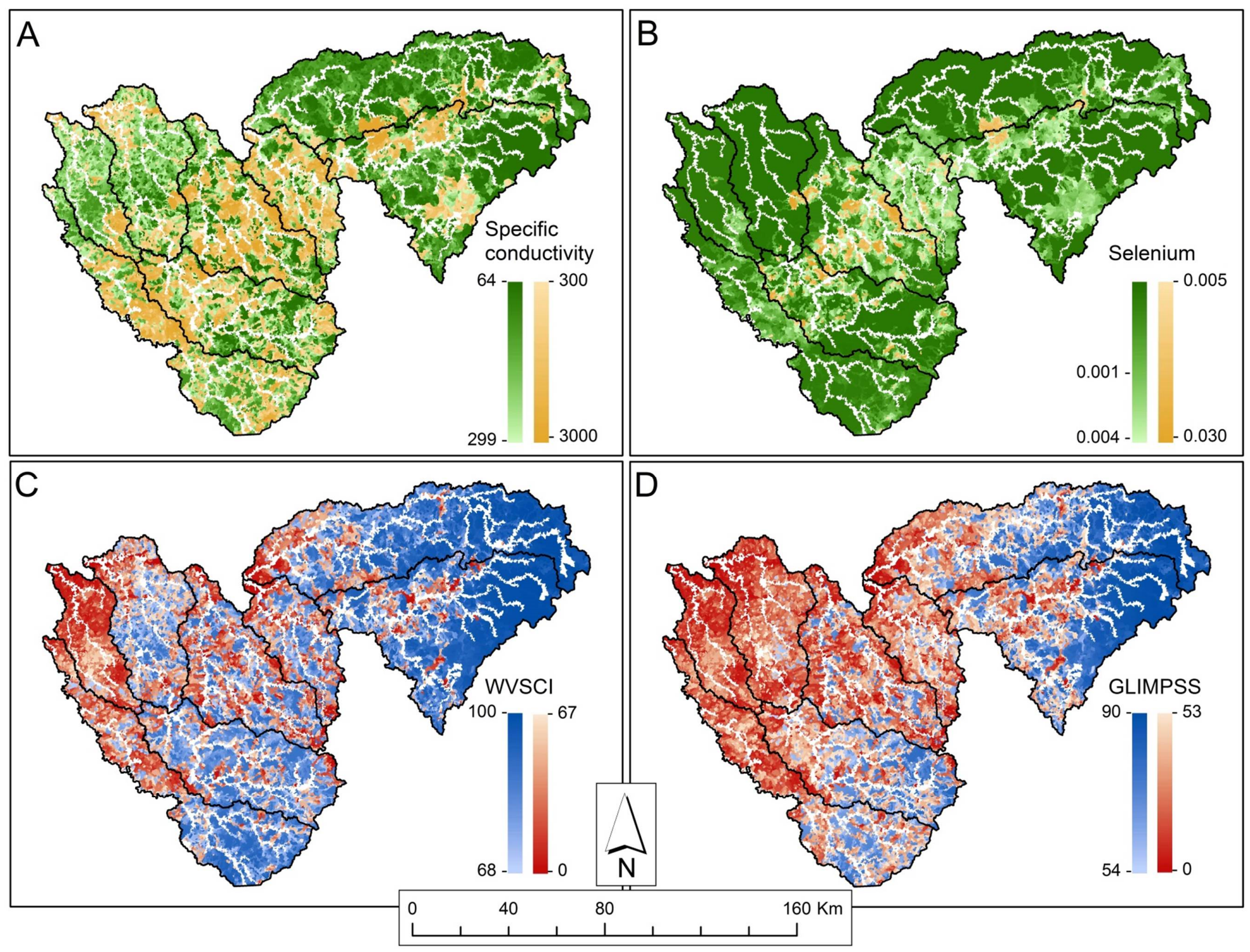

Fig. 4 


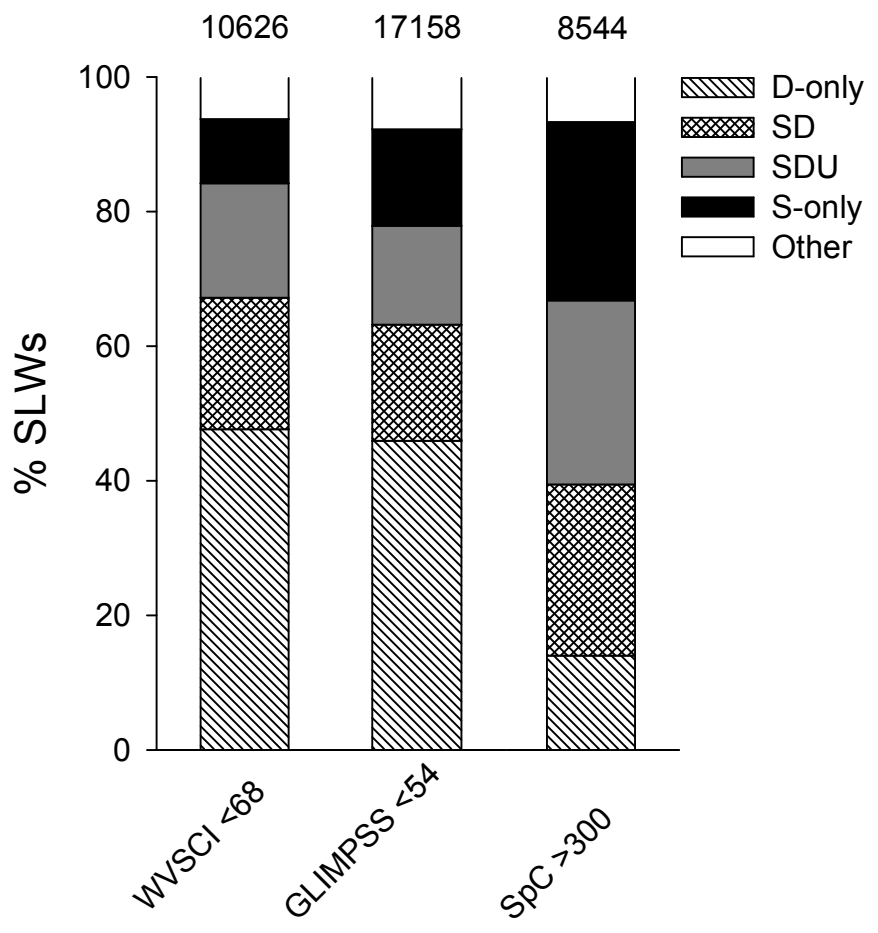

Fig. 5 
CHAPTER 3: Complex contaminant mixtures in multi-stressor Appalachian riverscapes.

This chapter has been accepted for publication in Environmental Toxicology and Chemistry and follows their required formatting.

Merriam, E. R., J. T. Petty, M. P. Strager, A. E. Maxwell, and P. Ziemkiewicz. 2015. Complex contaminant mixtures in multi-stressor Appalachian riverscapes. Environmental Toxicology and Chemistry doi: 10.1002/etc.3101. 
Runoff from mountaintop mining altered watersheds in the Appalachian region (USA) is known to pollute headwater streams, yet regional scale assessments of water quality have focused on salinization and selenium. We conducted a comprehensive survey of inorganic contaminants found in 170 stream segments distributed across a spectrum of historic and contemporary human land use. Principal component (PC) analysis identified 3 important dimensions of variation in water chemistry that were significantly correlated with contemporary surface mining ( $\mathrm{PC} 1$, elevated dominant ions, sulfate, alkalinity, and selenium), coal geology and legacy mines (PC2, elevated trace metals), and residential development (PC3, elevated sodium and chloride). The combination of these 3 dominant sources of pollutants produced a complex stream-to-stream patchwork of contaminant mixtures. Seventy-five percent of headwater streams (catchments $<5 \mathrm{~km}^{2}$ ) had water chemistries that classified as either reference (49\%), development only (18\%) or mining only $(8 \%)$. Only $21 \%$ of larger streams (catchments $>5 \mathrm{~km}^{2}$ ) were classified as having reference chemistries, and chemistries indicative of combined mining and development contaminants accounted for $47 \%$ of larger streams (compared to $26 \%$ of headwater streams). Extreme degradation of larger streams can be attributed to accumulation of contaminants from multiple human land use activities that include contemporary mountaintop mining, underground mining, abandoned mines, and untreated domestic wastewater. Consequently, water quality improvements in this region will require a multi-contaminant remediation approach. 


\section{INTRODUCTION}

Aquatic systems within the central Appalachian region have experienced widespread chemical degradation due to legacy impacts from acid precipitation $[1,2]$, acidic and alkaline mine drainage [3-5], and insufficient wastewater treatment infrastructure [6]. Recent research in this region has tended to focus on contemporary surface mining (i.e., mountaintop mining) and only on a few mining-related contaminants (e.g., $\mathrm{Se}$ and $\mathrm{SO}_{4}{ }^{2-}$ ) and ion mixtures [7-10]. Our own research, however, indicates that surface mining alone is a relatively rare land use context. Instead, most of the landscape is comprised of a combination of contemporary surface mining, historic surface and underground mining, and varying intensities of residential and industrial development [11].

The extent to which multiple land use activities interact to determine the full suite of dissolved water quality characteristics in this region is currently unknown. This represents an important knowledge gap, because different contaminant mixtures likely have different effects on biological communities and stream ecosystem processes $[3,12,13]$. Moreover, there has been a recent push to manage aquatic systems within this region toward recognized specific conductivity benchmarks [9]. Specific conductivity will likely be a difficult parameter to manage in systems where equivalent conductivities can reflect markedly different contaminant mixtures. Consequently, determining how various combinations of land use activities produce specific combinations of chemical contaminants should improve our ability to manage water resources in Appalachian watersheds.

An important constraint on our current understanding of how land use affects complex water quality characteristics is a lack of reliable water quality data from the region. Most existing data are collected over a long period of time and over a variety of stream flow conditions [14]. 
Ultimately, this has a strong influence on the underlying statistical relationships among water quality constituents and between water quality and land use characteristics.

We conducted a regional-scale, synoptic study of water quality in the mountaintop mining region of West Virginia. Dissolved inorganic water chemistry was analyzed from samples taken at 170 sites over a narrow time frame, and water quality data were linked to a simultaneous, comprehensive land cover and use dataset. The specific objectives of our study were to: 1- quantify stream-to-stream variability in the full suite of inorganic contaminants that occur in central Appalachian watersheds; 2- link variation in water chemistry to a temporally congruent land cover and use dataset; and 3- quantify the relative contribution of specific land use activities to chemical degradation within the region as a whole. We conclude that extensive water quality degradation in this region stems from complex contaminant mixtures that are produced by multiple, interacting human land use activities.

\section{STUDY AREA}

Our study area consists of the 8 8-digit hydrologic unit code watersheds that intersect the primary mountaintop mining region within West Virginia, including the Elk River, Gauley River, Upper Kanawha River, Upper and Lower Guyandotte River, Coal River, Tug Fork, and Twelvepole Creek watersheds (Figure 1). The study area drains approximately $20,795 \mathrm{~km}^{2}$ of predominately forested $(\sim 80 \%)$ land area. Coal mining and residential development represent the dominant land use activities. Mountaintop mining accounts for approximately $3 \%\left(600 \mathrm{~km}^{2}\right)$ of the total land area and there are $>2000$ underground mine national pollution discharge elimination system (NPDES) permits. Residential land use accounts for approximately $6 \%$ of the total land area. There are $>325,000$ residential and commercial structures [15], of which only 
$33 \%$ are within public water and sewer service districts. Geology consists of interbedded Pennsylvanian-age sandstone, siltstone and shale with multiple seams of low-sulfur coal. Coal outcrops predominantly represent Kanawha (78\%) and Allegheny groups (20\%), with remaining seams belonging to New River, Pocahontas, and Monongahela groups.

\section{METHODS}

We selected 170 streams throughout the mountaintop mining region as study sites (Figure 1). We selected study sites to be evenly distributed among all major drainage basins and attempted to sample across the full range of natural (i.e., geology) and anthropogenic landscape conditions. Basin areas were constrained to $<40 \mathrm{~km}^{2}$ and all sites were selected to be independent of one another and not linked by downstream drainage.

\section{Physicochemical attributes}

We measured water quality and chemistry once at each site during the summers (JulyAugust) of 2010, 2011, or 2012. We obtained instantaneous measures of temperature, $\mathrm{pH}$, dissolved oxygen $(\mathrm{mg} / \mathrm{L})$, and specific conductance $(\mu \mathrm{S} / \mathrm{cm})$ with a YSI 650 equipped with a 600XL sonde (Yellow Springs Instruments) calibrated prior to each sampling date. We collected 1 filtered sample from each site using a Nalgene filtration unit with a mixed cellulose ester membrane filter $(0.45-\mu \mathrm{m}$ pore size $)$ that was fixed with nitric acid to a $\mathrm{pH}<2$ for determination of dissolved $\mathrm{Al}, \mathrm{Ca}, \mathrm{Fe}, \mathrm{Mg}, \mathrm{Mn}, \mathrm{Na}, \mathrm{Zn}, \mathrm{K}$ (EPA method E200.7) and $\mathrm{Ba}, \mathrm{Cd}, \mathrm{Cr}$, Ni, and $\mathrm{Se}$ (EPA method E200.8; mg/L). We also collected 2 unfiltered water samples. The first was fixed with sulfuric acid to a $\mathrm{pH}<2$ for determination of $\mathrm{NO}_{2}$ and $\mathrm{NO}_{3}$ (EPA method $\mathrm{SM} 4110 \mathrm{~B}$ ) and total P (EPA method SM4500-PBE; mg/L). The second unfiltered sample was used to determine 
total and bicarbonate alkalinity (EPA method SM2320 B; mg/L CaCO 3 equivalents), $\mathrm{Cl}$ and $\mathrm{SO}_{4}$ (EPA method E300.0), and total dissolved solids (EPA method SM2540; mg/L). We stored samples at $4^{\circ} \mathrm{C}$ until analyses were completed at Research Environmental \& Industrial Consultants, Inc., Beaver, West Virginia. Analytical methods represent standard methods for water and wastes [16].

We obtained duplicate measurements and samples from $10 \%$ of sites and 1 field blank during each sampling event for quality assurance and quality control. YSI measurements and reported water chemistry parameters from duplicate sample pairs were within $+20 \%$. Results of field blanks were generally below method detection; however, several blanks showed slight contamination, particularly for $\mathrm{Mn}, \mathrm{Fe}$ and $\mathrm{Zn}$.

\section{Landscape data}

We timed stream sampling to coincide with the construction of a land cover and use classification derived from 2011 National Agriculture Imagery Program orthophotographs (1meter pixel resolution at a scale of 1:10,000) [17]. Base classifications included forest, grass and pasture lands, barren development, and open water. We used surface mining permit boundaries developed by the West Virginia Department of Environmental Protection (WV DEP), which includes permitted areas for all surface mine types and operations, to differentiate mining related grasslands (i.e., reclaimed mine lands and valley fill faces), barren development (i.e., active mine lands and mine facilities), and open water (i.e., mine impoundments). We summed all surface mining land cover classes derived from the WV DEP permit boundaries to obtain a measure of the total area of contemporary surface mining. We used topographic maps in conjunction with known abandoned mine land locations to delineate the area of surface mining conducted prior to 
the Surface Mining Control and Reclamation Act (1977). We used data developed by the West Virginia Geological and Economic Survey to summarize coal geology. We obtained national pollution discharge elimination system (NPDES) permit point locations from the WV DEP and used these data to calculate the density of underground mine NPDES permits $\left(\mathrm{no} . / \mathrm{km}^{2}\right)$. We summarized data created by the Statewide Addressing and Mapping Board [15] to calculate the density of residential and commercial structures (no. $\left./ \mathrm{km}^{2}\right)$.

We used spatial analysis functions within ArcGIS ArcMap 10.0 (Environmental Systems Research Institute) in conjunction with flow tables linking 1:24,000 national hydrography dataset (NHD) segment-level watershed (SLW) attributes in a downstream direction to calculate cumulative measures (i.e., all land area upstream of individual SLWs) of each landscape attribute [18].

\section{Statistical analyses}

Characterizing contaminant mixtures/linking to landscape characteristics. We used principal components analysis (PCA) to summarize patterns of covariation among water chemistry constituents. PCA identified 2 sites as extreme outliers. We removed these sites from all analyses. We transformed water chemistry variables (natural log) to approximate normality. Principal components (PC) with eigenvalues $\geq 1.5$ were considered significant. We regarded factor loadings $\geq|0.4|$ as significant contributors to a given PC [19]. We excluded $\mathrm{pH}$ and specific conductivity from PCA analysis because we were interested in quantifying covariation among individual ion and trace element concentrations. However, we used Spearman rank correlations to identify continuous relationships between specific conductivity and chemical constituents. We correlated individual chemical constituents with landscape-based indicators of mining (\% surface 
mining [11], \% valley fills [5,20], \% abandoned mine lands [21], and underground mine density [11]), residential development (structure density [11], \% development [8]), and coal geology (\% Allegheny and Kanawha formations [22]). We tested for correlations between landscape metrics and significant PCs. Correlations using PCs take into consideration covariation among variables and provide a good alternative to significance testing of multiple pairwise correlations [23].

We used cluster analysis (CA) to determine if variation within the water chemistry dataset results in discrete water chemistry types [24]. We used Ward's minimum-variance method with Euclidean distances to define clusters. Cluster analysis was performed on the same normalized dataset used during PCA. We used descriptive statistics (mean and standard deviation) and calculated milliequivalents of major ions to characterize types. We ran analysis of variance with post-hoc Tukey tests to determine if chemistry types were statistically distinguishable from one another as described by PC scores. We used the R package stats to perform PC and cluster analyses (version 3.1.2; R Development Core Team 2014).

Land use contribution to regional chemical degradation. We used multivariate analysis of variance (MANOVA) to test for overall differences in landscape (natural and anthropogenic) characteristics among water quality types. Percentage data were $\operatorname{arcsine} \sqrt{ }(\mathrm{x})$-transformed and density data were $\sqrt{ }(\mathrm{x})$-transformed to approximate multivariate normality. We then used linear discriminant function analysis (DFA) to determine if land use indicators of mining and residential development could be used to distinguish among water chemistry types. Finally, significant DFA models were used to predict water chemistry type for each SLW within the study region. We constrained predictions to SLWs with basin areas $<40 \mathrm{~km}^{2}(n=26,135)$ to remain consistent with basin areas of study sites. We summarized the relative contribution of each stream chemistry type and land use activity to water quality degradation (i.e., not reference 
chemistries) across small $\left(<5 \mathrm{~km}^{2}\right)$ and large $\left(5\right.$ to $\left.40 \mathrm{~km}^{2}\right)$ streams. We used the R package stats (version 3.1.2; R Development Core Team 2014) for MANOVA and the 'lda' function in the R package MASS for DFA analyses [25].

\section{RESULTS}

\section{Characterizing contaminant mixtures/linking to landscape characteristics}

Principal components analysis identified 3 significant water chemistry dimensions.

Principal component 1 explained $32 \%$ of the variation and was characterized by increasing ionic strength $\left(\mathrm{Ca}^{2+}, \mathrm{Mg}^{2+}, \mathrm{K}^{+}\right.$and $\left.\mathrm{SO}_{4}{ }^{2-}\right)$, bicarbonate alkalinity, and nitrogen and Se concentrations (Figure 2). Principal component 2 explained 14\% of the total variation in water chemistry and was characterized by increasing trace element $(\mathrm{Mn}, \mathrm{Zn}, \mathrm{Cd}$ and $\mathrm{Ni})$ concentrations and decreasing alkalinity (Figure 2). Principal component 3 explained 11\% of the variance and was characterized by increasing $\mathrm{Cl}-, \mathrm{Na}+$, and $\mathrm{Ba}$ concentrations (Figure 2). Specific conductivity correlated with PC 1 and all of its component constituents (Table 1). Individual components of PC 2 (Zn and Ni) and PC $3\left(\mathrm{Cl}^{-}\right.$and $\left.\mathrm{Na}^{+}\right)$were also significantly correlated with specific conductivity (Table 1).

Principal component 1 and all contributing constituents were positively correlated with landscape-based measures of surface and underground mining (Table 1). Major ion $\left(\mathrm{Ca}^{2+}, \mathrm{Mg}^{2+}\right.$, $\mathrm{K}^{+}$and $\mathrm{SO}_{4}{ }^{2-}$ ) and Se concentrations were also significantly correlated with Allegheny coal. Nitrogen concentrations were correlated with Kanawha coal (Table 1). Principal component 2 and all contributing constituents were positively correlated with Allegheny coal (Table 1). Individual constituents contributing to PC 2 were also associated with increased abandoned mine lands (Ni and $\mathrm{Zn}$ ), surface mining (Ni), and development (Mn). Principal component 3 and all 
contributing constituents were positively correlated with structure density and barren development (Table 1). Na was also correlated with surface and underground mining (Table 1).

Cluster analysis identified 6 discrete water chemistry types (Table 2), and ANOVA indicated significant differentiation among the water chemistry types along $\mathrm{PC} 1[F(5,162)=$ $126.1 ; p<0.0001], \mathrm{PC} 2[F(5,162)=41.5 ; p<0.0001)]$ and $\mathrm{PC} 3[F(5,162)=16.3 ; p<$ 0.0001] (Table 2, Figure 2). Combining correlation and cluster analyses suggest that the 6 chemistry types can be characterized first by major land use activity [reference (no major stressors), development (PC 3), mining (PC 1), and combined (PC 1 and 3)]. Mining and combined chemistries can be further differentiated as having low (mining and combined 1) and high (mining and combined 2) Allegheny coal and abandoned mine lands (PC 2) (Table 2, Figure 2). A comparison of landscape characteristics among water chemistry types further justifies this characterization (Table 2).

$\mathrm{Ca}^{2+}$ and $\mathrm{Mg}^{2+}$ accounted for approximately $40 \%$ of total milliequivalents per liter (mE/L) across all chemistry types (Figure 3). Reference type chemistries had an average specific conductivity of $77 \mu \mathrm{S} / \mathrm{cm}$, with $\mathrm{HCO}_{3}{ }^{-}$making up the greatest individual percentage $(30 \%)$ of total $\mathrm{mE} / \mathrm{L}$ (Figure 3). Development type chemistries had an average specific conductivity of $266 \mu \mathrm{S} / \mathrm{cm}$ characterized by higher relative contributions of $\mathrm{Na}+$ and $\mathrm{Cl}-\mathrm{mE}$ (Figure 3 ). Combined type chemistries had average specific conductivities of approximately $700 \mu \mathrm{S} / \mathrm{cm}$ characterized by an increase in the relative contributions of $\mathrm{Na}+, \mathrm{Cl}-$, and $\mathrm{SO}_{4}{ }^{2-} \mathrm{mE}$ and a decrease in $\mathrm{HCO}_{3}$ - (Figure 3). Mining type chemistries exhibited increases and decreases in the relative contribution of $\mathrm{SO}_{4}{ }^{2-}$ and $\mathrm{HCO}_{3}-\mathrm{mE} / \mathrm{L}$, respectively (Figure 3). Mining type chemistries had lower $\mathrm{Na}+$ and $\mathrm{Cl}-\mathrm{mE}$ than all other types. Mining $2(1.77 \mathrm{mg} / \mathrm{L})$ and combined 2 $(0.33 \mathrm{mg} / \mathrm{L})$ chemistries had average total trace element concentrations that were $25 \times$ and $5 \times$ that 
of reference type chemistries $(0.07 \mathrm{mg} / \mathrm{L})$, respectively (Table 2, Figure 3). Mn made up the greatest proportion of total trace element concentrations within mining $2(0.25 \mathrm{mg} / \mathrm{L})$ and combined $2(1.63 \mathrm{mg} / \mathrm{L})$ type chemistries at concentrations $10 \times$ and $62 \times$ that of reference chemistries (Figure 3). Mining 2 type chemistries had average $\mathrm{Ni}(0.05 \mathrm{mg} / \mathrm{L})$ and $\mathrm{Zn}(0.04 \mathrm{mg} / \mathrm{L})$ concentrations that were approximately $10 \times$ and $4 \times$ higher than any other type, respectively (Table 2, Figure 3). Mining 1 type chemistries had the highest average Se concentrations $(0.01 \mathrm{mg} / \mathrm{L})($ Table 2, Figure 3). Development, and combined chemistries had the highest Ba concentrations (approximately $0.06 \mathrm{mg} / \mathrm{L}$ ) at $2 \times$ that of reference chemistries.

We created a Sankey diagram to better illustrate complex interrelationships among land use activities and water chemistry types (Figure 4). The widths of the first connection approximate contributions of landscape attributes to each PC (as quantified by correlations with component chemical constituents). The widths of the second connection approximate the contribution of each PC to a given chemistry type and were calculated by dividing average PC scores for each type by those of reference water chemistries. Thus, the size of each PC reflects its combined exceedance of reference conditions across all water chemistry types and is a measure of overall contribution to chemical degradation. The size of each chemistry type reflects the summed exceedance of all $3 \mathrm{PCs}$ and is a measure of overall degradation relative to reference conditions. Numbers associated with the second connection reflect the relative contribution of PCs to each chemistry type. It is clear that contemporary surface mining has a dominant chemical signature (i.e., size of PC 1) that strongly contributes across chemistry types (relative contributions ranging from 0.48 to 0.80 ) (Figure 4). However, it is also clear that this contemporary mining signature occurs on top of signatures related to historic mining and 
geology and residential development and that the context within which contemporary mining occurs strongly dictates the resulting chemistry type and signature (Figure 4).

\section{Land use contribution to regional chemical degradation}

Multivariate analysis of variance showed significant differences in landscape characteristics among the 6 water chemistry types (Wilks' lambda $=0.782, F=5.54, p<0.0001$ ) Discriminant function analysis with land use indicators of mining (surface mining, valley fills, underground mining, and abandoned mine lands) and residential development (barren/development and structures) predicted major water chemistry type [reference (83\%), development (66\%), mining (73\%), and combined $(68 \%)]$ with a relatively high degree of overall accuracy (70\%). Consequently, we were confident in the ability of our DFA model to predict major water chemistry type for all un-sampled stream segments $(n=26,135)$. Small streams (i.e., $<5 \mathrm{~km}^{2}$ ) account for $82 \%$ of the total stream length, $49 \%$ of which were predicted to have reference water chemistries (Figure 5). Development and mining (1 and 2) chemistries were predicted in $18 \%$ and $8 \%$ of small streams, respectively. Combined chemistries (1 and 2) were predicted in $26 \%$ of small streams. Reference chemistries were predicted in $21 \%$ of large streams (i.e., basin areas ranging from 5 to $40 \mathrm{~km}^{2}$ ) (Figure 5). Development and mining chemistries were predicted in $25 \%$ and $6 \%$ of large streams, respectively. Combined chemistries were predicted in $47 \%$ (Figure 5).

\section{DISCUSSION}

Stream water quality conditions throughout the mountaintop mining region of West Virginia exist as a complex patchwork of distinct chemical signatures that are the result of 
multiple natural and anthropogenic landscape factors. Specifically, we identified 6 distinct water chemistry types that differed with respect to combinations of constituents associated with contemporary surface mines $\left(\mathrm{Ca}^{2+}, \mathrm{K}+, \mathrm{Mg}^{2+}, \mathrm{SO}_{4}{ }^{2-}, \mathrm{HCO}_{3}-\right.$, and $\left.\mathrm{Se}\right)$, abandoned mine lands and Allegheny coal geology $(\mathrm{Cd}, \mathrm{Mn}, \mathrm{Ni}$, and $\mathrm{Zn})$, and residential development $(\mathrm{Na}+, \mathrm{Cl}+$, and $\mathrm{Ba})$.

Previous efforts to characterize chemical degradation within the mountaintop region have largely focused on linking contemporary mountaintop mining to changes in water chemistry. In general, mountaintop mining has been associated with increases in selenium and specific conductivity and associated dissolved ion concentrations $[7,8,20,22,26]$. We identified a strong mountaintop mining signature (PC 1) that corroborates results of these previous efforts.

However, the majority of the water quality landscape in this region is not characterized exclusively by surface mining contaminants. We predicted surface mining only signatures (i.e., mining 1 or mining 2) in only $7 \%$ of streams. In contrast, $49 \%$ of streams were predicted to have developed or combined (i.e., surface mining and development) chemistries. The relative contribution of combined chemistries was much greater for large (48\%) than small (26\%) streams. Consequently, the tendency to focus solely on surface mining impacts risks oversimplifying physicochemical conditions in Appalachian watersheds and underestimating chemical degradation, particularly within larger streams.

Our results contribute to a growing body of literature documenting strong relationships between degraded chemical conditions and multiple land use activities (i.e., mining and residential development) within the mountaintop mining region $[11,27,28]$. Our study also adds to a growing body of evidence regarding geologic control over water chemistry within this region. Notably, Vengosh et al. [22] identified a distinctive isotopic signature associated with contemporary mountaintop operations targeting the Kanawha formation. We found significant 
correlations between our contemporary mining signature (PC 1) and the percentage of upstream Allegheny coal. Our results further suggest that legacy mining operations (i.e., abandoned mine lands) that targeted the Allegheny coal formation produced a metal and trace element-laden chemical signature (i.e., PC 2) that combines with contaminants associated with contemporary mountaintop mining and residential development to produce distinct chemical signatures (mining 2 and combined 2, respectively). It is important to note, however, that PC 2 represented the least dominant chemical signature. Moreover, only one (0.6\%), three (1.7\%), and seven $(4.2 \%)$ study sites exceeded aquatic life criteria (i.e., criterion continuous concentrations) for $\mathrm{Zn}(120 \mu \mathrm{g} / \mathrm{L}), \mathrm{Ni}$ $(52 \mu \mathrm{g} / \mathrm{L})$, and $\mathrm{Cd}(0.25 \mu \mathrm{g} / \mathrm{L})$, respectively. There are currently no aquatic life criteria for Mn. Further research is needed to verify the geologic source of mining-related contaminants and to determine the extent to which this degradation, particularly increased metals and trace elements, contributes to biological impairment throughout the region. Regardless, managers will likely need to take both anthropogenic and natural landscape factors into consideration when managing aquatic conditions in the face of past, present, and future mining within the mountaintop region.

The current results also add to a number of studies successfully identifying discrete water chemistry types within heavily impacted watersheds, such as urbanization [29], agriculture [30], and natural resource extraction [24]. Water chemistry classifications are valuable from a resource management perspective because they support cost-effective watershed monitoring programs [31]. Consequently, there has been a recent push to incorporate discrete chemistry types within watershed management frameworks designed to target streams for specific restoration actions in the face of current and future anthropogenic activity [31-32].

Broad-scale prediction of local conditions is an important first step in guiding aquatic resource management efforts within human-dominated landscapes [33]. Streams with similar 
water chemistries and chemistry types will likely have similar ecological conditions and benefit from similar restoration and mitigation activities [24]. Moreover, information on local conditions can be placed within the context of conditions at broader spatial scales, enabling a more complete characterization of the regional riverscape [31,34]. Consequently, our study represents an important next step in characterizing aquatic response to landscape patterns that should aid in efficiently and effectively managing current and future chemical conditions throughout the mountaintop mining region.

Perhaps the greatest strength of the current study was the consistency within and between our water quality and landscape datasets. Existing large-scale water quality datasets represent a compilation of individual monitoring efforts (e.g., 303(d) listing and associated total maximum daily load requirements and randomized sampling) collected over long time periods and across variable flow conditions. We were able to sample a large spatial extent within a relatively short time frame and across equivalent flow conditions. We were also able to link the timing of instream sampling to the collection of orthophotographs used to construct our landscape characterization [17]. This temporal congruency helped ensure accurate statistical relationships among water quality constituents and between water quality and landscape characteristics $[23,35-36]$.

Our results have important implications with respect to how aquatic systems within the mountaintop mining region should be managed moving forward. There has been a recent trend toward managing aquatic systems within this region toward specific conductivity benchmarks (i.e., $300 \mu \mathrm{S} / \mathrm{cm}$ ) [9]. We demonstrate that specific conductivity is significantly correlated with component constituents of all 3 significant PCs and associated land use activities. These results suggest high conductivities throughout much of the region are the result of increases in mining- 
$\left(\mathrm{K}+, \mathrm{Ca}^{2+}, \mathrm{Mg}^{2+}, \mathrm{SO}_{4}{ }^{2-}\right)$ and development-related $(\mathrm{Na}+, \mathrm{Cl}-)$ ions. Equivalent conductivities also have varying trace element concentrations ( $\mathrm{Se}, \mathrm{Zn}, \mathrm{Ni}, \mathrm{Cd})$. Studies have observed differing toxicities associated with dominant ions $\left(\mathrm{K}+>\mathrm{HCO}_{3^{-}} \approx \mathrm{Mg}^{2+}>\mathrm{Cl}->\mathrm{SO}_{4}{ }^{2-}\right)[37]$ and interactions among metals $(\mathrm{Zn}, \mathrm{Cd}$, and $\mathrm{Cu})$ [12]. Many of these chemical constituents are prevalent throughout the study region and vary considerably among water chemistry types. An important avenue of future research will be to determine the suitability of the $300 \mu \mathrm{S} / \mathrm{cm}$ conductivity benchmark, which was specifically designed for chemistries containing predominantly $\mathrm{HCO}_{3}{ }^{-}, \mathrm{SO}_{4}{ }^{2-}, \mathrm{Ca}^{2+}$, and $\mathrm{Mg}^{2+}$ (i.e., mining 1), across water chemistry types [9].

Previous research has demonstrated complex additive and interactive effects among multiple land use activities (i.e., mining and residential development) that result in widespread biological degradation throughout the mountaintop mining region $[11,27]$. Our results here indicate that chemical contaminants produced by each land use activity accumulate to become a dominant physicochemical driver of community composition. However, regional conditions and associated metacommunity processes often play an important role in structuring aquatic community structure [31,38,39]. Consequently, further research should be aimed at characterizing biological response to specific chemical mixtures and water chemistry types within the context of surrounding regional conditions.

Our results confirm the hypothesis that extreme degradation of central Appalachian rivers can be attributed to the combined effects of multiple historic and contemporary human induced impacts that include mountaintop mining and untreated wastewater. Management efforts that do not incorporate this complexity risk overgeneralizing sources of stress that likely drive observed ecological conditions in Appalachian streams. Consequently, we conclude that improved water 
quality in central Appalachian rivers will require that we balance regulation of new mine development with mitigation of legacy and non-mining related contaminant sources. 


\section{ACKNOWLEDGMENT}

We would like to thank the numerous individuals involved in the present study, especially E. Miller, A. Anderson, D. Hartman, and G. Merovich. Funding was provided by the US Geological Survey through support from the US Environmental Protection Agency (EPA) Region III. The present study was partially developed under STAR Fellowship Assistance Agreement number FP-91766601-0 awarded by the US EPA. This research has not been subjected to the US EPA's required peer and policy review and therefore does not necessarily reflect the views of the agency, and no official endorsement should be inferred. The present study was also sponsored in part by the Appalachian Research Initiative for Environmental Science (ARIES). The views, opinions and recommendations expressed herein are solely those

of the authors and do not imply any endorsement by ARIES employees, other ARIES-affiliated researchers or industrial members. Information about ARIES can be found at http://www.energy.vt.edu/ARIES. 


\section{REFERENCES}

1. Herlihy AT, Kaufmann PR, Church MR, Wigington Jr PJ, Webb JR, Sale MJ. 2010. The effects of acidic deposition on streams in the Appalachian Mountain and Piedmont Region of the Mid-Atlantic United States. Water Resources Research 29:2687-2703.

2. Pond GJ, North SH. 2013. Application of a benthic observed/expected model for assessing central Appalachian streams influenced by regional stressors in West Virginia and Kentucky. Environ Monit Assess 185:9299-9320.

3. Petty JT, Fulton JB, Strager MP, Merovich GT, Stiles JM, Ziemkiewicz PF. 2010. Landscape indicators and thresholds of stream ecological impairment in an intensively mined Appalachian watershed. J North Am Benthol Soc 29:1292-1309.

4. Hopkins II RL, Altier BM, Haselman D, Merry AD, White JJ. 2013. Exploring the legacy effects of surface coal mining on stream chemistry. Hydrobiologia 713:87-95.

5. Pond GJ, Passmore ME, Pointon ND, Felbinger JK, Walker CA, Krock KJG, Fulton JB, Nash WL. 2014. Long-term impacts on macroinvertebrates downstream of reclaimed mountaintop mining valley fills in central Appalachia. Environ Manag 54:919-933.

6. Cook NA, Krometis LA, Sarver EA. 2013. Inventory of bacterial impairments in central Appalachia. Environmental Considerations in Energy Productions 5:214-228.

7. Lindberg TT, Bernhardt ES, Bier R, Helton AM, Merola RB, Vengosh A, di Giulio RT. 2011. Cumulative impacts of mountaintop mining on an Appalachian watershed. Proc Natl Acad Sci U S A 108:20929-20934.

8. Bernhardt ES, Lutz BD, King RS, Fay JP, Carter CE, Helton AM, Campagna D, Amos J. 2012. How many mountains can we mine? Assessing the regional degradation of central Appalachian rivers by surface coal mining. Environ Sci Technol 46:8115-8122. 
9. Cormier SM, Suter II GW, Zheng L. 2013. Derivation of a benchmark for freshwater ionic strength. Environ Toxicol Chem 32: 263-271.

10. Cormier SM, Suter II GW, Zheng L, Pond GJ. 2013. Assessing causation of the extirpation of stream macroinvertebrates by a mixture of ions. Environ Toxicol Chem 32: 277-287.

11. Merriam ER, Petty JT, Strager MP, Maxwell AE, Ziemkiewicz PF. in press. Multi-stressor models for characterizing hierarchical stream condition in mined Appalachian watersheds. Freshwater Science 34:000-000.

12. Clements WH. 2004. Small-scale experiments support causal relationships between metal contamination and macroinvertebrate community responses. Ecol Appl 14:954-967.

13. Vander Laan JJ, Hawkins CP, Olson JR, Hill RA. 2013. Linking land use, in-stream stressors, and biological condition to infer causes of regional ecological impairment in streams. Freswhater Science 32:801-820.

14. US Environmental Protection Agency. 2011. A field-based aquatic life benchmarkfor conductivity in central Appalachian streams. EPA/600/R-10/023F. Office of Research and Development, National Center for Environmental Assessment, Washington, DC.

15. West Virginia State Address Mapping Board. 2003. 1:4,800 Scale Orthophography, Building Points and Polygons. West Virginia GIS Technical Center, Morgantown, WV.

16. US Environmental Protection Agency. 1983. Methods for chemical analysis of water and wastes. EPA-60014-79-020. Environmental Monitoring Systems Support Laboratory, Office of Research and Development, Cincinnati, $\mathrm{OH}$.

17. Maxwell AE, Strager MP, Yuill C, Petty JT, Merriam ER, Mazzarella C. 2011. Disturbance mapping and landscape modeling of mountaintop mining using ArcGIS. Proceedings of the Esri International User Conference, San Diego, CA, USA, July 11-15, 2011. 
18. Strager MP, Petty JT, Strager JM, Barker-Fulton J. 2009. A spatially explicit framework for quantifying downstream hydrologic conditions. J Environ Manag 90:1854-1861.

19. McCune B, Grace JB. 2002. Analysis of ecological communities. MjM Software Design, Gleneden Beach, OR, USA.

20. Hartman KJ, Kaller JD, Howell JW, Sweka JA. 2005. How much do valley fills influence headwater streams? Hydrobiologia 532:91-109.

21. Stoddard JL, Herlihy AT, Hill BH, Hughes RM, Kaufmann PR, Klemm DJ, Lazorchak JM, McCormck FH, Peck DV, Paulsen SG, Olsen AR, Larsen DP, Van Sickle J, Whittier TR. 2006. Mid-Atlantic intigrated assessment: flowing waters report. EPA/620/R-06/001. Office of Research and Development, US Environmental Protection Agency, Washington, DC.

22. Vengosh A, Lindberg TT, Merola BR, Ruhl L, Warner NR, White A, Dwyer GS, Di Giulio RT. 2013. Isotopic imprints of mountaintop mining contaminants. Environmental Science and Technology 47:10041-10048.

23. King RS, Baker ME, Whigham DF, Weller DE, Jordan TE, Kazyak PF, Hurd MK. 2005. Spatial considerations for linking watershed land cover to ecological indicators in streams. Ecol Appl 15:137-153.

24. Merovich GT, Stiles JM, Petty JT, Fulton J, Ziemkiewicz PF. 2007. Water cheistry based classification of streams and implications for restoring mined Appalachian watersheds. Environ Toxicol Chem 26:1361-1369.

25. Venables WN, Ripley BD. 2002. Modern applied statistics with S, $4^{\text {th }}$ edn. Springer, New York.

26. Cormier SM, Wilkes SP, Zheng L. 2013c. Relationship of land use and elevated ionic strength in Appalachian watersheds. Environ Toxicol Chem 32:296-303. 
27. Merriam ER, Petty JT, Merovich GT, Fulton JB, Strager MP. 2011. Additive effects of mining and residential development on stream conditions in a central Appalachian watershed. J North Am Benthol Soc 30:399-418.

28. Merriam ER, Petty JT, Strager MP, Maxwell AE, Ziemkiewicz PF. 2013. Scenario analysis predicts context-dependent stream response to land use change in a heavily mined central Appalachian watershed. Freshwater Science 32:1246-1259.

29. Kannel PR, Lee S, Kanel SR, Khan SP. 2007. Chemometric application in classification and assessment of monitoring locations of an urban river system. Anal Chim Acta 582:390-399.

30. Kowalkowski T. 2009. Classification of nutrient emission sources in the Vistula River system. Environ Pollut 157:1867-1872.

31. Merovich GT, Petty JT, Strager MP, Fulton JB. 2013. Hierarchical classification of stream condition: a house-neighborhood framework for establishing conservartion priorities in complex riverscapes. Freshwater Science: 874-891.

32. Linke S, Turak E, Nel J. 2011. Freshwater conservation planning: the case for systematic approaches. Freshw Biol 56:6-10.

33. Carlisle DM, Falcone J, Meador MR. 2009. Predicting the biological condition of streams: use of geospatial indicators of natural and anthropogenic characteristics of watersheds. Environ Monit Assess 151:143-160.

34. Fausch KD, Torgersen C, Baxter CV, Li HW. 2002. Landscapes to riverscapes: bridging the gap between research and conservation of stream fishes. BioScience 52:483-498.

35. Strayer DL, Beighley RE, Thompson LC, Brooks S, Nilsson C, Pinay G, Naiman RJ. 2003. Effects of land cover on stream ecosystems: roles of empirical models and scaling issues. Ecosystems 6:407-423. 
36. Allan JD. 2004. Landscapes and riverscapes: the influence of land use on stream ecosystems. Annu Rev Ecol Evol Syst 35:257-284.

37. Mount DR, Gulley DD, Hockett JR, Garrison TD, Evans JM. 1997. Statistical models to predict the toxicity of major ions to Ceriodaphnia dubia, Daphnia magna, and Pimephales promelas (fathead minnows). Environ Toxicol Chem 16:2009-2019.

38. Hitt NP, Angermeier PL. 2011. Fish community and bioassessment responses to stream network position. J North Am Benthol Soc 30:296-309.

39. Brown BL, Swan CM, Auerbach DA, Campbell Grant EH, Hitt NP, Maloney KO, Patrick C. 2011. Metacommunity theory as a multispecies, multiscale framework for studying the influyence of river network structure on riverine communities and ecosystems. $J$ North Am Benthol Soc 30:310-327. 


\section{FIGURE LEGENDS}

Figure 1. Map of study area showing target 8-digit hydrologic unit code watersheds that intersect the primary mountaintop removal-valley fill (MTR-VF) region. Major rivers and study sites are shown.

Figure 2. Scatter of mean (and 95\% confidence interval) water quality principal component (WQ PC) 1 and WQ PC2 (A) and WQ PC1 and WQ PC3 (B) scores for the 6 water chemistry types identified by cluster analysis. Water chemistry variables and associated factor loadings significantly contributing (i.e., factor ladings $>|0.4|$ ) are shown. See Table 2 for chemical descriptions of each type.

Figure 3. Proportional milliequivalents of mean ion concentrations across sites within each water chemistry type (top panel). Numbers represent mean specific conductivity $(\mu \mathrm{S} / \mathrm{cm})$. Mean trace element concentrations across each water chemistry type (bottom panel).

Figure 4. Sankey diagram wherein widths of connections approximate contributions of landscape attributes to each water chemistry principal component (PC) and relative contributions of each PC to a given water chemistry type relative to average reference conditions.

Figure 5. Pictures representing mining (top right), development (top left), and combined streams (bottom). Percentage of small (i.e., $\left.<5 \mathrm{~km}^{2}\right)$ and large $\left(>5 \mathrm{~km}^{2}\right)$ streams predicted to have reference, development, mining, and combined water chemistries. 
Table 1. Statistically significant $(p<0.05)$ Spearman correlations (alternative hypothesis: $r h o>0$ ) relating increases in water quality (WQ) principal component (PC) scores and component constituent concentrations ${ }^{\mathrm{a}}$ to specific conductivity and landscape-based measures of residential development, coal mining and coal geology $(n=168)$.

\begin{tabular}{|c|c|c|c|c|c|c|c|c|c|}
\hline & \multirow[b]{2}{*}{$\mathrm{SpC}^{\mathrm{b}}$} & \multicolumn{2}{|c|}{ Residential } & \multicolumn{4}{|c|}{ Coal mining } & \multicolumn{2}{|c|}{ Coal geology } \\
\hline & & $\begin{array}{l}\text { Structure } \\
\text { density }^{c}\end{array}$ & $\begin{array}{c}\text { Barren/ } \\
\text { developed }^{\mathrm{d}}\end{array}$ & $\begin{array}{l}\text { Surface } \\
\text { mining }^{\mathrm{d}}\end{array}$ & $\begin{array}{l}\text { Valley } \\
\text { fills }^{\mathrm{d}}\end{array}$ & $\begin{array}{l}\text { Underground } \\
\text { mine density }\end{array}$ & $\begin{array}{l}\text { Abandoned } \\
\text { mine lands }\end{array}$ & $\begin{array}{l}\text { Allegheny } \\
\text { formation }^{\mathrm{d}}\end{array}$ & $\begin{array}{l}\text { Kanawha } \\
\text { formation }^{\mathrm{d}}\end{array}$ \\
\hline WQ PC1 & 0.95 & -- & -- & 0.80 & 0.58 & 0.30 & 0.39 & 0.27 & -- \\
\hline $\mathrm{K}+$ & 0.93 & -- & -- & 0.80 & 0.58 & 0.26 & 0.40 & 0.32 & -- \\
\hline $\mathrm{Ca}^{2+}$ & 0.94 & -- & -- & 0.73 & 0.55 & 0.30 & 0.40 & 0.19 & -- \\
\hline $\mathrm{Mg}^{2+}$ & 0.94 & -- & -- & 0.83 & 0.66 & 0.31 & 0.50 & 0.24 & -- \\
\hline $\mathrm{SO}_{4}{ }^{2-}$ & 0.91 & -- & -- & 0.78 & 0.58 & 0.34 & 0.49 & 0.24 & -- \\
\hline Bicarb. alk & 0.69 & -- & -- & 0.54 & 0.49 & 0.22 & -- & -- & -- \\
\hline $\mathrm{Se}$ & 0.70 & -- & -- & 0.75 & 0.57 & 0.19 & 0.27 & 0.29 & -- \\
\hline $\mathrm{NO}_{2}-\mathrm{NO}_{3}$ & 0.45 & -- & -- & 0.53 & 0.39 & -- & 0.16 & -- & 0.20 \\
\hline WQ PC2 & -- & -- & -- & -- & -- & -- & -- & 0.22 & -- \\
\hline $\mathrm{Mn}$ & -- & -- & 0.15 & -- & -- & -- & -- & 0.21 & -- \\
\hline
\end{tabular}




\begin{tabular}{|c|c|c|c|c|c|c|c|c|c|}
\hline $\mathrm{Zn}$ & 0.13 & -- & -- & -- & -- & -- & 0.19 & 0.24 & -- \\
\hline $\mathrm{Ni}$ & 0.67 & -- & -- & 0.55 & 0.32 & -- & 0.38 & 0.35 & -- \\
\hline $\mathrm{Cd}$ & -- & -- & -- & -- & -- & -- & -- & 0.24 & -- \\
\hline WQ PC3 & -- & 0.65 & 0.57 & -- & -- & -- & -- & -- & "-- \\
\hline $\mathrm{Cl}-$ & 0.23 & 0.55 & 0.55 & -- & -- & -- & -- & -- & -- \\
\hline $\mathrm{Na}+$ & 0.52 & 0.28 & 0.36 & 0.24 & 0.15 & 0.37 & -- & -- & -- \\
\hline $\mathrm{Ba}$ & -- & 0.31 & 0.19 & -- & -- & -- & -- & -- & -- \\
\hline \multicolumn{10}{|l|}{$\mathrm{a}=\mathrm{mg} / \mathrm{L}$} \\
\hline \multicolumn{10}{|c|}{${ }^{b}=$ Specific conductivity $(\mu \mathrm{S} / \mathrm{cm})$} \\
\hline \multicolumn{10}{|c|}{${ }^{\mathrm{c}}=\mathrm{no} . / \mathrm{km}^{2}$} \\
\hline
\end{tabular}


Table 2. Means (and standard deviations) of water quality (WQ) parameters, principal component (PC) scores, and landscape characteristics for each water quality type

\begin{tabular}{|c|c|c|c|c|c|c|}
\hline & $\begin{array}{l}\text { Reference } \\
\quad(n=12)\end{array}$ & $\begin{array}{l}\text { Development } \\
\qquad(n=29)\end{array}$ & $\begin{array}{l}\text { Mined } 1 \\
(n=44)\end{array}$ & $\begin{array}{l}\text { Mined } 2 \\
(n=11)\end{array}$ & $\begin{array}{l}\text { Combined } 1 \\
\qquad(n=37)\end{array}$ & $\begin{array}{c}\text { Combined } 2 \\
(n=35)\end{array}$ \\
\hline \multicolumn{7}{|l|}{ Water chemistry } \\
\hline $\mathrm{pH}$ & $6.96(0.41)$ & $7.69(0.45)$ & $7.98(0.39)$ & $7.69(0.29)$ & $8.03(0.41)$ & $7.63(0.46)$ \\
\hline Spcific conductance ${ }^{\mathrm{d}}$ & $77(25)$ & $266(86)$ & $1259(530)$ & $1435(606)$ & $700(371)$ & $674(367)$ \\
\hline $\operatorname{Al}(1.3)^{b f}$ & $1.2(1.3)$ & $0.8(0.9)$ & $1.5(3.3)$ & $6.0(6.0)$ & $0.5(1.0)$ & $2.3(3.3)$ \\
\hline $\mathrm{Ba}(0.02)^{\mathrm{bf}}$ & $3.3(1.0)$ & $6.6(3.9)$ & $5.8(18.0)$ & $4.7(2.6)$ & $6.3(2.1)$ & $6.7(5.2)$ \\
\hline Bicarb alk ${ }^{\text {ef }}$ & $21.7(11.1)$ & $79.1(41.6)$ & $183.2(85.6)$ & $91.6(51.8)$ & $120.6(65.3)$ & $84.8(64.8)$ \\
\hline $\mathrm{Ca}(0.05)^{\mathrm{af}}$ & $6.6(3.2)$ & $25.1(9.2)$ & $123.6(68.1)$ & $188.3(125.9)$ & $62.8(36.6)$ & $68.9(52.2)$ \\
\hline $\mathrm{Cd}(0.2)^{\mathrm{cf}}$ & $1.5(1.7)$ & $1.1(0.58)$ & $1.0(0.0)$ & $2.5(2.4)$ & $1.0(0.0)$ & $1.0(0.17)$ \\
\hline $\mathrm{Cl}(0.10)^{\text {af }}$ & $0.9(0.4)$ & $13.7(11.1)$ & $8.5(7.6)$ & $14.4(13.6)$ & $7.1(6.3)$ & $20.5(27.3)$ \\
\hline $\operatorname{Cr}(10.0)^{\mathrm{cf}}$ & $5.0(0.0)$ & $5.0(0.0)$ & $5.2(1.1)$ & $5.0(0.0)$ & $5.0(0.0)$ & $5.0(0.0)$ \\
\hline $\mathrm{Fe}(1.0)^{b f}$ & $11.0(13.1)$ & $9.7(8.8)$ & $1.2(1.2)$ & $5.8(15.8)$ & $1.6(1.2)$ & $8.1(14.4)$ \\
\hline $\mathrm{K}(0.05)^{\text {af }}$ & $1.6(0.3)$ & $2.6(0.7)$ & $11.6(5.3)$ & $14.4(7.4)$ & $5.5(2.9)$ & $6.1(3.1)$ \\
\hline
\end{tabular}




\begin{tabular}{|c|c|c|c|c|c|c|}
\hline $\mathrm{Mg}(0.05)^{\text {af }}$ & $3.1(1.2)$ & $7.5(3.2)$ & $99.7(56.3)$ & $135.8(120.1)$ & $37.3(29.3)$ & $33.4(29.0)$ \\
\hline $\operatorname{Mn}(0.2)^{b f}$ & $2.7(3.2)$ & $5.8(7.0)$ & $2.8(3.6)$ & $163.2(138.8)$ & $1.3(1.1)$ & $25.3(33.7)$ \\
\hline $\mathrm{Na}(0.05)^{\mathrm{af}}$ & $2.2(1.1)$ & $17.5(18.4)$ & $24.5(16.6)$ & $36.6(31.1)$ & $28.8(29.2)$ & $33.7(55.7)$ \\
\hline $\mathrm{NO}_{2}-\mathrm{NO}_{3}(0.03)^{\text {af }}$ & $0.31(0.32)$ & $0.27(0.24)$ & $3.78(4.13)$ & $1.70(1.43)$ & $0.35(0.33)$ & $0.49(0.62)$ \\
\hline $\mathrm{Ni}(0.2)^{\text {bf }}$ & $0.1(0.0)$ & $0.1(0.05)$ & $0.5(0.4)$ & $4.9(5.2)$ & $0.2(0.1)$ & $0.5(0.5)$ \\
\hline $\operatorname{Se}(10.0)^{\mathrm{cf}}$ & $5.0(0.0)$ & $5.4(1.6)$ & $110.0(99.0)$ & $51.0(39.0)$ & $11.0(14.0)$ & $14.0(17.0)$ \\
\hline $\mathrm{SO}_{4}(1.0)^{\text {af }}$ & $9.6(4.5)$ & $28.7(26.4)$ & $512.8(309.5)$ & $894.0(658.5)$ & $239.8(195.5)$ & 239.7 (215.9) \\
\hline $\mathrm{TP}(2.0)^{\mathrm{bf}}$ & $1.0(0.0)$ & $1.3(0.7)$ & $3.9(17.4)$ & $1.0(0.0)$ & $1.5(1.8)$ & $6.2(21.5)$ \\
\hline $\mathrm{Zn}(0.3)^{\mathrm{bf}}$ & $0.5(0.2)$ & $0.6(0.8)$ & $0.6(0.6)$ & $3.7(6.0)$ & $0.5(0.6)$ & $1.0(1.0)$ \\
\hline WQ PC $1^{\mathrm{g}}$ & $-4.6 \mathrm{~A}(0.5)$ & $-2.4 \mathrm{~B}(0.7)$ & $2.3 \mathrm{D}(1.1)$ & $3.5 \mathrm{E}(1.1)$ & $-0.3 \mathrm{C}(1.2)$ & $-0.2 \mathrm{C}(1.4)$ \\
\hline WQ PC $2^{\mathrm{g}}$ & $0.4 \mathrm{AB}(1.4)$ & $0.1 \mathrm{~A}(0.8)$ & $-1.0 \mathrm{C}(1.1)$ & $3.4 \mathrm{D}(1.6)$ & $-1.0 \mathrm{C}(0.7)$ & $1.0 \mathrm{~B}(1.2)$ \\
\hline WQ PC $3^{\mathrm{g}}$ & $-2.1 \mathrm{~A}(0.68)$ & $0.9 \mathrm{~B}(1.2)$ & $-0.6 \mathrm{E}(0.9)$ & $-0.4 \mathrm{CDE}(0.8)$ & $0.2 \mathrm{BC}(1.1)$ & $0.7 \mathrm{BD}(1.6)$ \\
\hline \multicolumn{7}{|l|}{ andscape characteristics } \\
\hline Basin $\operatorname{area}^{\mathrm{h}}$ & $5.38(4.33)$ & $11.66(9.56)$ & $8.81(8.18)$ & $12.55(10.62)$ & $11.33(9.41)$ & $11.05(8.86)$ \\
\hline Structure density ${ }^{\mathrm{i}}$ & $1.33(1.77)$ & $36.9(30.3)$ & $6.28(6.61)$ & $6.22(7.14)$ & $16.8(15.4)$ & $21.8(25.2)$ \\
\hline Barren/development $\mathrm{t}^{\mathrm{j}}$ & $0.041(0.050)$ & $1.49(1.79)$ & $0.298(0.450)$ & $0.78(1.29)$ & $0.436(0.482)$ & $0.674(1.19)$ \\
\hline
\end{tabular}




\begin{tabular}{|c|c|c|c|c|c|c|}
\hline Surface mining ${ }^{\mathrm{j}}$ & $0.409(0.951)$ & $0.864(2.10)$ & $36.2(24.1)$ & $32.4(25.4)$ & $9.57(11.6)$ & $10.4(13.5)$ \\
\hline Valley fills ${ }^{\mathrm{j}}$ & $0(0)$ & $0.092(0.421)$ & $5.84(6.05)$ & $0.790(0.792)$ & $1.98(3.47)$ & $0.915(1.63)$ \\
\hline Underground mine density ${ }^{\mathrm{i}}$ & $0(0)$ & $0.068(0.178)$ & $0.188(0.281)$ & $0.162(0.227)$ & $0.199(0.257)$ & $0.132(0.254)$ \\
\hline Abandoned mine lands $\mathrm{s}^{\mathrm{j}}$ & $1.60(2.98)$ & $1.66(3.40)$ & $5.14(5.09)$ & $9.17(4.66)$ & $5.86(8.39)$ & $5.22(6.16)$ \\
\hline Allegheny coal ${ }^{\mathrm{j}}$ & $24.8(26.7)$ & $18.2(31.0)$ & $21.4(15.7)$ & $40.8(20.2)$ & $12.2(17.8)$ & $28.2(33.6)$ \\
\hline Kanawha coal ${ }^{\mathrm{j}}$ & $58.5(36.4)$ & $54.2(44.6)$ & $74.0(22.2)$ & $59.2(20.2)$ & $68.8(37.6)$ & $57.5(39.5)$ \\
\hline
\end{tabular}

${ }^{a}$ Means (and standard deviations) and minimum detection limits (presented in parentheses) reported in $\mathrm{mg} / \mathrm{L}$

${ }^{\mathrm{b}}$ Means (and standard deviations) and minimum detection limits reported in $\left(\mathrm{mg} \times 10^{-2}\right) / \mathrm{L}$

${ }^{\mathrm{c}}$ Means (and standard deviations) and minimum detection limits reported in $\left(\mathrm{mg} \times 10^{-4}\right) / \mathrm{L}$

${ }^{\mathrm{d}}$ Means (and standard deviations) reported in $\mu \mathrm{S} / \mathrm{cm}$

${ }^{\mathrm{e}}$ Means (and standard deviations) reported in $\mathrm{mg} / \mathrm{L} \mathrm{CaCO}_{3}$ equivalents

${ }^{\mathrm{f}}$ Constituents included in principal components and cluster analyses

${ }^{\mathrm{g}}$ Letters denote statistical differences among groups $(p<0.05$; analysis of variance, Tukey post hoc comparisons)

${ }^{\mathrm{h}}$ Means (and standard deviations) reported in $\mathrm{km}^{2}$

${ }^{\mathrm{i}}$ Means (and standard deviations) reported in no. $/ \mathrm{km}^{2}$

${ }^{\mathrm{j}}$ Means (and standard deviations) reported in \% 


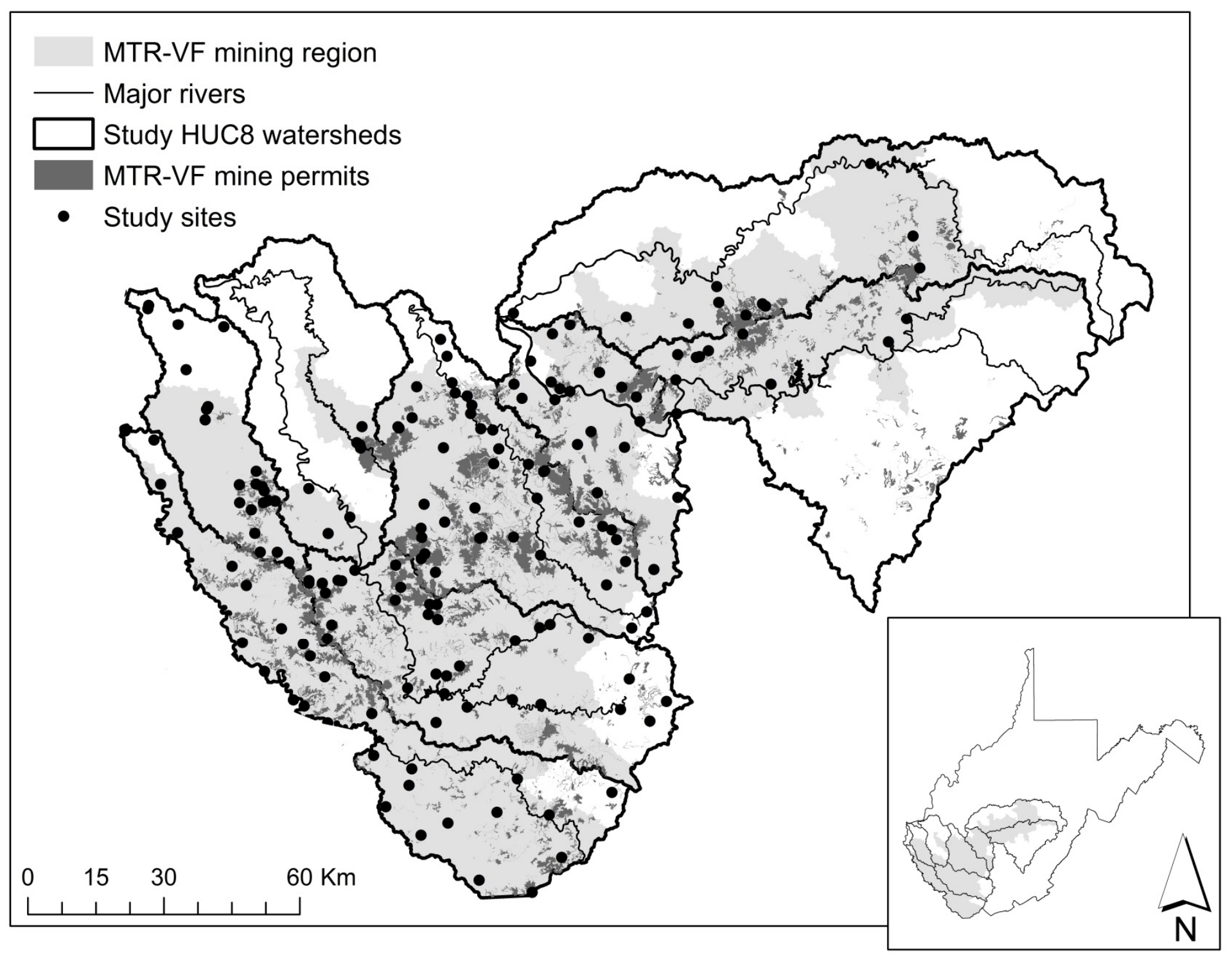

Figure 1 


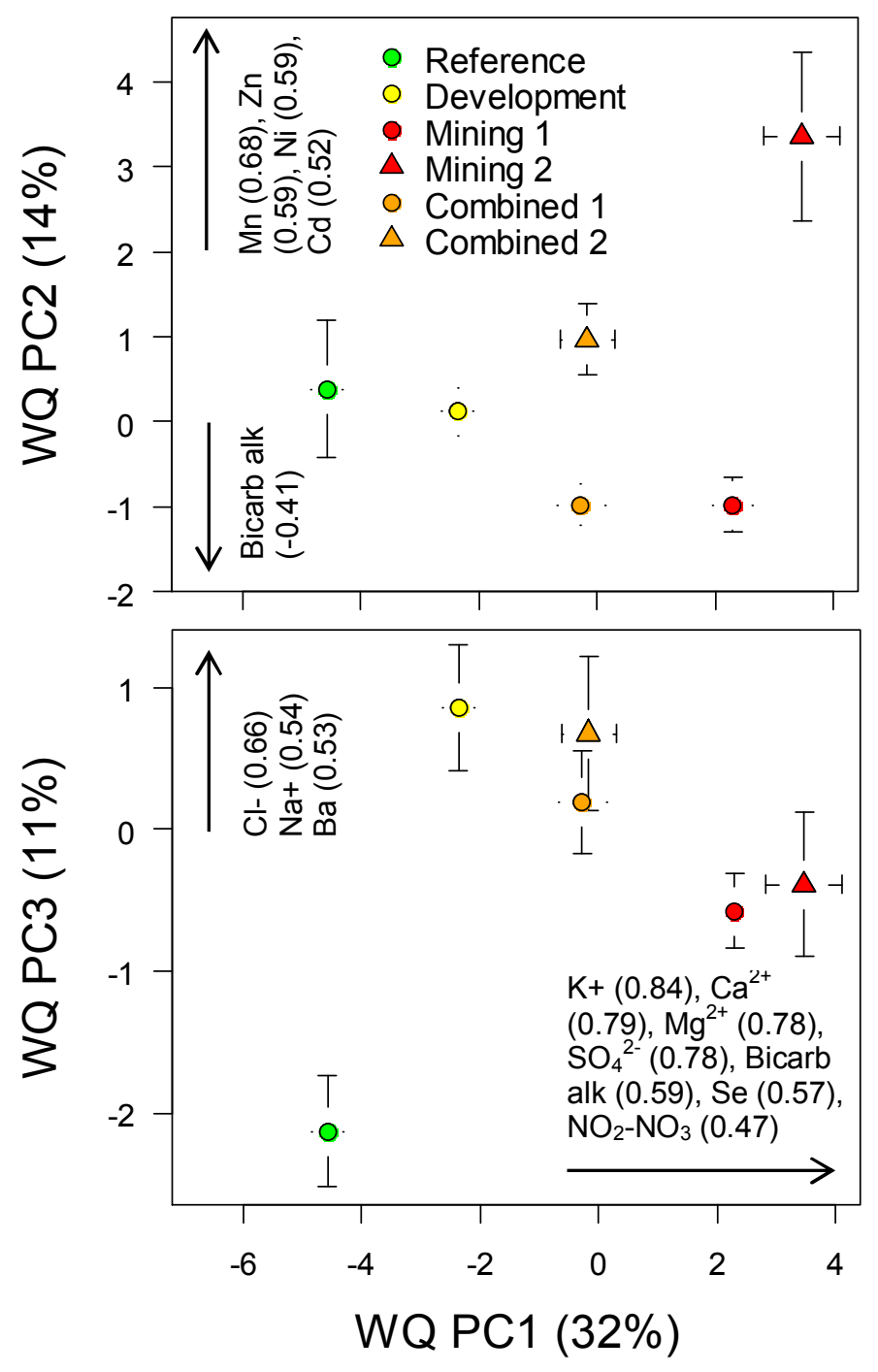

Figure 2 

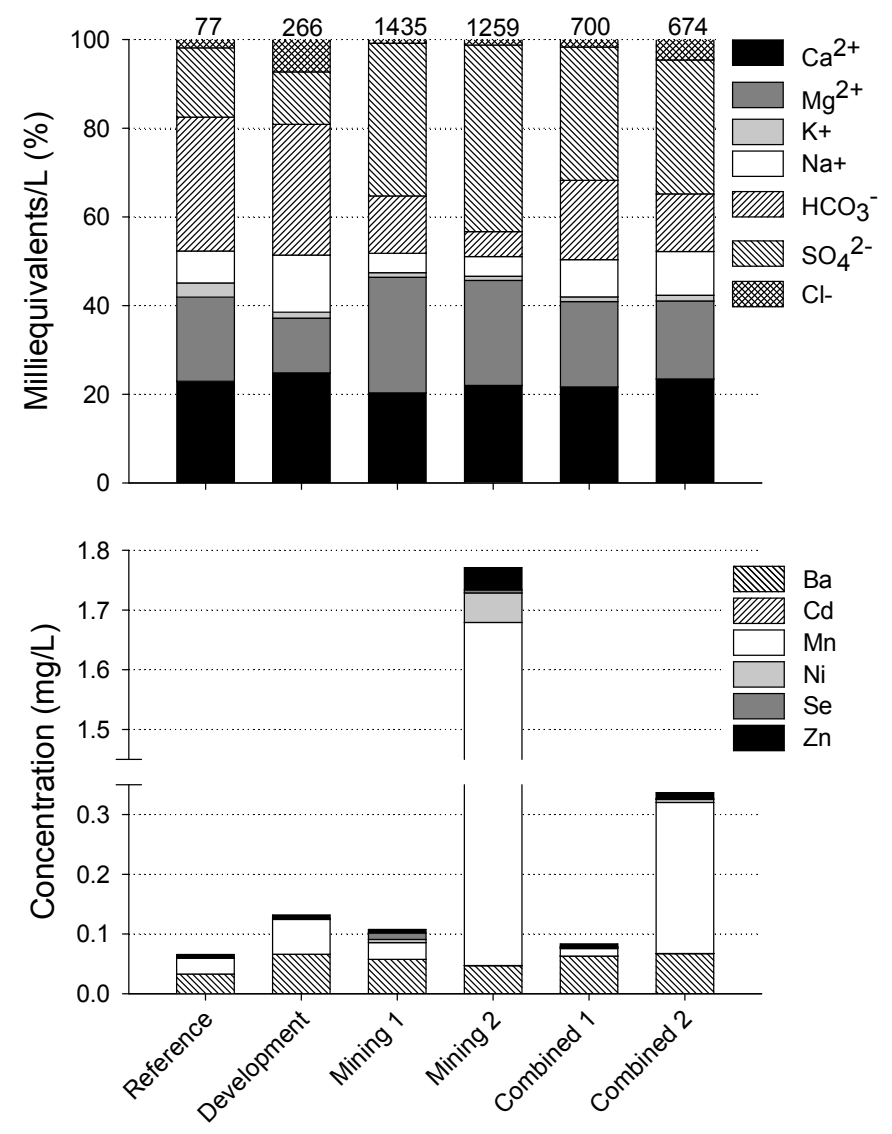

Figure 3 


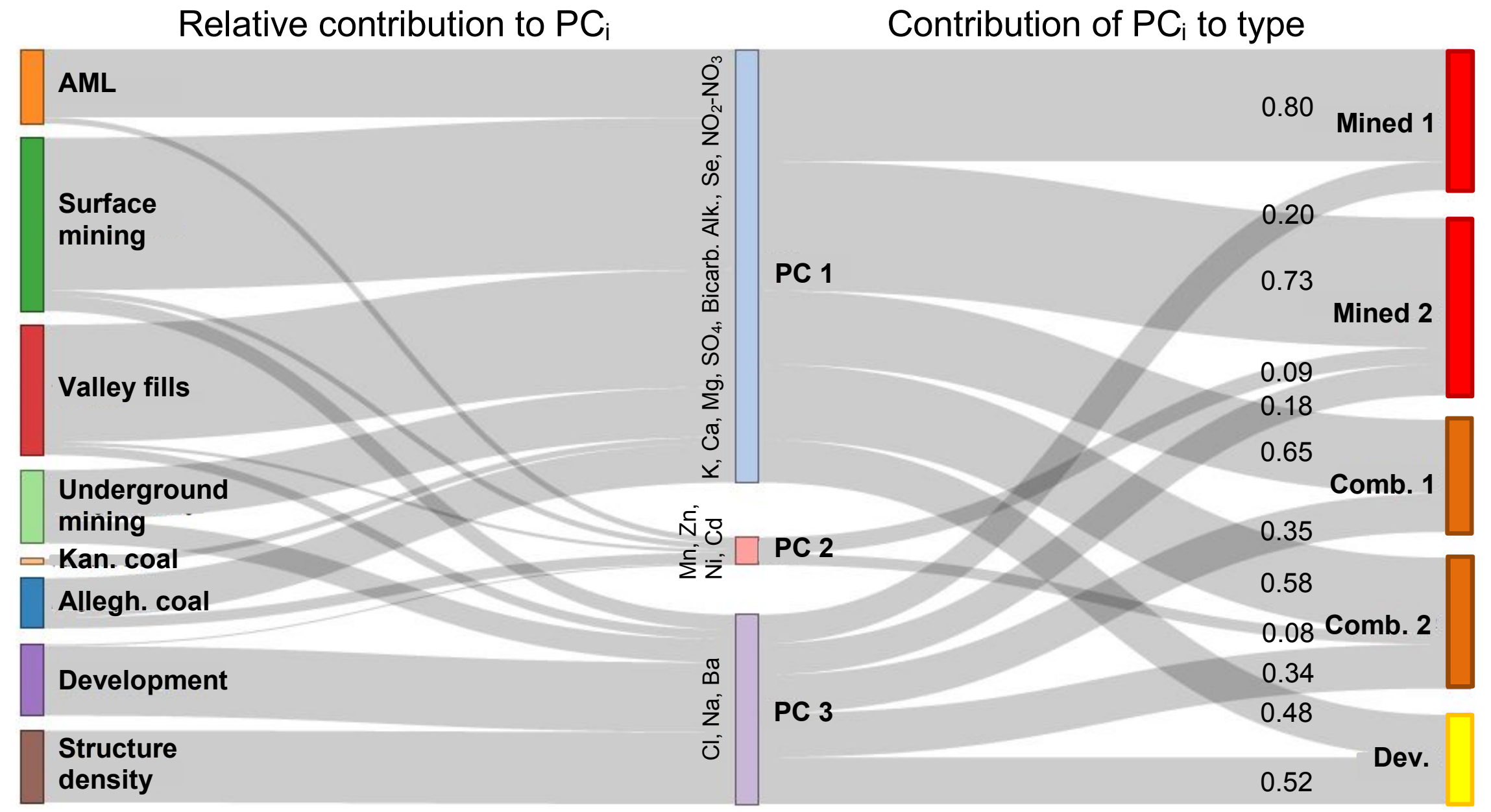

Figure 4 

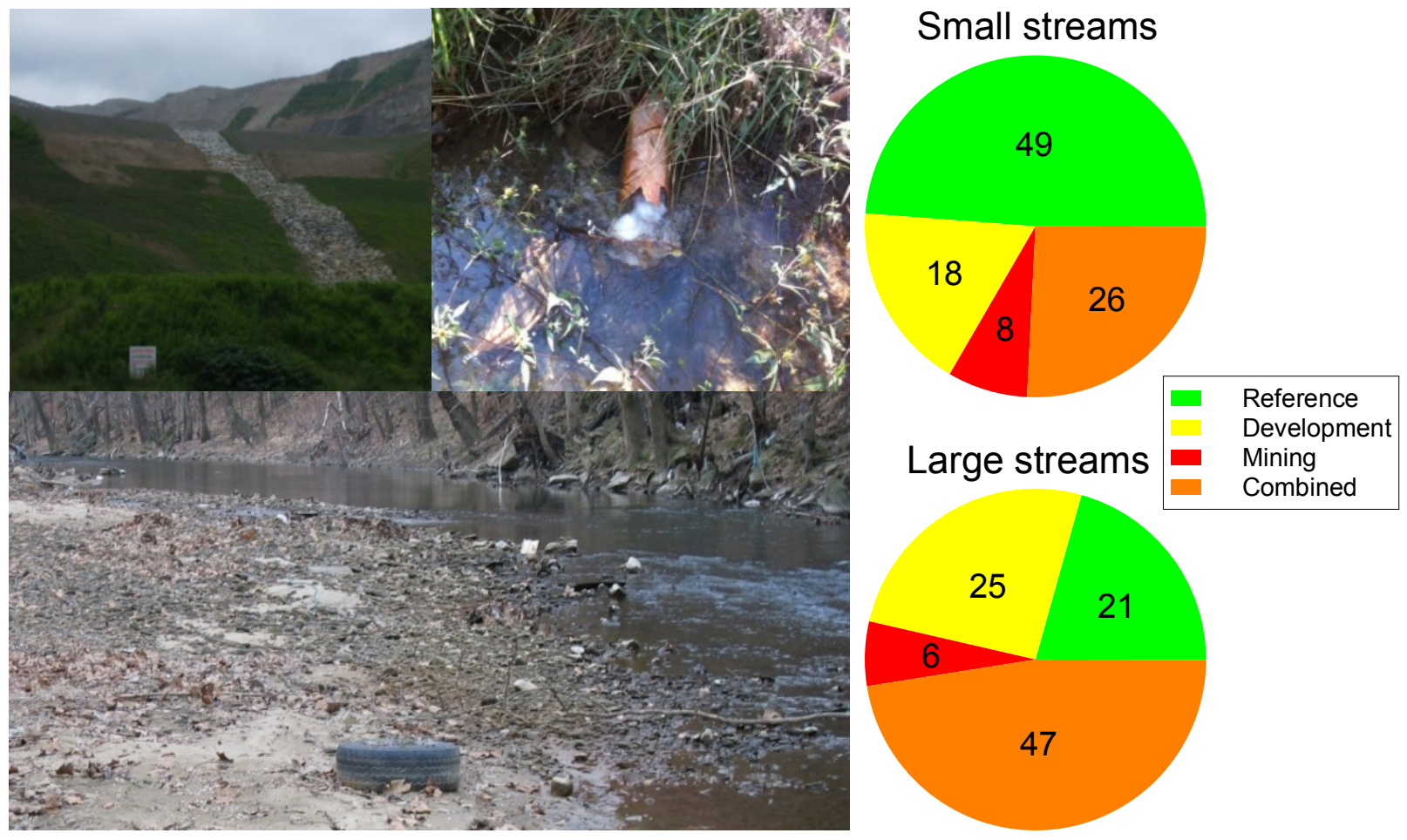

Figure 5 
CHAPTER 4: Under siege: isolated headwater tributaries are threatened by regionally impaired metacommunities 
Abstract.-Headwater streams are often targeted as conservation priorities within disturbed watersheds because of their ability to preserve regional biodiversity. However, such streams are often isolated within heavily degraded regions, leaving their communities at risk of losing sensitive, poor dispersing taxa (through decreased mass and rescue effects) and gaining tolerant, widely dispersing taxa (through increased dispersal and mass effects) from nearby degraded habitats. To test this hypothesis, we sampled invertebrate communities and physicochemical conditions from 168 headwater streams (basin areas $<40 \mathrm{~km}^{2}$ ) within the mountaintop removalvalley fill mining region of West Virginia. We used redundancy analysis to first test for significant effects of local (observed physicochemical conditions) and neighborhood (condition of streams within a $5 \mathrm{~km}$ buffer) degradation on assemblage structure across all taxa and then across stress tolerance (low, moderate, high) and dispersal (low, high) categories. We then constructed models to characterize local and neighborhood effects influencing community metrics and individual taxa. Local and neighborhood conditions explained significant variation in assemblage structure across all taxa and across low dispersing taxa with moderate and high tolerances and high dispersing taxa with high tolerances. Decreasing neighborhood condition was associated with decreased occurrence (Baetis, Ceratopsyche) and abundance (Maccaffertium) of several taxa and corresponding metrics (\%E, \%EPT). Several taxa with moderate and high tolerance values (Chironomidae, Hemerodromia, Chimarra) increased in occurrence and abundance. Invertebrate communities within even the most pristine streams appear to be at risk when isolated within heavily impacted neighborhoods. This isolation results in the simultaneous deflation of sensitive, poor dispersing taxa and inflation of tolerant, widely dispersing taxa from nearby degraded habitats. Consequently, protection of regional species' pools in heavily impacted regions will require more than simply conserving headwater streams. 


\section{INTODUCTION}

Advances in metacommunity ecology have led to an emerging paradigm recognizing the importance of regional factors (e.g., species pool and location within dispersal networks) and processes (e.g., dispersal) in structuring local assemblages (Heino et al. 2003, Leibold et al. 2004, Brown and Swan 2010, Hitt and Angermeier 2011). An important avenue of continued research concerns applying metacommunity theory to the management of disturbed ecosystems (Brown et al. 2011, Heino 2013). For example, preservation of undisturbed headwater catchments has become an important component of freshwater conservation efforts within actively developing watersheds (Lowe and Likens 2005). A major motivation for their preservation is the understanding that headwater streams contribute disproportionately to regional biodiversity and serve as critical habitat for the preservation of regionally rare and endangered taxa (Meyer et al. 2007, Lowe and Likens 2005, Finn et al. 2011).

However, extensive local disturbances have the potential to alter communities within undisturbed headwater streams through disruption of regional metacommunity structure and processes. Increasing isolation of intact headwaters through expanding human activity may result in dispersal limitation and decreased mass and rescue effects (i.e., dispersal of a taxa from suitable habitats to suboptimal or extirpated habitats), particularly for regionally sensitive taxa and/or taxa with low dispersal ability (Astorga et al. 2012, Vanschoenwinkel et al. 2013, Radkova et al. 2014, Heino et al. 2015). Moreover, extensive disturbance may also facilitate establishment and proliferation of subdominant competitors and disturbance tolerant specialists via mass effects (Pandit et al. 2009, Vanschoenwinkel et al. 2013). Consequently, the ability of intact headwaters to preserve regional biodiversity may be limited as they become increasingly 
isolated within heavily impacted systems (Heino 2013). To our knowledge, however, this has never been demonstrated.

We provide such an assessment by analyzing macroinvertebrate communities from the central Appalachian region in relation to their influence from local and regional (i.e., neighborhood, sensu Merovich et al. 2013) drivers of environmental degradation. We focus on the primary mountaintop removal-valley fill (MTR-VF) mining region because stream networks within this region offer a relevant opportunity to demonstrate regional metacommunity processes in an actively developing landscape with important current and future socioeconomic implications. Extensive contemporary and historic coal mining and residential development activities within this region have resulted in widespread ecological impacts (Bernhardt et al. 2012, Merriam et al. in press). However, the geography of land use activities within this region creates a unique juxtaposition of severely degraded streams within otherwise pristine stream networks and high quality streams within otherwise severely degraded networks (Merovich et al. 2013). Consequently, we had the rare opportunity to collect an un-confounded dataset with respect to local and regional controls over community composition across a large spatial scale (see Ewers and Didham 2005).

In a previous study, we characterized and predicted complex patterns in local physicochemical conditions across the mountaintop mining region of West Virginia and related these patterns to natural and anthropogenic landscape factors (Merriam et al. in press). Herein, we use observed and predicted local conditions to construct an index of neighborhood condition (sensu Merovich et al 2013). We utilized a series of multivariate and linear modeling techniques to directly test for significant effects of local and neighborhood conditions on assemblage structure. We extended these analyses to quantify and characterize the effects of local and 
neighborhood conditions on metacommunities classified based on dispersal ability and tolerance We hypothesize that increasing isolation (i.e., increasingly poor neighborhood conditions) will have a strong negative effect on sensitive taxa with low dispersal abilities due to decreased mass and rescue effects. We also expect streams isolated within highly degraded neighborhoods to have a greater proportion of tolerant taxa via mass effects from nearby degraded streams. Consequently, we expect to see strong effects of neighborhood condition on tolerant taxa, regardless of dispersal capacity. We demonstrate that communities within even the most pristine headwater streams are impacted by regionally altered metacommunities.

\section{METHODS}

\section{Study area and site selection}

The study region is comprised of the eight 8 -digit hydrologic unit code watersheds intersecting the mountaintop mining region within West Virginia (Fig. 1). These watersheds drain approximately $20,795 \mathrm{~km}^{2}$ and include the Tug Fork, Twelvepole Creek, and Elk, Gauley, Upper Kanawha, Upper and Lower Guyandotte, and Coal Rivers. We selected 168 streams as study sites (Fig. 1). We selected sites to be evenly distributed across drainage basins and to span the range of anthropogenic landscape conditions within each basin. All study sites had basin areas $<40 \mathrm{~km}^{2}$ and were independent of one another with respect to upstream-to-downstream flow (Petty et al. 2010).

\section{Macroinvertebrate community data}

We sampled benthic macroinvertebrate communities with procedures established by the West Virginia Department of Environmental Protection (WV DEP) Watershed Assessment 
Program (WV DEP 2009). We obtained kick samples (net dimensions $335 \times 508 \mathrm{~mm}$ with 500 $\mu \mathrm{m}$ mesh) from 4 targeted riffles and combined organisms and debris into a single composite sample for each site. Samples were immediately preserved with $95 \%$ ethanol. In the laboratory, we sub-sampled macroinvertebrate communities following the 200 count method (WV DEP 2009). We identified organisms to genus, except Mullusca (family), Chironomidae, Hydracarina, Oligochaeta, and Nematoda, with keys in Merritt and Cummins (2008). We categorized taxa based on tolerance [low (0-2), moderate (3-5), and high (6-10)] as specified by the WV DEP. We categorized taxa with respect to dispersal capacity (high, low) using 2 traits characterizing adult dispersal [female dispersal distance (high or low) and flying strength (high or low)] from a published database (Poff et al. 2006). Taxa were considered to have high dispersal capacity if they fell within the 'high' category for either dispersal trait. We obtained tolerance and dispersal characteristics for 84 taxa comprising $92 \%$ of all individuals. Trait data are presented in S1.

Abundance data were used to calculate community metrics. We calculated family-level (WVSCI; Gerritsen et al. 2000) and genus-level (GLIMPSS (CF); Pond et al. 2013) multi-metric indices developed for West Virginia. Both WVSCI and GLIMPSS (CF) score streams on a scale of $0-100$. We calculated 7 additional metrics shown to be responsive to stressors throughout the study region: total genus richness, Ephemeroptera, Plecoptera, Trichoptera (EPT) richness, E richness, $\mathrm{P}$ richness, \% EPT, \%E, and \%Chironomidae (Pond et al. 2008, Merriam et al. 2011).

\section{Local physicochemical condition}

We sampled physicochemical attributes once at each site during the summers (JulyAugust) of 2010, 2011, or 2012. A detailed description of our physicochemical sampling protocol is provided by Merriam et al. (2015). Briefly, reaches were defined as 40x mean stream 
width, with minimum and maximum reach lengths of 150 and $300 \mathrm{~m}$. We measured overall habitat quality with US Environmental Protection Agency (EPA) rapid visual habitat assessments (RVHA; Barbour et al. 1999). We obtained in-situ measures of specific conductance, dissolved oxygen, $\mathrm{pH}$, and temperature. We obtained filtered samples for determination of dissolved $\mathrm{Al}, \mathrm{Ba}, \mathrm{Ca}, \mathrm{Cd}, \mathrm{Cr}, \mathrm{Fe}, \mathrm{K}, \mathrm{Mg}, \mathrm{Mn}, \mathrm{Na}, \mathrm{Ni}, \mathrm{Se}$, and $\mathrm{Zn}$ and unfiltered samples for determination of $\mathrm{NO}_{3}, \mathrm{NO}_{2}$, total $\mathrm{P}$, alkalinity, $\mathrm{Cl}, \mathrm{SO}_{4}$, and total dissolved solids. The current study uses previously described chemical signatures (i.e., principal components) to describe patterns in local chemical conditions related to contemporary surface mining $\left[\mathrm{Ca}^{2+}, \mathrm{K}^{+}\right.$, $\mathrm{Mg}^{2+}, \mathrm{SO}_{4}{ }^{2-}$, and $\mathrm{HCO}_{3}{ }^{-}$, and $\mathrm{Se}$; henceforth referred to as mining water quality (mWQ)] and residential development $\left[\mathrm{Na}^{+}, \mathrm{Cl}^{-}\right.$, and $\mathrm{Ba}$; residential water quality (rWQ)] - the dominant land use activities within the study region (Merriam et al. in press).

\section{Neighborhood condition}

We summarized predicted local conditions to quantify condition at larger spatial scales (Merovich et al. 2013). We constructed boosted regression tree (BRT) models relating mWQ and rWQ to cumulative (i.e., all land area upstream) land cover and use characteristics. A general description of BRT and a detailed description of our landscape dataset and BRT models can be found in S2. In short, BRT explained 72 and 55\% of the variation in mWQ and rWQ and offered good predictive performance during 10 -fold cross-validation ( 65 and $45 \%$ total model deviance explained by CV), respectively. Variables related to surface mine activity accounted for $82 \%$ of the relative influence for the model predicting mWQ. Landscape variables characterizing residential land use were the only predictors retained in the final model for rWQ. We then predicted $\mathrm{mWQ}$ and $\mathrm{rWQ}$ for the entire study region using continuous landscape data (S1). 
Neighborhoods were defined as all 1:24:000 segment-level watersheds (SLWs) intersecting a $5 \mathrm{~km}$ buffer centered on each study site. Previous efforts have demonstrated $5 \mathrm{~km}$ to be the most appropriate distance when quantifying effects of surrounding communities on local assemblage structure (Sundermann et al. 2011). We followed general procedures outlined in Merovich et al. (2013) to calculate neighborhood condition. Predicted mWQ and rWQ values were scaled to range between 0 and 100 relative to the best and worst regional values, respectively. We then weighted the scaled mWQ and rWQ predictions by partial $R^{2}$ values obtained via redundancy analysis [RDA; rda () function in package vegan] relating Hellingertransformed and detrended abundance data to observed mWQ $\left(p R^{2}=0.05 ; p<0.01\right)$ and rWQ $\left(p R^{2}\right.$ $=0.03 ; p<0.01)($ a detailed description of our RDA methodology is presented in the next section). Weighting accounted for unequal effects of on assemblage structure. We then multiplied weighted mWQ and rWQ scores by stream segment length and standardized by total neighborhood stream length to calculate mining and residential neighborhood condition indices ( $\mathrm{mNCI}$ and $\mathrm{rNCI}$, respectively). We summed $\mathrm{mNCI}$ and $\mathrm{rNCI}$ values to create a combined index of neighborhood condition (cNCI). cNCI values were $\sqrt{x}_{\mathrm{x}}$-transformed to approximate normality.

\section{Statistical analyses}

We used redundancy analysis (RDA) to quantify the relative contributions of local (RVHA, mWQ, rWQ) and neighborhood (cNCI) environmental matrices to assemblage composition (Legendre and Legendre 2012). RDA analyses were run on taxa for which we had both tolerance and dispersal classifications $(\mathrm{n}=84)$. Abundance data were Hellinger-transformed to meet assumptions of linear ordination techniques (Peres-Neto et al. 2006). We also detrended transformed abundance data by using $\mathrm{X}$ and $\mathrm{Y}$ coordinates as predictor variables in an initial 
RDA model. Final RDA was on detrended residuals to account for spatial trends in assemblage composition that may confound environmental effects. We ran a forward selection procedure ( $p$ $<0.1$ for inclusion) to retain only the most important predictors (i.e., local only, neighborhood only, or their combination). We ran RDA first on all taxa. We then ran RDA separately on taxa within each tolerance and dispersal category. When both local and neighborhood conditions were significant, we used partial RDA to estimate the total variation in community composition explained by each component. We used adjusted $R^{2}$ to provide unbiased estimates of variance (Peres-Neto et al. 2006).

We used generalized linear models (GLM) within an information theoretic framework to test for local and neighborhood effects on community metrics. Each metric was detrended using $\mathrm{X}$ and $\mathrm{Y}$ coordinates as explanatory variables (specifying Gaussian and Poisson distributions for continuous and discrete response variables, respectively). Final models (Gaussian distribution) were run on detrended residuals. Because local effects (mWQ, rWQ, RVHA) are expected to vary among response variables, we applied a backward deletion (using deletion tests) to remove unimportant local variables. Deletion tests assess the significance of increased residual deviance with variable removal (likelihood ratio tests and Chi-squared tests; $\alpha=0.10)$ (Crawley 2005). We created 8 candidate models for each metric that represent a priori expectations regarding local and regional effects on community composition. The candidate set included a model testing for local-only effects, a model testing for neighborhood-only effects (i.e., cNCI), a model testing for a combination of local and neighborhood effects (i.e., local $+\mathrm{cNCI}$ ), and a null model. We used Akaike's information-criterion (AIC) to compare candidate models. We corrected AIC values for small sample size $\left(\mathrm{AIC}_{\mathrm{c}}\right)$. We calculated $\mathrm{AIC}_{\mathrm{c}}$ differences $\left(\triangle \mathrm{AIC}=\mathrm{AIC}_{\mathrm{i}}-\mathrm{AIC}_{\mathrm{min}}\right.$, where $\mathrm{AIC}_{\min }$ is the $\mathrm{AIC}_{\mathrm{c}}$ for the best candidate model) and Akaike weights $\left(w_{i}\right)$ for each model. 
We assessed multicollinearity among covariates using the variance inflation factor (VIF) statistic [function vif() in package $D A A G$ ]. All covariates had VIF $\leq 2$. Covariates were centered and scaled to enable comparison of effect strength. We present all models with $\triangle \mathrm{AIC}<2$, but make inferences based on the best candidate model in each set (Burnham and Anderson 2002).

We created regression models to also test for and characterize local and neighborhood effects on 9 individual taxa. We selected 7 EPT taxa [3 Ephemeroptera (Baetis, Maccaffertium, Caenis) and 4 Trichoptera (Chimarra, Rhyacophila, Ceratopsyche, and Cheumatopsyche) genera] previously shown to be responsive to local stressors (Pond et al. 2008, Pond 2010, Pond 2012). We also modeled 2 dominant Diptera (the family Chironomidae and the genera Hemerodromia). Individual taxon abundances data were zero-inflated. To account for this, we used hurdle count regression models [function hurdle() in package $p s c l$ ]. Hurdle models combine a binomial probability model component (binomial distribution with a logit link) that predicts occurrence and a zero-truncated component (negative binomial distribution with a logit link) that models positive counts (Zeileis et al. 2008). Chironomidae abundances were not zero-inflated and were modeled using GLM with a negative binomial distribution. The same a priori hypotheses were included within the candidate set (local-only, neighborhood-only, combined local and neighborhood, and null) as was described for GLMs. However, the candidate set included separate models testing for effects of cNCI on occurrence, abundance, and their combination. Spatial location (X and Y coordinates) was included as a potential predictor and was subject to initial deletion tests. Significant spatial effects were included in subsequent models to account for spatial trends while maintaining distributions required for hurdle models. We used the best candidate model in each set to predict taxonomic response to $\mathrm{cNCI}$ under optimal (i.e., best observed), average, and worst conditions for all local covariates. 


\section{RESULTS}

RDA models obtained by forward selection indicated that both local and neighborhood conditions explained significant variation in community composition across all taxa $(n=121)$

(Fig. 2A). However, the strength of local and neighborhood effects varied among tolerance and dispersal categories. When considering tolerance independent of dispersal capacity, both local and neighborhood factors were significantly associated with taxa having moderate and high tolerance values (Fig. 2A). Only local environmental conditions were retained for organisms with low tolerance. Both low and high dispersing organisms were significantly influenced by local and neighborhood factors, independent of tolerance (Fig. 2A). When simultaneously considering tolerance and dispersal, both local and neighborhood factors were retained by forward selection and explained significant variation in organisms with moderate tolerance and low dispersal capacity. Both local and neighborhood factors explained significant variation in organisms with high tolerance and low and high dispersal capacities (Fig. 2B). Only local environmental factors were retained for organisms with low tolerance, regardless of dispersal capacity (Fig. 2B). Only local factors were retained for organism with both moderate tolerance and high dispersal capacities.

The best models (i.e., lowest AICc) for 4 of 9 community metrics included both local and neighborhood condition factors (Table 1). cNCI had a negative effect on $\% \mathrm{E}$ and $\% \mathrm{EPT}$ and a positive effect on total genus richness and \% Chironomidae (Tables 2). However, effects of local physicochemical conditions were consistently stronger (1.8 to $2.9 \times$ ) than those of cNCI. The best models for GLIMPSS, WVSCI, EPT richness, E richness, and P richness included only local environmental factors (Tables 1, 2). 
The best models for 5 of 9 taxa included both local and neighborhood conditions (Table 3). Combined NCI was associated with decreased occurrence of Baetis and Ceratopsyche and decreased abundance of Maccaffertium. In contrast, $\mathrm{mNCI}$ had a positive effect on the occurrence of Chimarra and abundance of Chironomidae (Table 4). However, the effects of local conditions tended to be much stronger (1.5-2.2×) than those of $\mathrm{cNCI}$ (Table 4). Combined NCI was associated with increased occurrence and abundance of Hemerodromia in the absence of any local effect (Tables 3,4). Spatial location was included along with NCIs in the final models for Ceratopsyche, Hemerodromia, and Chironomidae (Table 4). The best models for Rhyacophila, Caenis, and Cheumatopsyche included only local and spatial effects.

Predicting occurrence and abundance for selected taxa illustrate differential response to the combined effects of local and neighborhood conditions (Fig. 3). The occurrence of Chimarra was predicted to increase with increasing $\mathrm{cNCI}$, and it was predicted to be higher at a given $\mathrm{cNCI}$ when local conditions were good (Fig. 3A). Baetis and Ceratopsyche occurrences were predicted to decrease with increasing cNCI; however, Baetis occurrence was predicted to be higher at a given cNCI when local conditions were good, while Ceratopsyche occurrence was predicted to be higher when local conditions were poor (Fig. 3B, C). Maccaffertium abundance was predicted to be very low in both average and poor local conditions, regardless of cNCI (Fig. 3D). Maccaffertium abundance in streams with good local conditions was strongly influenced by cNCI. The abundance of Hemerodromia was predicted to increase with increasing cNCI independent of local conditions (Fig. 3E). In contrast, Chironomidae abundance was predicted to increase with both decreasing $\mathrm{cNCI}$ and decreasing local condition (Fig. 3F).

\section{DISCUSSION}


Pervasive land use development within the MTR-VF region appears to degrade macroinvertebrate communities via two distinct and significant pathways: 1- degradation of local physicochemical conditions, and 2- degradation of surroundings streams (i.e., neighborhood). Direct impacts, particularly changes in water quality associated with mining (mWQ) and residential development (rWQ), represent the dominant driver of degraded macroinvertebrate communities throughout the study region (i.e., $\mathrm{p} R^{2} \leq 5 \times$ those of cNCI values). However, degraded neighborhood conditions further degrade communities via alteration of metacommunity processes related to dispersal and tolerance characteristics of surrounding communities. Consequently, our study suggests invertebrate communities within even the most pristine headwater streams are threatened when isolated within heavily impacted neighborhoods, potentially limiting their ability to maintain and protect regional diversity.

The current study supports the general tenant that local physicochemical conditions represent the dominant control over macroinvertebrate assemblage structure. More specifically, this work adds to a number of studies relating biological condition to local physical and chemical stressors within the MTR-VF region (Pond et al. 2008, Pond 2010, Pond 2012). Notably, our results corroborate previous findings of additive effects of residential development- and surface mining-related stressors on overall community condition (Merriam et al. 2011, Merriam et al. 2013, Merriam et al. 2015) and individual taxa (Pond 2010, Pond 2012). Nevertheless, our study also adds to a growing body literature demonstrating the importance of multi-scale and metacommunity processes in shaping local community composition in aquatic ecosystems (see Heino et al. 2003, Sanderson et al. 2005, Brown et al. 2011, Heino 2013).

Results support our hypothesis that degraded neighborhood conditions result in the regional expansion and proliferation of tolerant taxa. RDA found significant effects of $\mathrm{cNCI}$ on 
tolerant organisms, regardless of dispersal ability. Moreover, multiple regression and hurdle models suggested increased occurrence and abundance of several highly (Chironomidae, Hemerodromia) and moderately (Chimarra) tolerant taxa with decreasing neighborhood condition (i.e., increasing isolation), even in the most pristine headwater streams. Consequently, pervasive aquatic degradation appears to alter regional metacommunities through increased immigration and mass effects of tolerant taxa from highly stressed neighboring streams.

We also expected to see strong negative effects of degraded neighborhood condition on sensitive, poor dispersing taxa. However, we failed to observe significant associations between $\mathrm{cNCI}$ and sensitive taxa, regardless of dispersal ability. We did, however, observe significant effects of cNCI across moderately tolerant taxa with low dispersal capacity. Moreover, we saw significant decreases in \%E and \%EPT and in the probability of occurrence (Baetis and Ceratopsyche) and abundance (Maccaffertium) of several individual taxa with moderate and high tolerance values. These results generally support our hypothesis and suggest that increasingly poor neighborhood conditions do have an isolative effect that limits dispersal and associated mass and rescue effects of certain taxa known to be sensitive to regional stressors.

To our knowledge, ours is the first study to demonstrate the importance of both organism tolerance and dispersal capacity in structuring invertebrate metacommunities within humandominated landscapes, despite recent calls for such studies (Heino 2013). In fact, few studies quantifying processes governing metacommunity structure have been conducted within heavily degraded systems (but see Kitto et al. 2015, Smith et al. 2015). Nevertheless, recent studies have begun to demonstrate the importance of taxonomic characteristics in structuring natural metacommunities. Our results corroborate previous work documenting differential effects of regional and spatial factors on organisms with varying dispersal capabilities (Astorga et al. 2012, 
Canedo-Arguelles et al. 2015, Smith et al. 2015), as well as significant effects of isolation on community structure (Campbell and McIntosh 2013, Radkova et al. 2014). Previous work has also documented an increase in habitat generalists via mass effects in systems affected by natural disturbance (Vanschoenwinkel et al. 2013), while habitat specialists consistently respond only to local conditions and not spatial processes (Pandit et al. 2009, Radkova et al. 2014).

The lack of an observed effect of cNCI on the most sensitive taxa in the current study suggests they likely represent habitat specialists that are able to out-compete expanding tolerant taxa and avoid extirpation in the face of neighborhood degradation. However, biotic communities within impacted ecosystems often experience greater extinction rates as individual taxa reach new equilibria corresponding to current landscape (or riverscape) structure (Hanski and Ovaskainen 2002). This 'extinction debt' often occurs over long timeframes, particularly at large spatial scales (Hanski and Ovaskainen 2002, Vellend et al. 2006, Dullinger et al. 2013). It is possible that communities within heavily impacted regions, such as the MTR-VF region, experience greater extinction debts as a result of degraded neighborhood conditions and altered metacommunity processes. Consequently, the true effect of degraded neighborhood conditions on sensitive taxa may be occurring over timeframes not captured by the current study.

Ours is the first study to demonstrate regional control over local community composition within the MTR-VF region. Thus, it represents an important step toward the successful management of aquatic resources within this dynamic region. Management efforts within the MTR-VF region have focused on constructing models for predicting biological impairment from current and future land use activities (Merriam et al 2013, Petty et al. 2013, Merriam et al. 2015). Neighborhood condition did not contribute to community degradation as quantified by either index of biotic integrity currently used by West Virginia to designate impairment (i.e., WVSCI 
and GLIMPSS). Thus, the current results do not suggest previously constructed models to be inaccurately predicting impairment. Moreover, there is evidence that suggests metacommunity dynamics are often inherently imbedded within watershed-scale models of biological condition (Mykra et al. 2007, Heino et al. 2012). However, we caution that managing based solely on landscape attributes risks overgeneralizing the relative importance of neighborhood condition and its effects on community structure and may result in suboptimal regulatory decisions.

In general, the current results underscore previous calls for more holistic approaches to aquatic resource management that address conditions and processes at hierarchical spatial scales (Petty and Thorne 2005, Palmer 2009, Merovich et al. 2013). For example, previous research suggests restoration efforts should focus on impacted streams within relatively un-impacted neighborhoods because of ecological benefits associated with having good streams nearby (i.e., increased species pool and dispersal potential) (McClurg et al. 2007, Sundermann et al. 2011, Tonkin et al. 2014). We further argue that watershed management efforts should maximize improvement of neighborhood condition in an effort to maintain metacommunity processes.

Perhaps most importantly, our study suggests that the preservation of individual headwater catchments [i.e., designating them as protected areas, conservation priorities, or critical management zones (Meyer et al. 2007)] may not be sufficient to maintain regional diversity and integrity within this and other actively developing or highly altered landscapes. Moreover, degraded regional conditions likely influence the functional capacity of undisturbed headwater communities, particularly with respect to food webs and associated trophic linkages (see Meyer et al. 2007, Lowe and Likens 2005). It is important to note, however, that our study does not consider benefits of headwater streams related to water quality, hydrology, and linkages 
to terrestrial systems (Lowe and Likens 2005). Such benefits are further justification for the preservation of even individual headwater streams, particularly within heavily impacted regions.

We quantified significant effects of degraded neighborhood condition on macroinvertebrate communities independent of purely spatial (i.e., geographic coordinates) trends in assemblage structure. This enabled us to provide unbiased estimates of neighborhood effect strength with respect to spatial autocorrelation in community structure. It is possible, however, that significant linear trends represent effects of degraded neighborhood conditions resulting from spatial patterns in land use development. Consequently, our estimates of neighborhood effect strength may underrepresent the actual importance of regional (metacommunity) processes in structuring local assemblages.

Continued aquatic resource degradation under current land use development trends within the MTR-VF region of West Virginia may result in irreparable impacts to macroinvertebrate communities owing to the disruption of important metacommunity processes. Resource managers will need to have important discussions regarding realistic goals and expectations of regulatory (e.g., permitting) and management (e.g., protection and restoration) decisions in the face of continued land use development within this dynamic and globally important energyproducing landscape. We hope the results provided herein will provide an important starting point for such discussions. Perhaps more importantly, however, the results of this study should be extended to all ecosystem types within other actively developing landscapes in order to appropriately manage landscapes in an effort to ensure resource sustainability. 


\section{ACKNOWLEDGEMENTS}

We would like to thank the numerous individual involved in this study, especially Eric Miller, Alison Anderson, Donna Hartman, and George Merovich. Funding was provided by the U.S. Geological Survey through support from the U.S. Environmental Protection Agency (EPA) Region III. The present study was partially developed under STAR Fellowship Assistance Agreement number FP-91766601-0 awarded by the U.S. EPA. Although the research described in this article has been funded by the U.S. EPA, it has not been subjected to the agency's required peer and policy review and therefore does not necessarily reflect the views of the agency, and no official endorsement should be inferred. 


\section{LITERATURE CITED}

Astorga, A., J. Oksanen, M. Luoto, J. Soininen, R. Virtanen, and T. Muotka. Distance decay of similarity in freshwater communities: do macro- and microorganisms follow the same rules? Global Ecoloy and Biogeorgraphy 21:365-375.

Barbour, M. T., J. Gerritsen, B. D. Snyder, and J. B. Stribling. 1999. Rapid bioassessment protocols for use in streams and wadeable rivers: periphyton, benthic macroinvertebrates, and fish. $2^{\text {nd }}$ edition. EPA/841-B-99-022. US Environmental Protection Agency, Washington, DC.Bernhardt et al. 2012.

Bernhardt, E. S., B. D. Lutz, R. S. King, J. P. Fay, C. E. Carter, A. M. Helton, D. Campagna, and J. Amos. 2012. How many mountains can we mine? Assessing the regional degradation of central Appalachian rivers by surface coal mining. Environmental Science and Technology 46:8115-8122.

Brown, B. L. and C. M. Swan. 2010. Dendritic network structure constrains metacommunity properties in riverine ecosystems. Journal of Animal Ecology 79:571-580.

Brown, B. L. C. M. Swan, D. A. Auerbach, E. H. Campbell Grant, N. P. Hitt, K. O. Maloney, and C. Patrick. 2011. Metacommunity theory as a multispecies, multiscale framework for studying the influence of river network structure on riverine communities and ecosystems. Journal of the North American Benthological Society 30:310-327.

Burnham, K. P. and D. R. Anderson. 2002. Model selection and multimodel inference: a practical information-theoretic approach. New York, USA: Springer-Verlag.

Campbell, R. W. and A. R. McIntosh. 2013. Do isolation and local habitat jointly limit the structure of stream invertebrate assemblages? Freshwater Biology 58:128-141. 
Canedo-Arguelles, M., K. S. Boersma, M. T. Bogan, J. D. Olden, I. Phillipsen, T. A. Schriever, and D. A. Lytle. 2015. Dispersal strength determines meta-community structure in a dendritic riverine network. Journal of Biogeography doi:10.1111/jbi.12457.

Crawley, M. J. 2005. Statistics: an introduction using R. Wiley and Sons, Chichester, UK.

Dullinger, S., F. Essl, W. Rabitsch, K-H Erb, S. Gingrich, H. Haberl, K. Hulber, V. Jarosik, F. Krausmann, In Kuhn, J. Pergl, P. Pysek, and P. E. Hulme. 2013. Europe’s other debt crisis caused by the long legacy of future extinctions. Proceedings of the National Academy of Science 110:7342-7347.

Ewers, R. M. and R. K. Didham. 2006. Confounding factors in the detection of species responses to habitat fragmentation. Biological Reviews 81:117-142.

Finn, D. S., N. Bonada, C. Murria, and J. M. Hughes. 2011. Small but mighty: headwaters are vital to stream network biodiversity at two levels of organization. Journal of the North American Benthological Society 30:963-980.

Gerritsen, J., J. Burton, and M. T. Barbour. 2000. A stream condition index for West Virginia wadeable streams. Tetra Tech, Inc., Owings Mills, Maryland. (Available from: http://www.dep.wv.gov/WWE/watershed/bio_fish/Documents/WVSCI.pdf )

Hanski, I. and O. Ovaskainen. 2002. Extinction debt at extinction threshold. Conservation Biology 16:666-673.

Heino, J. 2013. The importance of metacommunity ecology for environmental assessment research in the freshwater realm. Biological Review 88:166-178.

Heino, J., M. Gronroos, J. Soininen, R. Virtanen, and T Muotka. 2012. Context dependency and metacommunity structure in boreal headwater streams. Oikos 121:537-544. 
Heino, J., A. S. Melo, T. Siqueira, J. Soininen, S. Valanko, and L. M. Bini. 2015.

Metacommunity organization, spatial extent and dispersal in aquatic systems: patterns, processes and prospects. Freshwater Biology 60:845-869.

Heino, J., T. Muotka, and R. Paavola. 2003. Determinants of macroinvertebrate diversity in headwater streams: regional and local influences. Journal of Animal Ecology 72:425434.

Hitt, N. P., and P. L. Angermeier. 2011. Fish community and bioassessment responses to stream network position. Journal of the North American Benthological Society 30:296-309.

Johnson, P. T. J., J. T. Hoverman, V. J. McKenzie, A. R. Blaustein, and K. L. D. Richgels. 2012. Urbanization and wetland communities: applying metacommuity theory to understand the local and landscape effects. Journal of Applied Ecology doi:10.1111/1365-2664.12022.

Kitto, J. A.J., D. P. Gray, H. S. Greig, D. K. Niyogi, and J. S. Harding. 2015. Meta-community theory and stream restoration: evidence that spatial position costrains stream invertebrate communities in a mine impacted landscape. Restoration Ecology doi:10.1111/rec.12179

Legendre, P. and L. Legendre 2012. Numerical ecology, $3^{\text {rd }}$ English edn. Elsevier, Amsterdam.

Leibold, M. A., M. Holyoak, N. Mouquet, P. Amarasekare, J. M. Chase, M. F. Hoopes, R. D. Holt, J. B. Shurin, R. Law, D. Tilman, M. Loreau, and A. Gonzalez. 2004. The metacommunity concept: a framework for multi-scale community ecology. Ecology Letters 7:601-613.

Lowe, W. H. and G. E. Likens. 2005. Moving headwater streams to the head of the class. BioScience 55:196-197.

McClurg, S. E., J. T. Petty, P. M. Mazik, and J. L. Clayton. 2007. Stream ecosystem response to limestone treatment in acid impacted watersheds of the Allegheny Plateau. Ecological 
Applications 17:1087-1104.

Merovich, G. T., J. T. Petty, M. P. Strager, and J. B. Fulton. 2013. Hierarchical classification of stream condition: a house-neighborhood framework for establishing conservartion priorities in complex riverscapes. Freshwater Science: 874-891.

Merriam, E. R., J. T. Petty, G. T. Merovich, J. B. Fulton, and M. P. Strager. 2011. Additive effects of mining and residential development on stream conditions in a central Appalachian watershed. Journal of the North American Benthological Society 30:399_ 418.

Merriam, E. R., J. T. Petty, M. P. Strager, A. E. Maxwell, and P. F. Ziemkiewicz. 2013. Scenario analysis predicts context-dependent stream response to land use change in a heavily mined central Appalachian watershed. Freshwater Science 32:1246-1259.

Merriam, E. R., J. T. Petty, M. P. Strager, A. E. Maxwell, and P. F. Ziemkiewicz. 2015. Landscape-based cumulative effects models for predicting stream response to mountaintop mining in multistressor Appalachian watersheds. Freshwater Science doi:10.1086/681970.

Merriam, E. R., J. T. Petty, M. P. Strager, A. E. Maxwell, and P. F. Ziemkiewicz. in press. Complex contaminant mixtures in multi-stressor Appalachian riverscapes. Submitted to Environmental Toxicology and Chemistry.

Merritt, R. W., and K. W. Cummins (EDITORS). 2008. An introduction to the aquatic insects of North America. $4^{\text {th }}$ edition. Kendall/Hunt Publishing Co., Dubuque, Iowa. 8

Meyer, J. L., D. L. Strayer, J. B. Wallace, S. L. Eggert, G. S. Helfman, and N. E. Leonard. 2007. The contribution of headwater streams to biodiversity in river networks. Journal of the American Water Resources Association 43:86-103. 
Meyers, N., R. A. Mittermeier, C. G. Mittermeier, G. A. B. da Fonseca, and J. Kent. 2000. Biodiversity hotspots for conservation priorities. Nature 403:853-858.

Mykra, H, J. Heino, and T. Muotka. 2007. Scale-related patterns in the spatial and environmental components of stream macroinvertebrate assemblage variation. Global Ecology and Biogeography 16:149-159.

Palmer, M. E. 2009. Reforming watershed restoration: science in need of application and applications in need of science. Estuaries and Coasts 32:1-17.

Pandit, S. N., J. Kolasa, and K. Cottenie. 2009. Contrasts between habat generalists and specialists: an empirical extension to the basic metacommunity framework. Ecology $90: 2253-2262$.

Peres-Neto, R., P. Legendre, S. Dray, and D. Borcard. 2006. Variation partitioning of species data matrices: estimation and comparison of fractions. Ecology 87:2614-2625.

Petty, J. T., J. B. Fulton, M. P. Strager, G. T. Merovich, J. M. Stiles, and P. F. Ziemkiewicz. 2010. Landscape indicators and thresholds of stream ecological impairment in an intensively mined Appalachian watershed. Journal of the North American Benthological Society 29:1292-1309.

Petty, J. T., M. P. Strager, E. R. Merriam, and P. F. Ziemkiewicz. 2013. Scenario analysis and the Watershed Futures Planner: predicting future aquatic condiditons in an intensively mined Appalachian watershed. Environmental Considerations in Energy Productions 5:5-19.

Petty, J. T., and D. Thorne. 2005. An ecologically based approach to identifying restoration priorities in an acid-impacted watershed. Restoration Ecology 13:348-357. 
Poff, N.L.R., J. D. Olden, N. K. M Vieira, D. S. Finn, M. P. Simmons, B. C. Kondratieff. 2006. Functional trait niches of North American lotic insects: traits-based ecological applications in light of phylogenetic relationships. Journal of the North American Benthological Society 25:730-755.

Pond, G. J. 2010. Patterns of Ephemeroptera taa loss in Appalachian headwaters treams (Kentucky, USA). Hydroblogia 64:185-201.

Pond, G. J. 2012. Biodiversity loss in Appalachian headwater streams (Kentucky, USA): Plecoptera and Trichoptera communities. Hydrobiologia 679:97-117.

Pond, G. J., M. E. Passmore, F. A. Borsuk, L. Reynolds, and C. J. Rose. 2008. Downstream effects of mountaintop coal mining: comparing biological conditions using family- and genus-level macroinvertebrate bioassessment tools. Journal of the North American Benthological Society 27:717-737.

Pond, G. J., J. E. Bailey, B. M. Lowman, and M. J. Whitman. 2013. Calibration and validation of a regionally and seasonally stratified macroinbertebrate index for West Virginia wadeable streams. Environmental Monitoring and Assessment 185:1515-1540.

Radkova, V., J. Bojkova, V. Kroupalova, J. Schenkova, V. Syrovatka, and M. Horsak. 2014. The role of dispersal mode and habitat specialization in metacommunity structuring of aquatic macroinvertebrates in isolates spring fens. Freshwater Biology 59:2256-2267.

Sanderson, R. A., M. D. Eyre, and S. P. Rushton. 2005. The influence of stream invertebrate composition at neighbouring sites on local assemblage composition. Freshwater Biology $50: 221-231$. 
Smith, R. F., P. D. Venugopal, M. E. Baker, W. O. Lamp. 2015. Habitat filtering and adult dipsersal determine the taxonomic composition of stream insects in an urbanizing landscape. Freshwater Biology doi:10.1111/fwb.12605.

Sundermann, A., S. Stoll, and P. Haase. 2011. River restoration success depends on the species pool of the immediate surroundings. Ecological Applications 21:1962-1971.

Tonkin, J. D., S. Stoll, A. Sundermann, and P. Haase. 2014. Dispersal distance and the pool of taxa, but not barriers, determine the colonization of restored river reaches by benthic invertebrates. Freshwater Biology doi: 10.1111/fwb.12387.

Vanschoenwinkel, B., F. Buschke, and L. Brendonck. 2013. Disturbance regime alters the impact of dispersal on alpha and beta diversity in a natural metacommunity. Ecology 94:25472557.

Vellend, M. K. Verheyen, H. Jacquemyn, A. Kolb, H. V. Calster, G. Peterken, and M. Hermy. 2006. Extinction debt of forest plants persists for more than a century following habitat fragmentation. Ecology 87:542-548.

WV DEP (West Virginia Department of Environmental Protection). 2009. Standard operating proceedures. West Virgina Department of Environmental Protection, Charleston, West Virginia. (Available from: http://www.dep.wv.gov/WWE/watershed/wqmonitoring/ Documents/SOP\%20Doc/WAB\%20SOP.pdf)

Zeileis, A., C. Kleiber, S. Jackman. 2008. Regression models for count data in R. Journal of Statistical Software 27:1-25. 


\section{FIGURE CAPTIONS}

Fig. 1. Map of study area showing target 8-digit hydrologic unit code watersheds that intersect the primary mountaintop removal-valley fill (MTR-VF) region. Major rivers, surface mine permits, and study sites are shown.

Fig. 2. Proportion of community data explained (i.e., adjusted partial $\mathrm{R}^{2}$ ) by local (mWQ, rWQ, and RVHA scores) and neighborhood (cNCI) conditions as calculated by redundancy analysis (RDA). When both local and neighborhood factors were significant, partial RDA was used to calculate fractions due to local, neighborhood, and shared localneighborhood effects. Results are presented for all taxa and separately for the 3 tolerance (low, moderate, and high) and 2 dispersal (low and high) categories (A). We also present results run on each of the 6 unique combinations of tolerance and dispersal capacity (B). A forward selection procedure was used to select predictor variables.

Fig. 3. Probability of occurrence and abundance of selected taxa as a function of cNCI given optimal (i.e., best observed), average, and worst observed conditions for all local covariates (mWQ, rWQ, and RVHA scores) and geographic coordinates. Taxa are shown with respect to tolerance and dispersal categories. Only taxa falling within tolerance and dispersal categories with significant neighborhood effects are shown. 
Table 1. Model selection metrics for generalized linear models relating detrended $[\mathrm{g} \operatorname{lm}($ metric $\sim \mathrm{X}$ $+\mathrm{Y})$ ] community metrics to local and neighborhood conditions. Models with $\Delta \mathrm{AIC}<2$ are presented.

\begin{tabular}{llccc}
\hline Metric & Model & $\mathrm{AIC}_{\mathrm{c}}$ & $\Delta \mathrm{AIC}$ & $w_{i}$ \\
\hline GLIMPSS $^{\mathrm{a}}$ & mWQ + rWQ + RVHA & -167.6 & 0.00 & 0.742 \\
WVSCI & mWQ + rWQ + RVHA & 1294.2 & 0.00 & 0.700 \\
& mWQ + rWQ + RVHA + cNCI & 1295.9 & 1.69 & 0.300 \\
Genus rich & mWQ + rWQ + cNCI & -11.0 & 0.00 & 0.702 \\
& mWQ + rWQ & -9.3 & 1.71 & 0.298 \\
EPT rich & mWQ + rWQ + RVHA & 159.8 & 0.00 & 0.736 \\
E rich & mWQ & 346.0 & 0.00 & 0.738 \\
P rich & mWQ + rWQ & 507.3 & 0.00 & 0.737 \\
\% EPT & rWQ + RVHA + cNCI & -21.1 & 0.00 & 0.595 \\
& rWQ + RVHA & -20.4 & 0.77 & 0.405 \\
\% E & mWQ + cNCI & -67.1 & 0.00 & 0.859 \\
\% Chiron & mWQ + rWQ + cNCI & 658.7 & 0.00 & 0.580 \\
& mWQ + rWQ & 659.4 & 0.65 & 0.419 \\
\hline
\end{tabular}

$\mathrm{m}=$ mining; $\mathrm{r}=$ residential; $\mathrm{c}=$ combined; $\mathrm{WQ}=$ water quality; $\mathrm{RVHA}=$ rapid visual habitat assessment score; $\mathrm{NCI}=$ neighborhood condition index; $\mathrm{E}=$ Ephemeroptera; $\mathrm{P}=$ Plecoptera; $\mathrm{T}=$ Trichoptera; Chiron $=$ Chironomidae; rich $=$ richness; GLIMPSS $=$ Genus Level Index of Most Probable Stream Status; WVSCI = West Virginia Stream Condition Index ${ }^{\mathrm{a}}=\operatorname{arcsine} \sqrt{ } \mathrm{x}-$ transformed $\mathrm{b}=\sqrt{\mathrm{x}}-$ transformed 
Table 2. Scaled parameter estimates (and standard errors) for best approximating models (i.e., lowest $A I C_{c}$ ) relating detrended $[\mathrm{g} \operatorname{lm}($ metric $\sim \mathrm{X}+\mathrm{Y})]$ community metrics to local and neighborhood conditions.

\begin{tabular}{|c|c|c|c|c|}
\hline Metric & $\mathrm{mWQ}$ & rWQ & RVHA & $\mathrm{cNCI}$ \\
\hline GLIMPSS $^{\text {ad }}$ & $-6.6(1.2)$ & $-8.1(1.2)$ & $2.5(1.2)$ & - \\
\hline WVSCI & $-3.8(0.9)$ & $-5.3(0.9)$ & $1.7(0.9)$ & - \\
\hline Genus richness ${ }^{\mathrm{d}}$ & $-11.5(2.0)$ & $-9.9(1.8)$ & - & $4.0(2.1)$ \\
\hline EPT richness ${ }^{c}$ & $-2.1(0.3)$ & $-1.5(0.3)$ & $0.6(0.3)$ & - \\
\hline E richness $^{\mathrm{c}}$ & $-5.0(0.5)$ & - & - & - \\
\hline P richness ${ }^{c}$ & $-5.6(0.8)$ & $-5.3(0.8)$ & - & - \\
\hline$\% \mathrm{EPT}^{\mathrm{ad}}$ & - & $-4.4(1.8)$ & $5.4(1.8)$ & $-3.0(1.7)$ \\
\hline$\% \mathrm{E}^{\mathrm{ad}}$ & $-8.5(2.0)$ & - & - & $-4.1(2.0)$ \\
\hline$\%$ Chironomidae & $-3.89(1.5)$ & $4.41(1.3)$ & - & $2.5(1.5)$ \\
\hline
\end{tabular}

$\mathrm{WQ}=$ water quality; RVHA = rapid visual habitat assessment score; $\mathrm{cNCI}=$ combined neighborhood condition index; $\mathrm{E}=$ Ephemeroptera; $\mathrm{P}=$ Plecoptera; $\mathrm{T}=$ Trichoptera; GLIMPSS

$=$ Genus Level Index of Most Probable Stream Status; WVSCI $=$ West Virginia Stream Condition Index

${ }^{\mathrm{a}}=\operatorname{arcsine} \sqrt{ } \mathrm{x}-$ transformed

$\mathrm{b}=\sqrt{\mathrm{x}}-$ transformed

${ }^{\mathrm{c}}=$ Values presented as $1 \times 10^{-1}$

$\mathrm{d}=$ Values presented as $1 \times 10^{-2}$ 
Table 3. Model selection metrics for hurdle models relating probability of occurrence and abundance of selected taxa to local and neighborhood conditions. Models with $\triangle \mathrm{AIC}<2$ are shown.

\begin{tabular}{|c|c|c|c|c|}
\hline Taxon & Model structure & $\mathrm{AIC}_{\mathrm{c}}$ & $\Delta \mathrm{AIC}_{\mathrm{c}}$ & $w_{i}$ \\
\hline \multicolumn{5}{|c|}{ Moderate tolerance, low dispersal } \\
\hline \multirow[t]{2}{*}{ Maccaffertium } & $\mathrm{mWQ}^{\mathrm{ab}}+\mathrm{cNCI}^{\mathrm{b}}$ & 573.6 & 0.00 & 0.618 \\
\hline & $\mathrm{mWQ}^{\mathrm{ab}}+\mathrm{cNCI}^{\mathrm{ab}}$ & 574.9 & 1.32 & 0.320 \\
\hline \multirow[t]{2}{*}{ Chimarra } & $\mathrm{mWQ}^{\mathrm{ab}}+\mathrm{RVHA}^{\mathrm{ab}}+\mathrm{cNCI}^{\mathrm{a}}$ & 459.6 & 0.00 & 0.436 \\
\hline & $\mathrm{mWQ}^{\mathrm{ab}}+\mathrm{RVHA}^{\mathrm{ab}}+\mathrm{cNCI}^{\mathrm{ab}}$ & 459.8 & 0.24 & 0.388 \\
\hline Rhyacophila & $\mathrm{mWQ}^{\mathrm{ab}}+\mathrm{rWQ}^{\mathrm{a}}+\mathrm{RVHA}^{\mathrm{b}}+\mathrm{Y}^{\mathrm{a}}$ & 184.5 & 0.00 & 0.555 \\
\hline \multicolumn{5}{|c|}{ High tolerance, low dispersal } \\
\hline \multirow[t]{4}{*}{ Baetis } & $\mathrm{mWQ}^{\mathrm{a}}+\mathrm{RVHA}^{\mathrm{b}}+\mathrm{cNCI}^{\mathrm{a}}$ & 1142.6 & 0.00 & 0.334 \\
\hline & $\mathrm{mWQ}^{\mathrm{a}}+\mathrm{RVHA}^{\mathrm{b}}$ & 1143.4 & 0.75 & 0.230 \\
\hline & $\mathrm{mWQ}^{\mathrm{a}}+\mathrm{RVHA}^{\mathrm{b}}+\mathrm{cNCI}^{\mathrm{ab}}$ & 1143.5 & 0.86 & 0.217 \\
\hline & $\mathrm{mWQ}^{\mathrm{a}}+\mathrm{RVHA}^{\mathrm{b}}+\mathrm{cNCI}^{\mathrm{b}}$ & 1143.5 & 0.86 & 0.217 \\
\hline \multirow[t]{3}{*}{ Caenis } & $\mathrm{rWQ}^{\mathrm{a}}+\mathrm{X}^{\mathrm{ab}}+\mathrm{Y}^{\mathrm{b}}$ & 234.7 & 0.00 & 0.402 \\
\hline & $\mathrm{rWQ}^{\mathrm{a}}+\mathrm{X}^{\mathrm{ab}}+\mathrm{Y}^{\mathrm{b}}+\mathrm{cNCI}^{\mathrm{b}}$ & 235.3 & 0.63 & 0.294 \\
\hline & $\mathrm{rWQ}^{\mathrm{a}}+\mathrm{X}^{\mathrm{ab}}+\mathrm{Y}^{\mathrm{b}}+\mathrm{cNCI}^{\mathrm{a}}$ & 236.6 & 1.91 & 0.155 \\
\hline \multirow[t]{3}{*}{ Hemerodromia } & $\mathrm{X}^{\mathrm{b}}+\mathrm{Y}^{\mathrm{b}}+\mathrm{cNCI}^{\mathrm{ab}}$ & 964.4 & 0.00 & 0.447 \\
\hline & $\mathrm{mWQ}^{\mathrm{ab}}+\mathrm{rWQ}^{\mathrm{a}}+\mathrm{X}^{\mathrm{b}}+\mathrm{Y}^{\mathrm{b}}+\mathrm{cNCI}^{\mathrm{b}}$ & 965.4 & 0.98 & 0.274 \\
\hline & $\mathrm{mWQ}^{\mathrm{ab}}+\mathrm{rWQ}^{\mathrm{a}}+\mathrm{X}^{\mathrm{b}}+\mathrm{Y}^{\mathrm{b}}+\mathrm{cNCI}^{\mathrm{ab}}$ & 965.5 & 1.14 & 0.253 \\
\hline
\end{tabular}

High tolerance, high dispersal

Ceratopsyche $\quad \mathrm{mWQ}^{\mathrm{ab}}+\mathrm{rWQ}^{\mathrm{ab}}+\mathrm{RVHA}^{\mathrm{b}}+\mathrm{X}^{\mathrm{ab}}+\mathrm{Y}^{\mathrm{ab}}+\mathrm{cNCI}^{\mathrm{a}} \quad 967.6 \quad 0.00 \quad 0.487$ 
$969.1 \quad 1.56 \quad 0.224$

$\begin{array}{lllll}\text { Cheumatopsyche } & \mathrm{RVHA}^{\mathrm{a}}+\mathrm{X}^{\mathrm{a}}+\mathrm{Y}^{\mathrm{b}} & 1423.4 & 0.00 & 0.362\end{array}$

$$
\mathrm{RVHA}^{\mathrm{a}}+\mathrm{X}^{\mathrm{a}}+\mathrm{Y}^{\mathrm{b}}+\mathrm{cNCI}^{\mathrm{a}} \quad \begin{array}{lll}
1424.5 & 1.03 & 0.216
\end{array}
$$

$\begin{array}{lllll}\text { Chironomidae } & \mathrm{mWQ}+\mathrm{rWQ}+\mathrm{cNCI} & 1621.2 & 0.00 & 0.683\end{array}$

$\begin{array}{llll}\text { mWQ + rWQ } & 1622.8 & 1.53 & 0.317\end{array}$

$\mathrm{a}=$ variables included in the probability of occurrence model component

$\mathrm{b}=$ variables included in the abundance model component

$\mathrm{m}=$ mining; $\mathrm{r}=$ residential; $\mathrm{c}=$ combined; $\mathrm{WQ}=$ water quality RVHA = rapid visual habitat

assessment score; $\mathrm{NCI}=$ neighborhood condition index; $\mathrm{XY}=$ latitude and longitude; $\mathrm{H}=$ high;

$\mathrm{L}=$ low 
Table 4. Scaled parameter estimates (and standard errors) for hurdle models relating probability of occurrence and abundance of selected macroinvertebrate taxa to local and neighborhood conditions.

\begin{tabular}{|c|c|c|c|c|c|c|}
\hline & mWQ & rWQ & RVHA & $\mathrm{cNCI}$ & $\mathrm{X}$ & $\mathrm{Y}$ \\
\hline & \multicolumn{6}{|c|}{ Probability of occurrence component } \\
\hline \multicolumn{7}{|c|}{ Moderate tolerance, low dispersal } \\
\hline Maccaffertium & $-1.53(0.25)$ & - & - & - & - & - \\
\hline Chimarra & $0.34(0.22)$ & - & $0.68(0.21)$ & $0.50(0.22)$ & - & - \\
\hline Rhyacophila & $-0.45(0.23)$ & $-1.21(0.33)$ & - & - & - & $0.45(0.28)$ \\
\hline \multicolumn{7}{|c|}{ High tolerance, low dispersal } \\
\hline Baetis & $-0.78(0.24)$ & - & - & $-0.37(0.22)$ & - & - \\
\hline Caenis & - & $0.66(0.23)$ & - & - & $-0.82(0.27)$ & - \\
\hline Hemerodromia & - & - & - & $0.67(0.24)$ & - & - \\
\hline \multicolumn{7}{|c|}{ High tolerance, high dispersal } \\
\hline Ceratopsyche & $0.59(0.21)$ & $-0.36(0.18)$ & - & $-0.39(0.21)$ & $0.38(0.18)$ & $-0.34(0.19)$ \\
\hline Cheumatopsyche & - & - & $0.54(0.29)$ & - & $-0.61(0.31)$ & - \\
\hline Chironomidae & NA & NA & NA & NA & NA & NA \\
\hline
\end{tabular}


Abundance component

Moderate tolerance, low dispersal

$\begin{array}{lccc}\text { Maccaffertium } & -0.98(0.22) & - & - \\ \text { Chimarra } & 0.54(0.3) & - & 0.84(0.41) \\ \text { Rhyacophila } & -0.86(0.39) & - & 1.17(0.77)\end{array}$

High tolerance, low dispersal

Baetis

$\begin{array}{ll}- & -0.32(0.14)\end{array}$

Caenis

Hemerodromia

- - -

$-0.32(0.14)$

-

$-$

$0.45(0.17)$

High tolerance, high dispersal

Ceratopsyche

$0.55(0.13)$

$-0.33(0.15)$

$0.27(0.13)$

$0.36(0.09)$

$-0.49(0.29)$

$-0.43(0.19)$

Cheumatopsyche

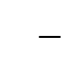

Chironomidae

$-0.18(0.06)$

$0.19(0.05)$

$\begin{array}{ll}- & 0.13(0.06)\end{array}$

$-0.33(0.09)$

$0.11(0.10)$

$\mathrm{m}=$ mining; $\mathrm{r}=$ residential; $\mathrm{c}=$ combined; $\mathrm{WQ}=$ water quality RVHA = rapid visual habitat assessment score; $\mathrm{NCI}=$ neighborhood condition index; XY = latitude and longitude, which were included in all models 


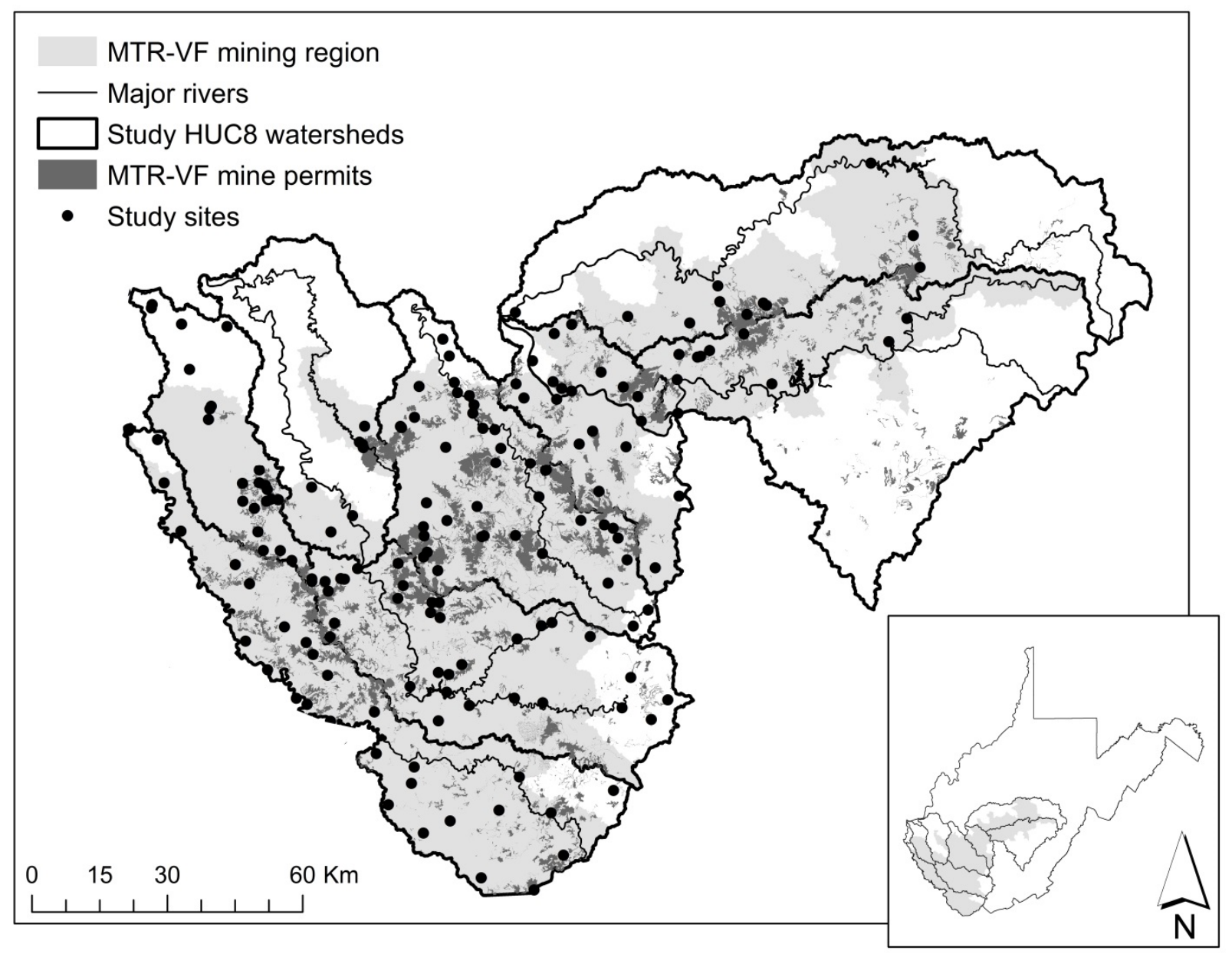

Fig. 1 


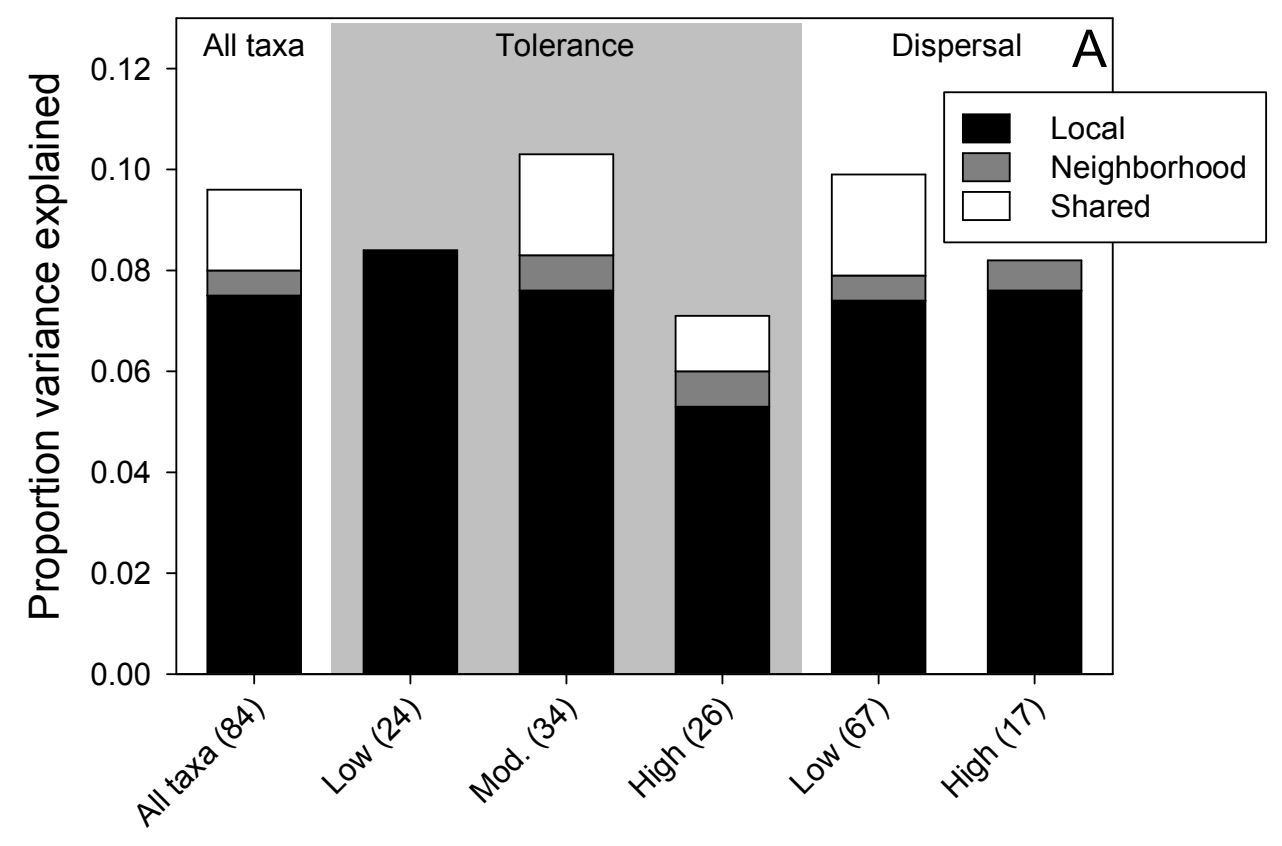

Category

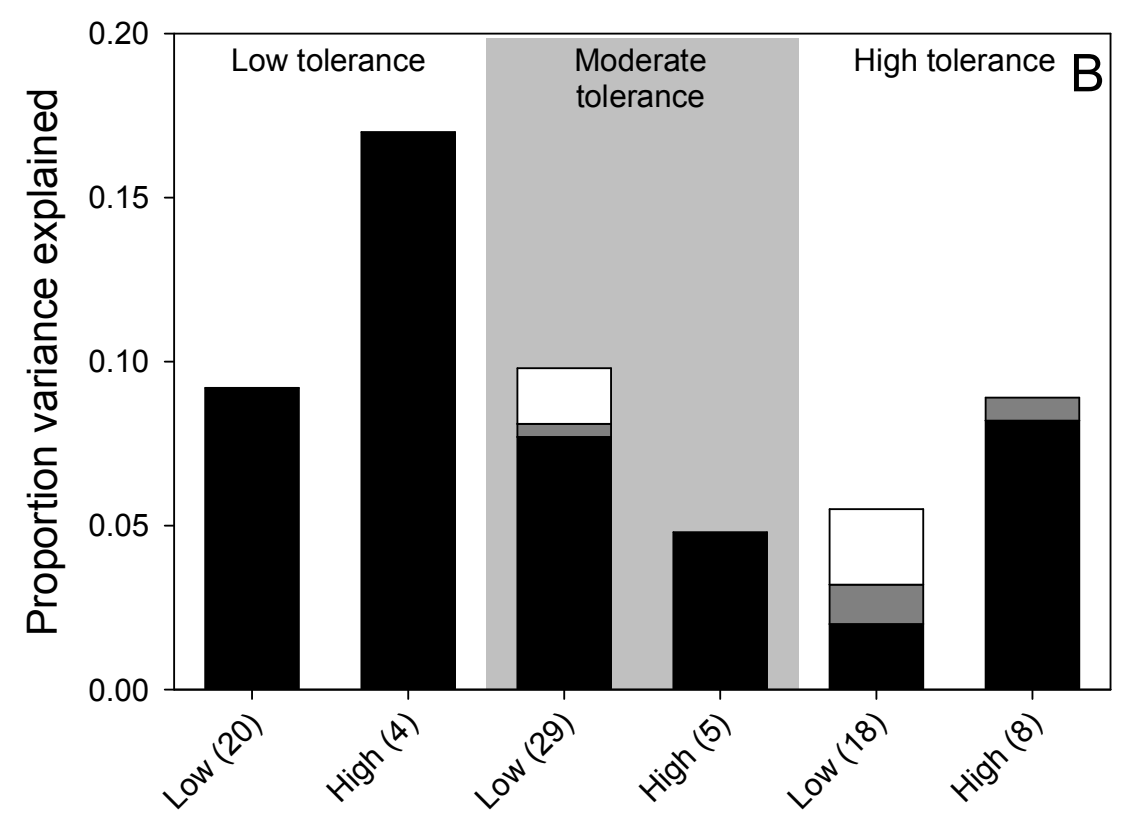

Dispersal category

Fig. 2 


\section{Low dispersal}
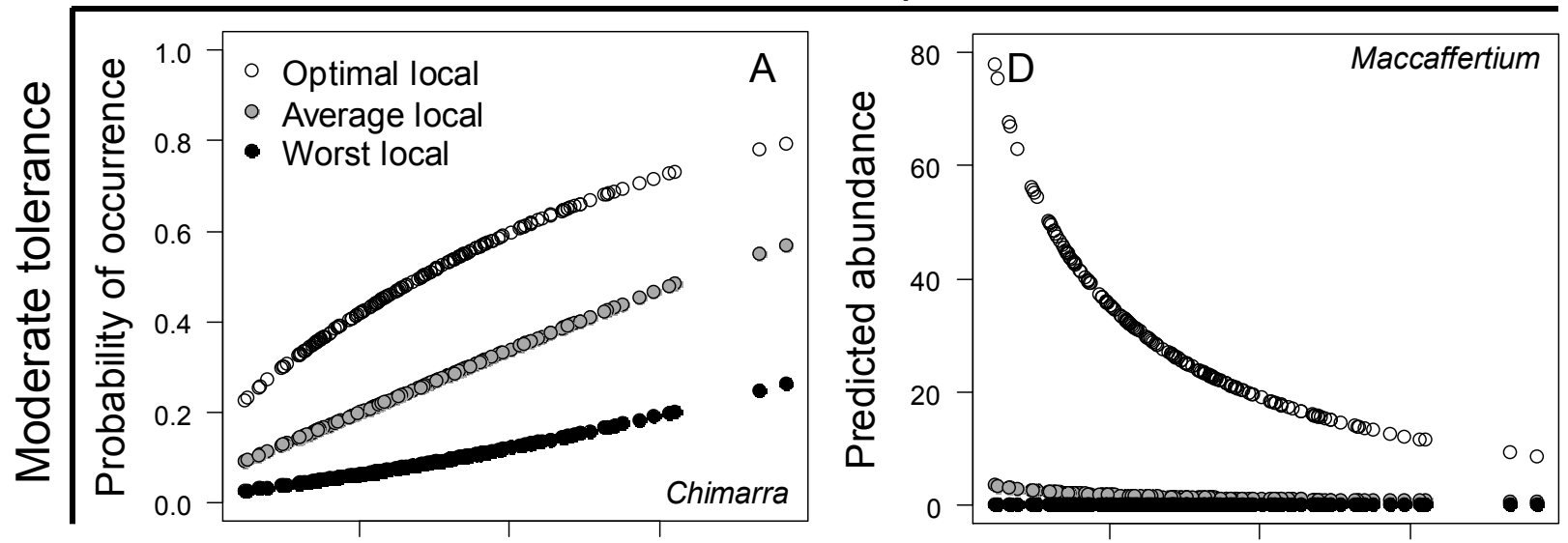

Low dispersal

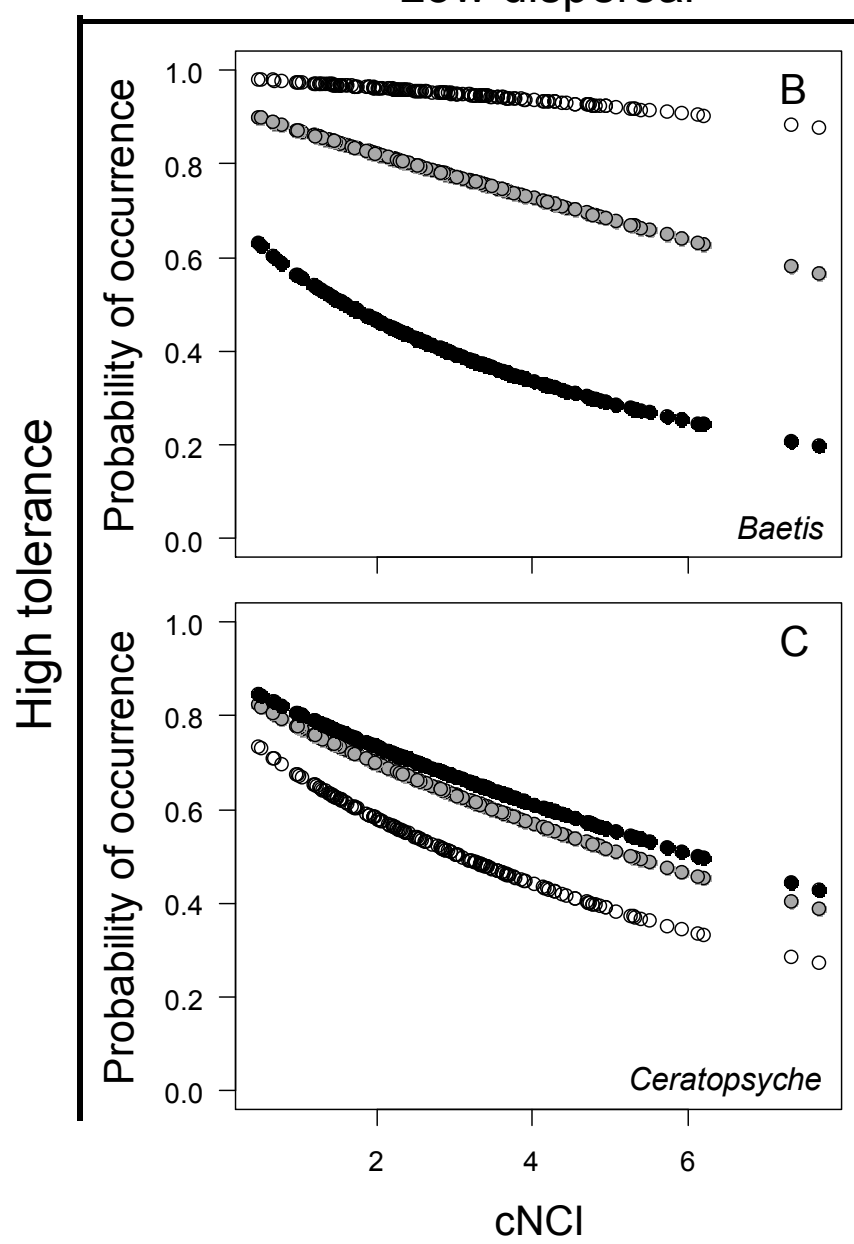

High dispersal
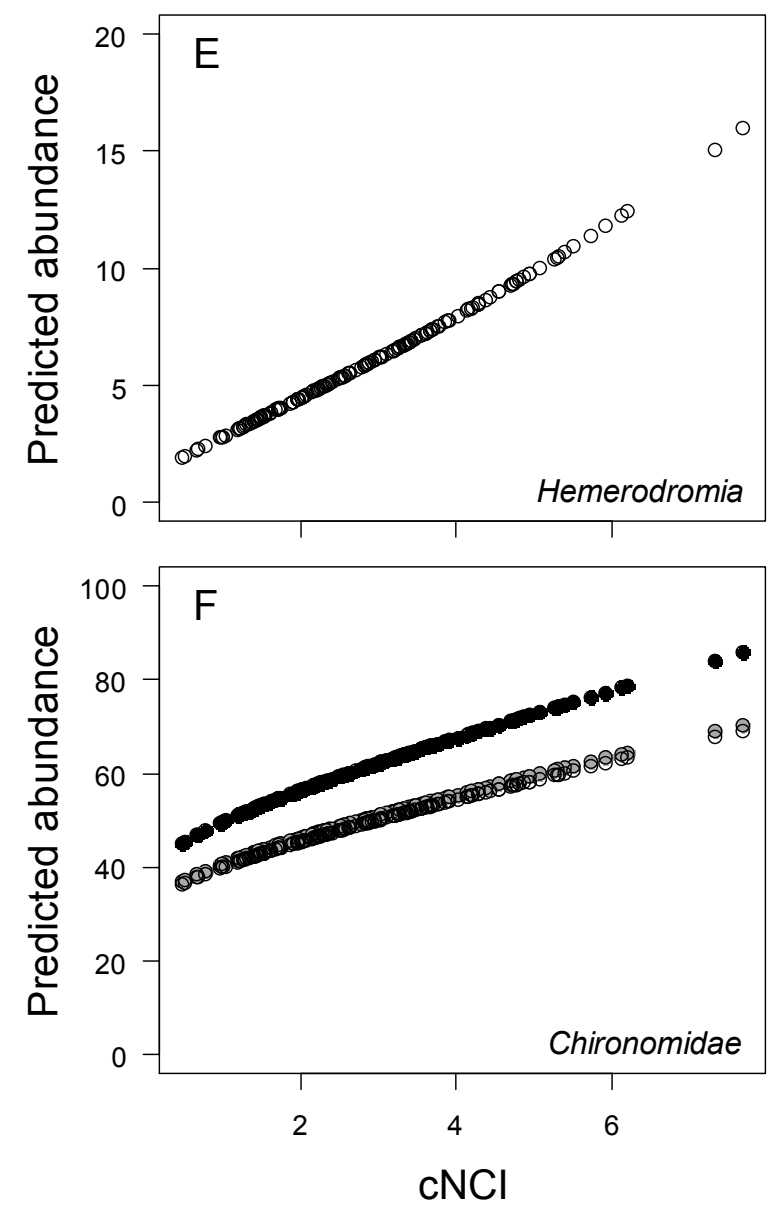

Fig. 3 
S1. Tolerance and dispersal values and categories for the 84 taxa for which data were available.

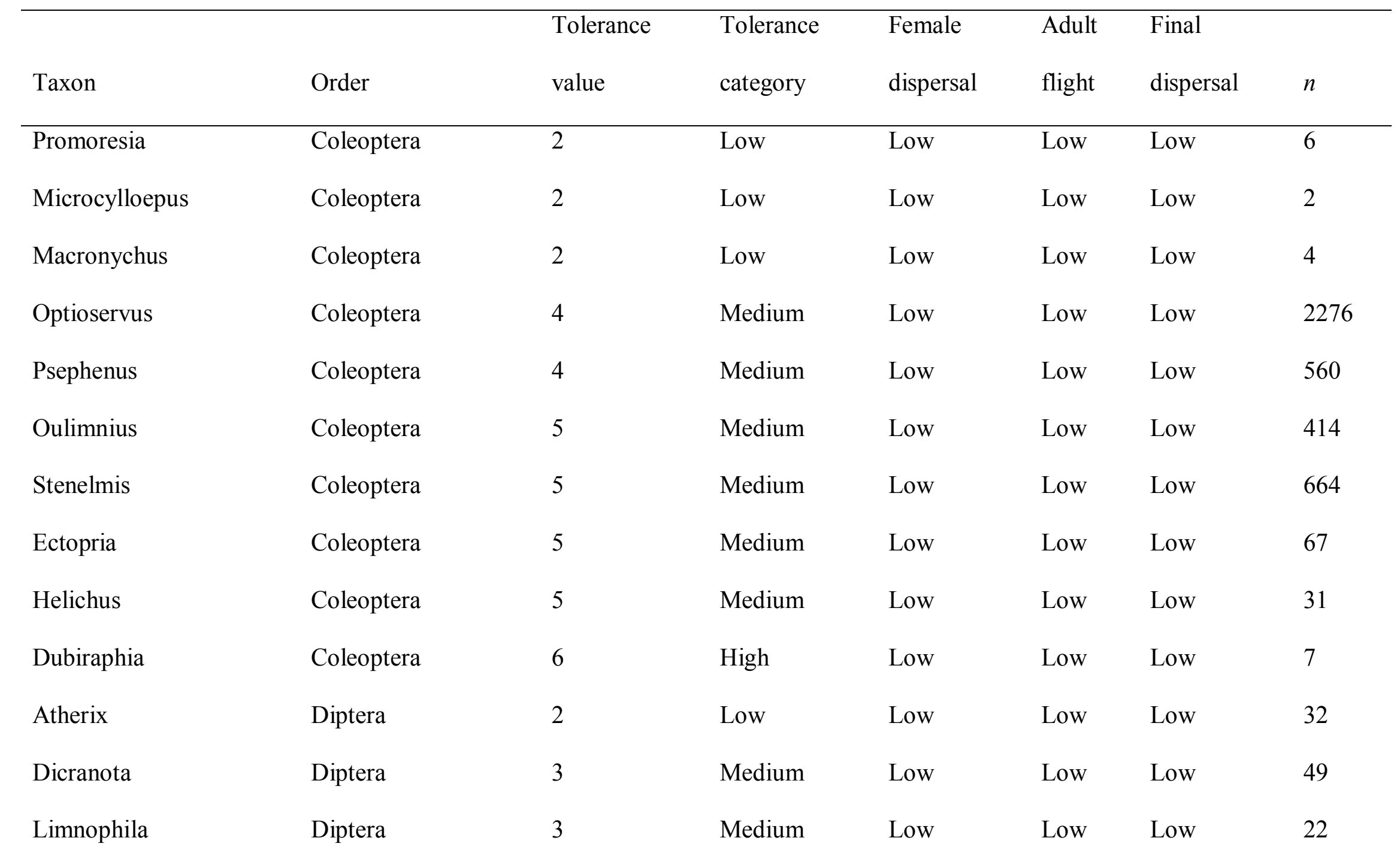




\begin{tabular}{|c|c|c|c|c|c|c|c|}
\hline Pseudolimnophila & Diptera & 3 & Medium & Low & Low & Low & 3 \\
\hline Antocha & Diptera & 4 & Medium & Low & Low & Low & 154 \\
\hline Hexatoma & Diptera & 4 & Medium & Low & Low & Low & 34 \\
\hline Molophilus & Diptera & 4 & Medium & Low & Low & Low & 3 \\
\hline Prosimulium & Diptera & 4 & Medium & Low & Low & Low & 111 \\
\hline Atrichopogon & Diptera & 4 & Medium & Low & Low & Low & 146 \\
\hline Tipula & Diptera & 6 & High & Low & Low & Low & 86 \\
\hline Simulium & Diptera & 6 & High & Low & Low & Low & 879 \\
\hline Chelifera & Diptera & 6 & High & Low & Low & Low & 188 \\
\hline Clinocera & Diptera & 6 & High & Low & Low & Low & 19 \\
\hline Hemerodromia & Diptera & 6 & High & Low & Low & Low & 1114 \\
\hline Bezzia & Diptera & 6 & High & Low & Low & Low & 135 \\
\hline Dasyhelea & Diptera & 6 & High & Low & Low & Low & 57 \\
\hline Forcipomyia & Diptera & 6 & High & Low & Low & Low & 1 \\
\hline Probezzia & Diptera & 6 & High & Low & Low & Low & 2 \\
\hline Chironomidae & Diptera & 6 & High & High & Low & High & 8794 \\
\hline
\end{tabular}




\begin{tabular}{|c|c|c|c|c|c|c|c|}
\hline Limonia & Diptera & 7 & High & Low & Low & Low & 21 \\
\hline Paraleptophlebia & Ephemeroptera & 1 & Low & Low & Low & Low & 50 \\
\hline Attenella & Ephemeroptera & 2 & Low & Low & Low & Low & 18 \\
\hline Ephemera & Ephemeroptera & 2 & Low & Low & Low & Low & 6 \\
\hline Heptagenia & Ephemeroptera & 3 & Medium & Low & Low & Low & 16 \\
\hline Maccaffertium & Ephemeroptera & 3 & Medium & Low & Low & Low & 792 \\
\hline Stenacron & Ephemeroptera & 4 & Medium & Low & Low & Low & 9 \\
\hline Isonychia & Ephemeroptera & 4 & Medium & Low & Low & Low & 169 \\
\hline Habrophlebiodes & Ephemeroptera & 4 & Medium & Low & Low & Low & 38 \\
\hline Eurylophella & Ephemeroptera & 4 & Medium & Low & Low & Low & 5 \\
\hline Tricorythodes & Ephemeroptera & 4 & Medium & Low & Low & Low & 12 \\
\hline Baetisca & Ephemeroptera & 4 & Medium & Low & Low & Low & 7 \\
\hline Acentrella & Ephemeroptera & 5 & Medium & Low & Low & Low & 105 \\
\hline Baetis & Ephemeroptera & 6 & High & Low & Low & Low & 2521 \\
\hline Procloeon & Ephemeroptera & 6 & High & Low & Low & Low & 32 \\
\hline Caenis & Ephemeroptera & 6 & High & Low & Low & Low & 78 \\
\hline
\end{tabular}




\begin{tabular}{|c|c|c|c|c|c|c|}
\hline Rhagovelia & Hemiptera & 9 & High & Low & Low & Low \\
\hline Microvelia & Hemiptera & 9 & High & Low & Low & Low \\
\hline Nigronia & Megaloptera & 5 & Medium & Low & Low & Low \\
\hline Corydalus & Megaloptera & 5 & Medium & Low & Low & Low \\
\hline Sialis & Megaloptera & 6 & High & Low & Low & Low \\
\hline Lanthus & Odonata & 3 & Medium & Low & High & High \\
\hline Cordulegaster & Odonata & 3 & Medium & High & High & High \\
\hline Gomphus & Odonata & 5 & Medium & Low & High & High \\
\hline Boyeria & Odonata & 5 & Medium & High & High & High \\
\hline Calopterygidae & Odonata & 6 & High & Low & High & High \\
\hline Coenagrionidae & Odonata & 9 & High & Low & Low & Low \\
\hline Haploperla & Plecoptera & 0 & Low & Low & Low & Low \\
\hline Sweltsa & Plecoptera & 0 & Low & Low & Low & Low \\
\hline Soyedina & Plecoptera & 0 & Low & Low & Low & Low \\
\hline Pteronarcys & Plecoptera & 0 & Low & High & High & High \\
\hline Alloperla & Plecoptera & 1 & Low & Low & Low & Low \\
\hline
\end{tabular}




\begin{tabular}{|c|c|c|c|c|c|c|c|}
\hline Capniidae & Plecoptera & 1 & Low & Low & Low & Low & 5 \\
\hline Leuctra & Plecoptera & 2 & Low & Low & Low & Low & 649 \\
\hline Malirekus & Plecoptera & 2 & Low & Low & Low & Low & 20 \\
\hline Acroneuria & Plecoptera & 2 & Low & High & High & High & 109 \\
\hline Eccoptura & Plecoptera & 2 & Low & High & High & High & 8 \\
\hline Goera & Trichoptera & 0 & Low & Low & Low & Low & 7 \\
\hline Wormaldia & Trichoptera & 1 & Low & Low & Low & Low & 4 \\
\hline Dolophilodes & Trichoptera & 1 & Low & Low & Low & Low & 97 \\
\hline Lepidostoma & Trichoptera & 1 & Low & Low & Low & Low & 4 \\
\hline Glossosoma & Trichoptera & 1 & Low & Low & Low & Low & 55 \\
\hline Lype & Trichoptera & 2 & Low & Low & Low & Low & 6 \\
\hline Psychomyia & Trichoptera & 2 & Low & High & Low & High & 4 \\
\hline Rhyacophila & Trichoptera & 3 & Medium & Low & Low & Low & 57 \\
\hline Neophylax & Trichoptera & 3 & Medium & Low & Low & Low & 3 \\
\hline Diplectrona & Trichoptera & 4 & Medium & Low & Low & Low & 586 \\
\hline Chimarra & Trichoptera & 4 & Medium & Low & Low & Low & 387 \\
\hline
\end{tabular}




\begin{tabular}{llllllll} 
Hydropsyche & Trichoptera & 5 & Medium & High & High & High & 703 \\
Ceratopsyche & Trichoptera & 6 & High & High & High & High & 1640 \\
Cheumatopsyche & Trichoptera & 6 & High & High & High & High & 4227 \\
Polycentropus & Trichoptera & 6 & High & High & Low & High & 47 \\
Oecetis & Trichoptera & 6 & High & High & Low & High & 4 \\
Hydroptila & Trichoptera & 6 & High & High & Low & High & 279 \\
Leucotrichia & Trichoptera & 6 & High & High & Low & High & 29 \\
\hline
\end{tabular}


S2. Boosted regression tree (BRT) analysis description

BRT analysis is an extension of traditional classification and regression trees, whereby large numbers of individual models are iteratively fit to random subsets (bag fraction) of the data Elith et al. (2008). Successive trees focus on explaining residual variance, resulting in final composite models with enhanced descriptive and predictive performance Elith et al. (2008). We constructed initial models using all cumulative (i.e., all land area upstream of each sample site) natural and anthropogenic landscape variables (S2.1). We identified optimal models by varying interaction depth (tree complexity) and learning rates. We calculated mean model deviance [and standard error (SE)] and cross-validated (CV) predictive deviance (and SE) from 10 folds of the data. We simplified initial models by removing variables for which removal did not result in increased CV error rate Elith et al. (2008). Final models had tree complexities of 1 (i.e., performance did not improve with greater interaction depth), learning rates of 0.001 , and bag fractions of 0.5 . We quantified relative importance of variables retained in final models. We constructed models with package $g b m$ and functions provided by Elith et al. (2008).

BRT explained 72 and $55 \%$ of the variation in $\mathrm{mWQ}$ and rWQ and offered good predictive performance during 10-fold cross-validation (65 and 45\% total model deviance explained by CV), respectively (S2.2). Variables related to surface mine activity [\% total surface mining ( $43 \%$ relative influence), $\%$ barren mine lands $(25 \%)$, and $\%$ reclaimed mine lands $(15 \%)]$ accounted for $82 \%$ of the relative influence for the model predicting mWQ (S2.2). Landscape variables characterizing residential land use [road density ( $36 \%$ relative influence), $\%$ grass pasture (33\%), and structure density $(30 \%)]$ were the only predictors retained in the final model for rWQ (S2.2). Predicting mWQ and rWQ for all un-sampled stream segments $(n=26,135)$ suggests strong spatial patterns in chemical degradation (S2. 3). 
S2.1. Descriptions and means (and standard deviations) of local and accumulated (when appropriate) landscape variables summarized across all 1:24,000 segment level watersheds within the study region with basin areas $<40 \mathrm{~km}^{2}$

\begin{tabular}{|c|c|c|}
\hline Source & Description & Accumulated \\
\hline \multicolumn{3}{|l|}{ Maxwell et al. (2011) } \\
\hline Forest $(\%)$ & Total forested area & $89.9(15.5)$ \\
\hline Grass / pasture (\%) & Grass and pasture lands outside mine permits & $4.5(8.0)$ \\
\hline Barren developed (\%) & Barren and developed lands outside mine permits & $0.64(2.0)$ \\
\hline Open water $(\%)$ & Open water outside mine permits & $0.2(1.6)$ \\
\hline Reclaimed mine land (\%) & Grass and pasture lands inside mine permits & $2.3(7.1)$ \\
\hline Barren mine land $(\%)$ & Barren land inside mine permits & $1.6(6.8)$ \\
\hline Valley Fills (\%) & Land area of valley fill faces & $0.6(3.0)$ \\
\hline Mine impoundments (\%) & Open water inside mine permits & $0.2(2.0)$ \\
\hline Mine facilities (\%) & Land area of mine facilities & $0.1(0.8)$ \\
\hline Total surface mining (\%) & Summation of all surface mine attributes & $4.7(13.6)$ \\
\hline Abandoned mine lands (AMLs) (\%) & Delineated from topographic maps and known locations & $2.7(6.3)$ \\
\hline
\end{tabular}

WV DEP Technical Applications GIS Office 
Total NPDES permits $\left(\# / \mathrm{km}^{2}\right)$

Underground mine NPDES $\left(\# / \mathrm{km}^{2}\right)$

Septic NPDES permits $\left(\# / \mathrm{km}^{2}\right)$

Sewage NPDES permits $\left(\# / \mathrm{km}^{2}\right)$

Well permits $\left(\# / \mathrm{km}^{2}\right)$

WV Division of Forestry

Timber harvest points $\left(\# / \mathrm{km}^{2}\right)$

WV Statewide Addressing and Mapping Board

Total structures $\left(\# / \mathrm{km}^{2}\right)$

Serviced structures $\left(\# / \mathrm{km}^{2}\right)$

Unserviced structures $\left(\# / \mathrm{km}^{2}\right)$

Structures within $200 \mathrm{~m}$ buffer $\left(\# / \mathrm{km}^{2}\right)$

US Census Bureau, Geography Division

Road density $\left(\mathrm{km} / \mathrm{km}^{2}\right)$

WV Geological and Economic Survey

Kanawha formation (\%)
\# NPDES permit point locations

$0.3(1.3)$

\# Underground mine NPDES permit point locations

$0.1(0.6)$

\# Septic NPDES permit point locations

$0.2(1.0)$

\# Sewage NPDES permit point locations

$0.1(0.5)$

Known well point locations

$0.9(1.6)$

Timber harvest point locations

Total \# residential and commercial structures

$10.6(24.6)$

Structures falling within public service boundaries

$2.1(18.7)$

Structures outside of public service boundaries

Structures within $200 \mathrm{~m}$ of stream channel

Length of all public and private roads

Coal outcrop length belonging to Kanawha formation
$41.2(42.4)$ 
Allegheny formation (\%)

New River formation (\%)

Pocahontas formation $(\%)$

Monongahela formation (\%)
Coal outcrop length belonging to Allegheny formation

$18.2(30.0)$

Coal outcrop length belonging to New River formation

$7.1(24.5)$

Coal outcrop length belonging to Pocahontas formation

$4.0(18.3)$

Coal outcrop length belonging to Monongahela formation 
S2.2. Performance and validation statistics for boosted regression tree models relating landscape variables to water quality principal component (WQ PC) scores and relative influences (\%) of variables retained in final models

\begin{tabular}{|c|c|c|}
\hline Statistic & $\mathrm{mWQ}$ & rWQ \\
\hline Number of trees & 4600 & 4550 \\
\hline Mean total deviance & 5.842 & 1.942 \\
\hline Mean residual deviance & 1.620 & 0.866 \\
\hline $\mathrm{CV}$ residual deviance & 2.048 & 1.063 \\
\hline $\mathrm{CV}$ residual deviance $\mathrm{SE}$ & 0.131 & 0.172 \\
\hline$\%$ deviance explained & 72.3 & 55.4 \\
\hline$\% \mathrm{CV}$ deviance explained & 64.9 & 45.3 \\
\hline Predictor variable & \multicolumn{2}{|c|}{$\%$ relative influence } \\
\hline Surface mine land $(\%)$ & 43.0 & - \\
\hline Barren mine land (\%) & 24.6 & -- \\
\hline Forested $(\%)$ & 17.6 & -- \\
\hline Reclaimed mine land (\%) & 14.8 & -- \\
\hline Allegheny coal (\%) & -- & -- \\
\hline Valley fills (\%) & -- & -- \\
\hline Abandoned mine land (\%) & -- & -- \\
\hline Road density $\left(\mathrm{km} / \mathrm{km}^{2}\right)$ & -- & 36.2 \\
\hline Grass/pasture (\%) & -- & 33.3 \\
\hline Structure density $\left(\# / \mathrm{km}^{2}\right)$ & -- & 30.5 \\
\hline
\end{tabular}




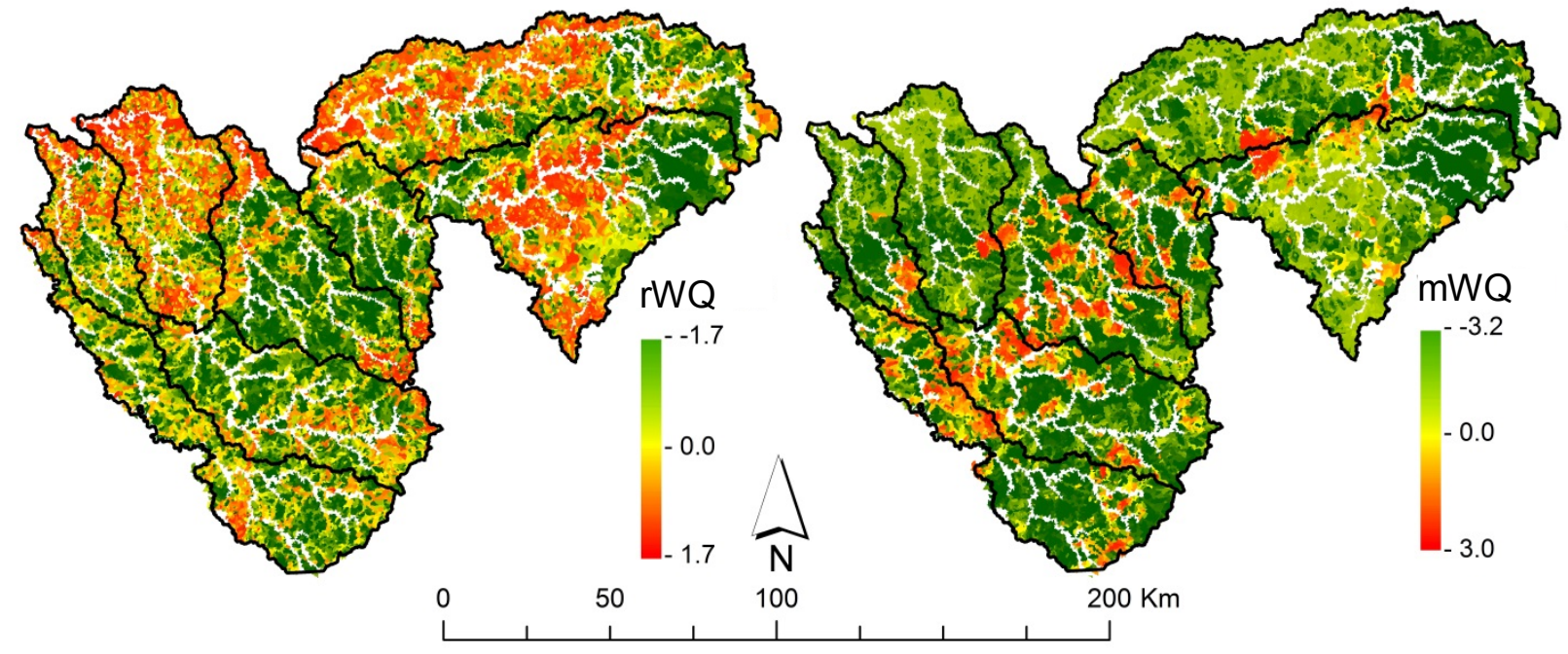

S2.3. Predicted residential (rWQ) and mining (mWQ) water quality signatures for all unsampled stream segments within the study region. Predictions were derived from boosted regression tree models predicting WQ from continuous landscape attributes. 